\title{
LOOKING FOR A LIFE RAFT: CITIZEN VOICE AND VOTES OF NO CONFIDENCE
}

\author{
Mae Kuykendall*
}

2020 Mich. ST. L. REV. 411

\begin{abstract}
The nonprofit world of the university has long segregated the approved public voices of the administrative class from the underground voices that carried a narrative about pathologies in the workings of power, an underground not suited to enter the realm of something public and serious. The no confidence vote has partially filled the gap in the management of approved internal voice, but certain traditions of secrecy have resisted exposure through unmanaged group challenge. Recent scandals at major universities
\end{abstract}

* Professor of Law, Michigan State University College of Law. This Article is a companion to a long-term project on votes of no confidence. It contains some passages from the author's forthcoming book (with co-author Sean McKinniss), Votes of No Confidence: Theory and Practice (in draft). An early draft of this Article was presented at "Amending America's Unwritten Constitution" at Boston College School of Law for panel discussion with other papers (May 2019), and a fragment at the 2014 Law \& Society conference in Minneapolis. I have thought about and talked about votes of no confidence with colleagues at the College of Law (and witnessed two). I owe special gratitude for encouragement, chastisement, and helpful comments to Texas writer James P. McCollom and Michigan novelist Lev Raphael as well as colleagues in the academy and law, to wit, Anita Bernstein, David BlankfeinTabachnick, Adam Candeub, June Carbone, Jeff Goodwin, Carmen V. Harris, Brian Kalt, Harry Lewis, Anne Lawton, Amy C. McCormick, Robert A. McCormick, Sean McKinniss, Cyril Moscow, the late Marc Poirier, Michael Sant'Ambrogio, Renée Steinhagen, Sheila Teahan, and Bert Westbrook as well as to many of my late colleagues who passed onto me in conversations their searing experience with a vote of no confidence in the Detroit College of Law and who thereby preserved, for me, a part of the institutional history of the MSU College of Law. It is no longer possible to list all the students with whom I have discussed the paper and from whose commentary I have benefitted but I am indebted to students beyond hopes of counting. I am grateful to persons who agreed to be interviewed, often anonymously for fear of reprisal, about their experience with votes of no confidence in their institutions and to the \#MeToo movement for breaking silences that were too long shatter proof. The opportunities provided by my long career to witness the highs and lows of human behavior are also worth a note. Tyler Silvestri, a recent Michigan State University College of Law graduate, provided useful readings of a near complete draft of this Article. I am grateful to the editors of the Law Review for their care and diligence. I am responsible for any errors and for all flaws of exposition or clarity. 
have helped energize an examination of administrative practices designed to insulate the university from meanings revealed by persons subjected to the abuse of power. The \#MeToo movement has recently burst forth into the university setting, powered by journalists and students bringing university secrets into public view. \#MeToo reveals to the public accountability pathologies in nonprofit institutions that have been periodically, but only partially, addressed by votes of no confidence brought by faculty or other professionals. \#MeToo has a primary goal that meshes with the purposes of the no confidence tradition of self-help, deployed by groups to expel bad leaders supported by an institutional hierarchy. Relief from an abusive or failed leader is the short-term goal in a vote of no confidence, but the uncovering and dissemination of social knowledge that has been successfully suppressed is an epistemological enterprise as well. The effect is to rescue private shared knowledge from dismissal by administrators and others possessing a voice deemed serious and public. The methods by which \#MeToo and other disclosures about pathologies within the academic setting can be exposed are little analyzed or compared. This Article is a preliminary examination and evaluation of the techniques by which groups composed of faculty members, and to a lesser extent, students work to bring private knowledge into a public forum for immediate response and long-term reform. \#MeToo presents an opportunity to compare methods for any group facing a problematic leader or other person the hierarchy will neither correct nor dismiss. The comparison addresses the comparative efficacy of expert group voice, student self-help, litigation, and investigative journalism in forcing leader exit as well as producing a long-term enhancement of social knowledge of the patterns of organizational dysfunction and abuse.

\section{TABLE OF CONTENTS}

INTRODUCTION

I. FRAMING THE ISSUE: THE VOTE OF NO CONFIDENCE AND THE SEARCH FOR ACCOUNTABILITY IN THE AMERICAN NONPROFIT SECTOR

II. THE Vote OF No CONFIDENCE: DEFINITIONS AND

FEATURES, FUNCTION, ORIGINS, STRENGTHS, LIMITATIONS, CONTEXTS.

A. No Confidence Vote: Defined

B. The Model: Normative Content, Parliamentary Origin, and Application to Private Entities. 
1. History of the Vote of No Confidence

2. Donors, Money, Sex, and Silence: The Missing Group Voice. 440

3. Where Votes of No Confidence Happen Today 443

III. EPIC FAILURES IN THE NONPROFIT SECTOR:

PROBLEMS AND RESPONSES IN THE UNIVERSITY TO SEXUAL PREDATION...

A. A Preliminary Overview of Recent Sexual Scandals in Universities

B. A Very Sad Story: Leader Failures and Social Harm at Michigan State University...

C. Case Western Reserve University School of Law Previews \#MeToo: Individual Faculty Litigation as a Substitute for Group Voice 458

1. Introduction: Individual Litigation in Place of Group Voice. 461

2. The Ku Lawsuit: A Brief Account 467

3. Denouement: Exit as Dean, Promise to Return as Faculty.

D. Et Tu, \#MeToo? Administrators Feeling Ambushed ...... 474

E. Empirical Treatment of Votes of No Confidence ........... 478

F. Limitations and Alternatives to Avoid Epic Failures ...... 481

G. Summary ....................................................................... 483

IV. NARRATIVE BLACK HOLES: LOSING CONFIDENCE IN NO CONFIDENCE? 485

A. Narrators and Their Limitations-Then and Now, Paradoxes of Secrecy Over Time 485

B. Motives to Speak? 486

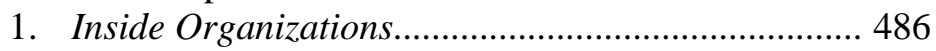

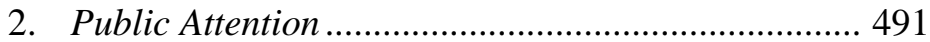

C. \#MeToo: Social Knowledge in Search of a Voice ........... 495

V. MOVING ForWARD AND NAVIGATING \#METOO WITH VOTES OF NO CONFIDENCE. CONCLUSION 503

\section{INTRODUCTION}

What do Benito Mussolini and Lawrence Summers have in common? You may be surprised to learn that the Prime Minister of Italy during World War II, informally known as, "Il Duce," and the 
President of Harvard University both suffered votes of no confidence. ${ }^{1}$ Although the two men have virtually no similarities of either leadership or character, both were vulnerable to and ultimately ousted by the enigmatic vote of no confidence. Neither vote was binding; nevertheless, both leaders resigned. ${ }^{2}$

Two very different leaders yielded to the force of a demand that was not backed by the clarity of a formal rule and that carried with it a sense of existential risk (the lives of Mussolini's dissenters and the professional standing of Summers's). Perhaps Mussolini detected something more than the moral force of opinion in a body he formally led that made yielding the right choice. A courteous soldier with a machine gun may have had some persuasive force as well. In contrast to the peaceful farewell encouraged by his council and backed by the suggestion of force, his ultimate fate after two safe years in exile was death as a captive of partisans. ${ }^{3}$ Lawrence Summers remains secure in exile, with an exit package conferred on him by the governing body of Harvard University. ${ }^{4}$ Despite the differing post-service fates, the two leaders nonetheless share an experience: forced exit by means of nonviolent improvisation resorted to by groups that reach a collective judgment about their leader. The judgment is simple. He or she must go.

1. See Christopher Hibbert, Benito Mussolini: The Rise and Fall of IL DuCE 173 (1962) (describing the plotting to pass a resolution in the Grand Council, a group created by Mussolini to preside over the Italian cabinet, and also describing a resulting censure motion that led to Mussolini's dismissal by King Emanuel of Italy); see also Marcella Bombardieri \& David Abel, Summers Gets Vote of No Confidence, Boston GlOBE (Mar. 16, 2005), http://archive.boston.com/news/education/higher/ articles/2005/03/16/summers_gets_vote_of_no_confidence/ [https://perma.cc/ZL2FED6Z] [hereinafter Summers Gets Vote].

2. See HiBBERT, supra note 1, at 197 (explaining that the King had accepted Mussolini's resignation); see also Alan Finder et al., President of Harvard Resigns, Ending Stormy 5-Year Tenure, N.Y. TIMES (Feb. 22, 2006), https://www.nytimes.com/2006/02/22/education/22harvard.html [https://perma.cc/7MBA-9ZPQ].

3. See HibBERT, supra note 1, at 313, 315 (describing the capture and execution of Mussolini by partisans). It is beyond the scope of this Article to review historical evidence about the details of the execution of Mussolini during a period of disorder in Italy at the ending of World War II.

4. See Peter F. Zhu, Summers Salary Data Released, HARV. CRIMSON (Apr. 6, 2009), https://www.thecrimson.com/article/2009/4/6/summers-salary-datareleased-in-addition/ [https://perma.cc/2SFN-T32S] (providing a summary of Summers's post-service financial compensation from Harvard and other activities). Though not especially lavish, the exit package provided for Summers included a university professorship from which he might maintain his preeminence in national and intellectual political life. See id. 
Even with the vast differences between the two men and their settings, the underlying stories of their exits contain commonalities. Groups have the ability to force a leader's exit. The risks of forming a group and communicating within it are seen as high. The sense of danger limits the number of such undertakings. Yet dysfunctions arise that prompt groups to assign responsibility to the top operating authority, whether in a government or a private institution, for bad results and/or for offensive personal behavior. Given incentives to be cautious, group actions are not a complete answer to dysfunction. Secrecy and caution prevent detailed after-the-fact recounting of specific cases, in wartime Italy or in leafy Cambridge, Massachusetts. Yet history can yield some facts that help fill out the story of an uncertain group power that provides one source of a check on leaders who become problematic in the eyes of their followers but whose term would continue in the absence of intervention.

Despite the critical role they play, a focus on leaders as a source of problems requiring an intervention does not address general accountability problems in universities and other nonprofits in the United States. Leaders often are the source of a problem, and group outcry a potential resolution, but there may be recurring patterns of misconduct within organizations that groups fail to oppose with demands for the exposure of the misconduct and termination of the wrongdoer. The general subject of group dynamics that may or may not address a problematic, abusive, or immoral organizational culture, caused at the top or tolerated, is in need of comparison between votes of no confidence that focus on a leader exit and other responses to organizational dysfunction or internal misconduct. Leaders can be the clear source of a problem, or there may be cultural patterns - as illuminated in the course of \#MeToo- that go deeper than the impact of one leader. But the vote of no confidence is a salient tool of groups to raise an outcry demanding action. Leaders often do harm, and groups sometimes react with a demand for their expulsion.

The formal power of dismissal does not lie with the group, but the moral power does. In Western democracies, the resort to a claim of moral power by a group to demand a leader's exit arises from a congeries of values in a free society, especially one where scholars and other commentators have identified a problem of rampant organizational corruption. Yet relatively little is known about the inner dynamics and overall results of these forced exits of leaders. Mussolini's two-stage exit left a gap in social knowledge about a deeply symbolic punctuation mark to an era of Italian fascism. The departure of Summers from the presidency of Harvard is somewhat 
better understood, but the general topic of votes of no confidence in American nonprofit institutions, including leading universities, lacks reliable narratives.

For reasons less fraught than wartime intrigue, social knowledge about peaceful forced exits of leaders in American institutions is subject to dispute and misinformation. Further, the departure of one person from leadership is not easily interpreted in regard to its meaning for the organization's present or future. There is always disagreement about the process by which a group expels a leader, and there is similar uncertainty about the import of such an expulsion for the trajectory of the institution.

Did the leader cause a problem that needs to be solved? If so, what is it? Are trends the leader may have embodied still in effect? Does a leader's forced exit transmit social knowledge that will cause change, or does it allow the institution to repackage an approach the leader sought to bring into the organization? What do votes of no confidence tell us in a particular case and in general about American institutional life? What do they teach us about our shared institutional life? Does the practice of forcing out a leader because of group protest sufficiently address the types of institutional problems that recurring institutional scandals seem to reveal? What other methods might supplement votes of no confidence? What might they achieve that such votes do not?

In America's organizational life, spasms of truncated accountability appear, and after limited public disclosure of the narrative of wrongdoing, often accompanied by misleading counter commentary, the facts that prompted a spasm of disclosure disappear into a vacuum of participant reticence and institutional misdirection. Though it is a leading method for groups to demand that leaders be brought to account, the vote of no confidence is vulnerable to disappearance from sight or sound. Moreover, groups do not readily find the common voice needed to organize a vote demanding a leader's dismissal. The \#MeToo movement has exposed the failure of mission-related groups to organize internally to raise a cry about sexual misconduct that is not perceived to affect the group or the institutional mission as a whole. Those targeted by sexual misconduct have thus found outlets for exposure of misconduct that an organization fails to root out, either by command from above or by group clamor. In response, organizations have spawned new kinds of secrecy, proceedings lacking in due process, with punishment meted, and secrecy imposed. 
Those subjected to secret proceedings may succumb to the preference for silence that organizations, and those affected by the endings engineered within them, generally embrace and achieve with pressure backed by power. The latter is a concern worthy of attention and is another feature of the problem of organizational secrecy. The focus here will be on the first-order problem of primary bad conduct in organizations and the methods that groups deploy to force the exit of leaders whose conduct is a cause of group remedial demand. Given the limitation of the known methods for forced leader exit as a solution to a crisis of dishonesty in institutional culture, that focus must include thinking about a basis to remedy the damage done in American organization life that has energized command logic over the citizenship logic needed for our democracy.

For this Article, I have devised the term "command logic" to describe the overuse in organizations of hierarchy as a means to authorize undiluted, top-down orders emanating from the person of a leader. Hierarchy and the associated use of leaders in various entities is a method of coordination designed to reduce the transaction costs of contracting in a free market. ${ }^{5}$ As I use the term, "command logic" is an assertion of a scope of authority in a person that overpowers the economic benefit of using leadership to reduce transaction costs and enhance coordination within an organization. ${ }^{6}$ I also argue that such overuse and monopolization of coordination efficiencies in a single individual afforded backing from the higher tiers of an organization damages citizenship by training participants in organizations to be passive subjects rather than active partners in coordinating exchanges within the entity. \#MeToo fiascos do not necessarily arise from misconduct by top leaders in an organization but perhaps more problematically from the loss of democratic citizenship arising from a culture of passivity and consequent abdication of moral agency. Such abdication may well be encouraged by leadership that largely supports

5. See ERIC Alston et AL., The LOGIC OF LeAdership AND OrganiZATIONAL HiERARCHIES 1 (2019) https://econ2017.sites.olt.ubc.ca/files/ 2019/11/pdf_seminar-paper_-Lee-J.-Alston_27-Nov.pdf [https://perma.cc/XJQ4$4 \mathrm{TUH}]$ (reviewing the economic analysis of organizational hierarchies).

6. My use of the term supports my argument that such top-down occupation by a leader of the whole organizational space for reaching optimal results, where the leader does not efficiently substitute for market exchanges, is bad for a given organization's mission but is also critically damaging the undertaking of citizenship in a democratic society. Those subjected to command logic in their organizational life are being trained to be subjects rather than fully contracting citizens in a democratic/republican order. 
lower-level administrators and thereby reinforces passivity from the ranks.

Finally, the broad significance of the search for accountability in nonprofit bodies is epistemological, an aspect of self-rule addressed in a recent book, Democracy and Truth: A Short History. ${ }^{7}$ A critical component of "the work of democracies" is building an infrastructure for the production and dissemination of knowledge. ${ }^{8}$ Doing the work involves broadening the shared base from which citizens understand and collaborate to produce deeper shared knowledge about the patterns that underlie and drive a common life. This work of democracies aspires to build a capacity for intervention against flawed depictions supportive of continuing wrongs in a shared civic life. Where organizations suppress the production of shared knowledge, improvisation to oust incompetent or abusive leaders contributes to social knowledge. Creative workarounds to undo institutional regimes of silence are voluntary gifts to democracy. ${ }^{9}$ They are vital but insufficient, a signal of work undone.

The Article proceeds in the following order. Part I provides a brief overview discussion of no confidence votes in the nonprofit sector. ${ }^{10}$ It also presents an account of "a gap in the gap," that is, the inadequacy of the vote of no confidence as a means of protecting students, and even faculty, from sexualized mistreatment, such as assault disguised as medical treatment, sexual licentiousness with students, retaliation against faculty members for reporting sexual

7. See generally Sophia Rosenfeld, Democracy and Truth: A Short HISTORY (2019) (discussing epistemological conventions as an aspect of self-rule).

8. See id. at 16-17.

9. A comparison of similar improvisation relying on a legal structure of corporate and securities law tied to the profit motive to uncover sexual misconduct in corporations has been provided by some scholars. See, e.g., Daniel Hemel \& Dorothy S. Lund, Sexual Harassment and Corporate Law, 118 ColuM. L. ReV. 1583, 1583 (2018). See Paula Loop et al., PricewaterhouseCoopers LLP, The Changing Face of Shareholder Activism, HARV. L. SCH. F. ON CORP. GOVERNANCE \& FIN. REG. (Feb. 1, 2018), https://corpgov.law.harvard.edu/2018/02/01/the-changing-face-ofshareholder-activism/ [https://perma.cc/8S75-YLED] for a brief discussion of the resources of the for-profit corporation for uncovering scandal inside the organization. Hemel and Lund suggest that concern, though worthwhile, that profit-driven corporate shareholder monitoring of sexual misconduct creates discursive harm by foregrounding harm to shareholders rather than victims and overlooks the larger critical epistemological work of democracy to which the profit motive tied to the structure of corporate law makes a contribution. See Hemel \& Lund, supra note 9, at 1671-73.

10. See infra Part I. 
misconduct, and sexual or gendered harassment of faculty members. ${ }^{11}$ Part II lays out the history, contemporary logic, and typical patterns of votes of no confidence. ${ }^{12}$ Part III addresses specific university shortfalls-Epic Failures - in which no official exercised vigilance against morally odious conduct by persons abusing the position of trust in which the institution had placed them and provides a case study of \#MeToo-related litigation that resembled, but also differed from, the typical vote of no confidence. ${ }^{13}$ Part III also examines factors that might explain failures of accountability in the nonprofit sector. ${ }^{14}$ Part IV analyzes the failure of the vote of no confidence to serve as an internal monitor of sexual misconduct, with specific examination of the events at Michigan State University involving sexual predation, and describes and assesses forms of outsider intervention. ${ }^{15}$ Part $\mathrm{V}$ assesses the strengths and weaknesses of the various responses to the unique challenges of the sexual predation and the silences about it that brought \#MeToo into being. ${ }^{16}$ A Conclusion notes the shortfalls in organizational culture and in outsider forces that might substitute for outcry by knowledgeable insiders. ${ }^{17}$

The harm of organizational silence and denial accrues to citizenship broadly conceived, and the cure, if one can be had, is civic

\section{See id.}

12. See infra Part II.

13. See infra Part III. The shortfall of collective voice and individual litigation to create general reform in nonprofit institutions provides the occasion to consider the difficulty of regular reliance on human risk-taking where the rewards are not, in the estimation of the risk taker, commensurate with the risk. That shortfall has been especially pronounced in connection with sexual misconduct mainly directed at women and girls. The shortfall reflects societal failures to respect women's voice about harassment and even sexual violence. See Rebecca Solnit, The Harvey Weinstein Verdict is a Watershed-and a Warning, N.Y. TIMES (Feb. 25, 2020), https://nyti.ms/2wfV440 [https://perma.cc/8YBZ-3USS] (describing her experience of invisibility and the failure of her words in connection with harassment).

Facts circulate freely in a democracy of information that results from a democracy of voices. We have something else instead, from personal life to national politics: a hierarchy of audibility and credibility, a brutal hierarchy, in which people with facts often cannot prevail, because those who have more power push those facts out of the room and into silence or make the cost of stating those facts dangerously high.

Id.

14. See infra Part III.

15. See infra Part IV.

16. See infra Part V.

17. See infra Conclusion. 
courage. ${ }^{18}$ The existing combination of weak but knowledgeable insider voices and external but less knowledgeable outsider voices lends itself to a failure of republican government. ${ }^{19}$ The health of democracy in the United States depends on aligning the governance of the university and other nonprofits with their public missions to support free inquiry, robust expression, public service, and engaged citizenship.

\section{FRAMING THE ISSUE: THE VOTE OF NO CONFIDENCE AND THE SEARCH FOR ACCOUNTABILITY IN THE AMERICAN NONPROFIT SECTOR}

Votes of no confidence have played an increasing role in nonprofit enterprises as a means for correcting social damage caused by the failure of oversight by boards of trustees or governmental monitoring. ${ }^{20}$ These self-help statements by group members fill an

18. See infra Part IV.

19. The failure of accountability in a critical location for the formation and enhancement of citizenship undermines the republican health of the states and is in dire need of an intervention in the guise of a republican guarantee with clout. See Melissa Murray, Sex and the Schoolhouse, 132 HARV. L. REV. 1445, 1446 (2019) (reviewing Justin Driver, The Schoolhouse Gate: Public Education, the Supreme Court, AND THE BATTLE FOR THE AMERICAN Mind (2018)) (describing schools as "sites of values inculcation - places where the state may instruct a common core of citizenship values. Some of these ... values [are] associated with the project of constructing citizens. But schools . . . also inculcate values of sexual citizenship").

20. The vote of no confidence is defined and analyzed in detail in Parts II and III. Part II addresses its origins in the British Parliament, describes how the logic has been transferred to organizations in the United States and in other democratic contexts, and indicates specific problems, results, and processes that typify these votes. For initial purposes, here is a definition offered by one faculty member to colleagues in a speech to explain the impact of a no confidence vote. The definition was recovered by this faculty speaker from an oral tradition and after study and distillation of certain writings to capture its essence:

What is a vote of no confidence? It's a formal declaration of nonsupport for a leader whose legitimacy rests partly on a core group within an organization. In a university setting, that group is the faculty. We do not have the authority to select the Chancellor or to remove him from office, but he needs our confidence for the university to function.

See Lizabeth Zack, Professor, No Confidence Vote Address at the University of South Carolina Upstate (Apr. 24, 2015). The legal system provides remedies for proven legal injuries to individuals (and to an aggregation of individuals in some instances) and provides a system for collective bargaining by unionized employees of various organizations. Corporate law permits shareholders of corporations to sue on behalf of 
accountability gap in organizations that have missions to address critical social need yet experience internal governance failures that threaten to impair the mission, transgress ethical and moral precepts, or violate the entity's core governance rules. As a gap filler, the vote of no confidence takes pride of place in reviewing the urgent need for improved accountability of organizations for wrongdoing, and within the organization, the accountability of leaders to the groups they claim to lead. The vote of no confidence is a response to the leadership role in certain organizational corruption, as well as the group psychology that supports assertions of command as a means of maintaining silence about a bad leader. These votes have significant strength as a safety valve but given their reliance on serendipitous inspiration within groups and on word of mouth, they cannot serve as a check on systemic patterns of bad behavior. Because they often arise outside the formal processes of the enterprise and depend on improvisation loosely informed by an oral tradition, their strengths come with limitations as well. ${ }^{21}$ They have episodic but limited power in a

the corporation for injuries to the corporation or to sue as shareholders for direct injury to the value of their shares. All of these systems are designed to identify interests for which the legal system provides protection and, where injury is proven to individual or collective interests, to provide a remedy suited to the nature of the identified protectable interest. They are part of a formal system of law by which legal remedies can follow for proven transgressions against entity interests or shared values. There are no simple counterparts for universities or, in most states, for other nonprofits to bring lawsuits for collective injuries to the institution or to individuals. The resort for accountability is primarily to the state attorneys general. See Dana Brakman Reiser, Enron.Org: Why Sarbanes-Oxley Will Not Assure Comprehensive Nonprofit Accountability, 38 U.C. DAVIS L. REV. 205, 206-07 (2004) (predicting that attorneys general will fail to address lapses in nonprofit governance); see also infra Part II (providing a discussion of the governance structure of American universities and the limited capacity of the boards to function as monitors over the conduct of administrators).

21. See infra Section II.B (addressing the origins of the term). When first used in Parliament to demand the forced exit of Robert Walpole as First Minister to the King, the concept was unprecedented and hence an improvisation drawing on the regular procedures for making motions. See infra Section II.A (describing the variation in methods by which groups undertake to organize a vote and the efforts by institutions to prevent the use of official university channels to communicate and cast votes, as well as arguments that ensue after a vote over its credibility as representing a relevant subset of the whole membership within the organization). On occasion, faculties bring a motion in a faculty meeting, though the capacity to bring motions is the sole basis of the action, not a specific provision for a no confidence motion. See $i d$. (discussing the fraught nature of votes and the secrecy often associated with the planning). Journalism about the votes can be hostile. In a 2018 Wall Street Journal article about them that required corrections because of overstatements about their frequency, the claim was made that the votes typically occur in faculty senates, along 
societal setting that still honors dispersed voices as carriers of actionable social truth yet fears unmanaged voice from the ranks. ${ }^{22}$ They rely on moral suasion as a substitute for formal power.

with the assertion that just one "adamant" faculty member can trigger one, an assertion that is not consistent with the case studies my coauthor and I have done on specific cases. See Douglas Belkin, No Confidence: College Faculties Rebel with More Votes Against Leadership, WALl Street J. (May 19, 2018), https://www.wsj.com/articles/

no-confidence-college-faculties-rebel-with-more-votes-against-leadership-

1526727601 [https://perma.cc/9RKW-EKDS]. The pattern is one of fraught consultations among risk-averse faculty or nonprofit members before an effort is attempted. Notably, the Journal acknowledged that "[t]hey are purely symbolic, but they frequently carry significant weight." See id. The concession that they are only symbolic belies any suggestion that they are a formality embedded in the governance process of an institution. As a practical matter, faculty senates and the like need not have a formal provision for a vote of no confidence. See Jeremy Barlow, Vote of NoConfidence: Yea or Nay?, BOARD EFFECT (July 30, 2016), https://www.boardeffect.com/blog/vote-of-no-confidence-yea-or-nay/

[https://perma.cc/4VZU-2NQL]. A good example of a no confidence motion done using existing governance rules for voting is available in an undated posting disclosing the ground rules for a vote of no confidence in the president of California State University, San Bernardino, which contains a link to the general Senate rules for voting. See Cal. State Univ., San Bernadino, What is a Vote of No CONFIDENCE?, https://www.csusb.edu/sites/default/files/upload/file/VNC_FAQ_2rev.pdf [https://perma.cc/9JJB-8877]; see also Mark Muckenfuss, Vote Goes Against Cal State San Bernardino President Tomas Morales, PRESS-ENTERPRISE (May 26, 2017), https://www.pe.com/2017/05/26/vote-goes-against-cal-state-san-bernardinopresident-tomas-morales/ [https://perma.cc/2STN-FCPZ].

22. See generally RosENFELD, supra note 7. For an abstract economic depiction of "collective conservatism" in public opinion broadly conceived outside the institutional setting, see generally Timur Kuran, Private Truths, Public Lies: The Social Consequences of Preference Falsification (1995). The thesis of the book does not rely on a concept of coercion from above, but from the "utility" calculations of individuals assessing the climate of opinion generally, and by comparing the "utility" to them of expressing their genuine, private beliefs against the marginal effect of adding one dissenting voice to public discourse and the cost of going against the perceived strong consensus. See, e.g., id. at 22-44 (deploying concepts of intrinsic utility, reputational utility, expressive utility, and total utility to model the process of "choosing a public preference"). Using the example of attachment by lower caste persons in India to the caste system, Kuran explains "collective conservatism" as a result over time of accumulating "acts of individual prudence" by persons actually skeptical of caste until many low caste persons believe in the system and participate in strengthening the status quo. See id. at 200-01. Kuran summarizes: "they have deprived one another of facts and arguments essential to defining their lot in life as unacceptable." Id. at 201. Briefly, Kuran's explanation of societal opinion formation is somewhat at odds with the thesis in Democracy and Truth: A Short History by Sophia Rosenfeld concerning the presumably positive values of an organizational epistemology of what I call "dispersion of actionable communal truth." See RoSENFELD, supra note 7, at 36 (referring to aspirations in early 
In the university setting, the effort of putting together a public expression of "no confidence" depends on forming group cohesion among risk-averse faculty members. Though a vote of no confidence sends a message, individual votes neither necessarily provide rich information about the specific problems prompting such a vote nor cumulatively provide deep or wide knowledge as to why issues in enterprises cause recurring outcries. Their powers lie in the simplicity of their message: no confidence in a leader. That simple but bold message has a predictably short shelf life, however. Its intensity coincides with its promulgation, often conveying shock value to the attentive audience for the entity's affairs. After a rejection by the group with formal authority to dismiss the target, a period of quiet often ensues. If an exit occurs, the institutional spokesmen ordinarily deny all connection to the group's demand for the leader's departure. The institution lapses into silence about the matter except on the occasion of appointing a permanent replacement, which requires acknowledgment of a vacancy by resignation.

Public silence by the institution then prevails publicly and inside the institution. Collaboration of the kind that would support a shared authority, or epistemic democracy, goes begging for volunteers. ${ }^{23}$ Nothing so grand as an "undogmatic but usable, communal truth" emerges from a group's successful outcry to expel a leader. ${ }^{24}$ Hence, even after a successful vote manages to oust a leader, the how-to disappears into the receding memories and the silences of the culture that produced the vote and the leader who prompted it. After all, the

democratic development of the production of "usable, communal truth"). Nonetheless, the idea of intrinsic utility provides a kernel of common analytic assumption - that personal preferences lurk and are blocked by some kind of barrier to open discourse. Kuran compares how opinion formation can be influenced by the pressures that emanate from nondemocratic or democratic government forms but suggests the difference between them is only of degree. See KURAN, supra note 22, at 90. Kuran does not provide a model for how an organizational subculture influenced by hierarchical controls over discourse functions within a democratic political system attached, formally, to free expression. See id. at xi (describing his undertaking to "provide an integrated account of the role of preference falsification in guiding, distorting, stabilizing, constraining, and changing the social order"). For a powerful and influential treatment of how perceptions of a predominant group view affect not just willingness to dissent, but also privately held views, see generally ELISABETH Noelle-Neumann, The Spiral of Silence: Public Opinion-Our Social Skin (1980).

23. See ROSENFELD, supra note 7, at 37 (referring to an aspiration of republics after eighteenth century revolutions to a "fully collaborative, trusting, enlightened "regime of truth"' in political life).

24. Id. at 36. 
institutional hierarchy possesses the greater speech capacity-the production of bland but seemingly authoritative speech routines. The group lacks the resources to mount counter speech, in public or in governing bodies, and within the group there is a sorting out of possible advantage and disadvantage. Advantage is gained from bland acceptance of the public narrative of normality, and disadvantage from undue interest in maintaining, developing, and spreading for newcomers' consumption accounts supporting institutional awareness of the ins and outs of the conflict. With relative ease, the institution typically seizes control of the public narrative of its history and erases or pushes the counternarrative into deep background, fragmenting and even erasing public memory of the episode.

The result is to reinstate formal, organizational control over enterprise history. An epistemology of the organization built from internal communication and shared experience is buried with the loss of knowledge gained in the turmoil, the opening up of "talk" within the group is closed down and arrested from further development, and system-wide "organizational truth" disseminated by an ethos of collaborative production of knowledge is supplanted by the sequential work of individual enterprise narrative control. ${ }^{25}$ Useful documentation which would provide faculties or other organization professionals a working how-to handbook is lost to history. ${ }^{26}$ So we see that, despite their operational impacts on the targeted leaders, votes of no confidence do not spread information into the public record about characteristic shortfalls in organization leadership, or group remedial response. What then is the larger systemic message of these episodes of group outcry? If the pattern of no confidence votes sends a decipherable message, it might be a distress signal: systemic trouble in organizational culture in certain nonprofit sectors.

What other message might votes of no confidence add to the store of social knowledge about nonprofit institutional life? Are there areas of concern about which we have gained knowledge but which

25. See id. at 16 (suggesting that a grasp of "truths," and hence of what is "conveyed as legitimate, reliable knowledge" arises from personal experience and "as a result of communication with those around us"); see also id. at 32 (discussing how plain speech was a method of communication for theorists).

26. That gap will be filled, at least in part, by my forthcoming book with Sean McKinniss. See generally Mae Kuykendall \& SeAn McKinniss, Votes of No CONFIDENCE: THEORY AND PRACTICE (forthcoming 2020). I have written this Article separately, but I will refer throughout to "our work," except where I refer to precollaboration work by either of us. Some excerpts of the materials contained in this Article may be included in the book. 
have not produced votes of no confidence? Is the silence of professional groups in some areas of misconduct also a signal about a problem in organizations that implicates problems even deeper than poor leadership? This Article offers a preliminary sorting of issues that prompt outcry about organizational failures: first, problems that trigger votes of no confidence, and second, issues that become a crisis but do not prompt votes of no confidence, at least not before the crisis is made public by other means. In the \#MeToo era, the latter-severe failures of internal accountability not brought to light by internal group voice - becomes what might be called epic failures (hereinafter "Epic Failures"). These Epic Failures expand the scope of our work on votes of no confidence to undertake a survey of alternative methods by which voices emerge to expose suppressed social knowledge and demand accountability for pathologies in the workings of power and in the social life of organizations.

In the university and other nonprofit enterprises, the problems no confidence votes address are ordinarily matters of internal academic or professional concern. Though the particulars may attract some public interest, press coverage tends to be limited: little more than the printing of press releases at the beginning and, if a resolution occurs that supports an announcement, the printing of a final press release. Attracting interest or concern from the general population for the issues at stake is a challenge due to lack of empathy for or understanding of faculty concerns and possible resentment over the ability of faculties to "fire their bosses." In addition, faculties are overmatched in a public relations battle with university public relations departments that command formidable resources to shape a public narrative. Faculties, who sometimes receive deferential treatment from students who address them as "Professor," find the general public simply indifferent, inclined toward support of power, or hardened against them by their perceived privilege. As will be explained, no confidence votes can succeed in dislodging a leader who has become obnoxious to the faculty, and the general message they send by their steady occurrence is that the academy has a governance problem that periodically requires unauthorized group voice to prompt action from the hierarchy. The fact of their recurring appearance both affirms the problem, and, given the structure placing institutional narrative in the hands of administrative hierarchy, falls short as a longrange solution to a culture of overreaching administrators and faculty who have lost heart for regular engagement sufficient to prevent crisis.

By contrast, Epic Failures can confound administrative efforts to restore a sense of normalcy. Certain problems may be so explosive 
that group silence prevails, but in the long run, administrative efforts at concealment fail because voices of victims emerge and are magnified by the legal process, journalism, and social media. Further, Epic Failures have the potential to shift narrative power away from institutional control to narrators in possession of long-suppressed social knowledge about the management of voice within nonprofit institutions to protect entrenched power, even power expressed in forms that are morally odious. Such a shift in narrative power moves "epistemic authority" at least a notch. ${ }^{27}$ Yet it also cedes narrative power to outsiders who may lack a sufficient understanding of the internal culture to provide an improved body of social knowledge and may have motives to shape narratives without careful regard for evidence.

If the vote of no confidence is an occasional avenue for faculties to demand an end to a period of disarray as well as fear and/or maladministration caused by an individual abusing any or all of faculty members, school resources, or academic norms, can we identify the problems that have failed to prompt faculty voice by extraformal or nonroutine means? While proving a nonevent is difficult, my coauthor and I agree that we cannot think of faculty votes of no confidence that brought attention to sexual misconduct affecting fellow faculty members, staff members, or students. Yet recent highprofile scandals that resonate with the \#MeToo movement have brought attention to shocking gaps in university systems for accountability to faculty targets and student victims of sexual predation.

Once exposed, public interest in such scandals at the intersection of sex and power is intense and sustained. Moral suasion has done its own work as facts emerge - but rarely from group self-reporting. Sad to say, internal means for bringing to light allegations of sexual assaults of students by university employees and sexual harassment of faculty members by more powerful faculty members have been elusive. Such allegations have not been brought into the public arena by votes of no confidence. The work of breaking silence falls to investigative journalism and the voice, courage, and litigation of victims who go public. In addition, a single faculty member (or nonprofit professional) can, rarely, break silence with narrative-rich litigation about the alleged seamy conduct of a leader and also achieve

27. See RoSENFELD, supra note 7, at 20 (referring to "a struggle over people as holders of epistemic authority"). 
personal vindication. ${ }^{28}$ Litigation by a courageous internal speaker under attack can substitute for group voice when a group, such as a faculty aware of possible misconduct, will not speak. Hence, morally fraught accountability failures can be exposed even when they are not brought to light by group voice.

That story-the story of the \#MeToo movement as a vehicle of delayed accountability and social knowledge-is still unfolding. As noted above, the institutional response to the movement may include recourse to the kind of narrative control to which organizations are attached. A result can be, and has been in known instances and in instances not yet revealed, secret processes that subject accused individuals in institutions to violations of due process, often for an extended period, with high stakes for their constitutionally protected interests, and attendant violations of basic fairness and respect. ${ }^{29}$ These

28. See infra Part III. Note that the "whistleblower" is a separate idea, one that relies on legal permissions for a single individual to expose organizational wrongdoing that may be pervasive and supported within the group as a necessity for the organization to remain secure. The whistleblower is not a carrier of group voice and may suffer severe personal harm by way of retaliation and group shunning. Several recent books have addressed the whistleblower. See AlLison STANGer, WHISTLEBLOWERS: HONESTY IN AMERICA FROM WASHINGTON TO TRUMP 12 (2019); see also Robert G. Kaiser, With These Two Whistleblower Books, Read Cautiously, VIRGINIAN-PILOT (Oct. 2, 2019, 7:24 PM), https://www.pilotonline.com/ entertainment/books/vp-db-book-whistleblowers-20191002-dus5gbskubaxrfnlne7 bcxhi3u-story.html [https://perma.cc/3SP7-MRTF] (commenting on the timeliness of the books but noting problems, variously, of oversimplification and factual error). See generally TOM Mueller, CRISIS OF CONSCIENCE: Whistleblowing IN AN AGE OF FRAUD (2019) (discussing the many cases of whistleblowing in America). See Stephen Martin Kohn, The New Whistleblower's HandboOK: A SteP-By-SteP Guide to Doing What's Right AND PROTECTING Yourself xvii (2011) (providing advice to persons considering using whistleblower protections to expose organizational wrongdoing).

29. See Am. Ass'n of Univ. Professors, The History, Uses, And Abuses OF TITLE IX 69-70 (2016) (discussing problems in university administration of its obligations under Title IX of the Education Amendments of 1972).

Success stories about compelling colleges and universities to address problems of sexual assault are matched by reports of cases in which university administrators have failed to punish gross and repeated sexual harassment or in which title IX administrators from the Department of Education and within the University have sought to punish protected academic speech. These cases have compromised the realization of meaningful educational goals that enable the creation of sexually safe campuses; they have also undermined due-process rights and shared governance in unprecedented ways.

Id. at 69 . 
due process issues are outside the scope of this Article but are of significant concern. Notably, though, institutional secrecy is usually based on a claimed concern for victims of mistreatment. This, however, is also a manifestation of the drive by institutions to manage public knowledge to the advantage of the institution, with damage to the interests served by a social commitment nurturing an epistemology of the organization produced by the "dissemination of undogmatic but usable, communal truth." 30 Individual rights are harmed, but so is a basis in shared knowledge to address recurring problems of misbehavior, accusation, and institutional response.

This Article addresses the shortfalls in formal processes of accountability in nonprofit institutions. In addition, it describes and analyzes the informal interventions brought to bear by internal groups, or, when internal groups fail, by individuals who break the silence and stir public uproar. In it, I provide the first close look at a confluence of trends: (1) frequent resort by faculties to votes of no confidence to address leadership problems and to attempt to force a leader out; (2) the emergence of sexual scandals involving long-term abuse of students or other vulnerable persons without intervention by university or other institutional officials or outcry by faculties or group members; (3) the \#MeToo movement with its insistence on revealing submerged facts about the patterns in the abusive use of power to coerce sexual favors; and (4) a new determination to speak up exemplified by an individual faculty member's use of litigation as a partial substitute for group voice to allege abusive sexualized conduct by an official in a law school. The approach is a description and analysis of the accountability gap in nonprofits, especially universities, with comparison of the strengths and weaknesses of techniques that have supplemented the vote of no confidence as a tool for accountability driven by disclosure. The general background, about which there is increasing scholarly and other treatment, is the pervasiveness of corruption in American institutions, including those of higher learning. Recent books have addressed the spread of corruption permeating many American institutions, ${ }^{31}$ such as

30. See RosENFELD, supra note 7 , at 36 .

31. See generally LARRY LESSIG, AMERICA, COMPROMISED (2018) (arguing that American institutions, including Congress, have been corrupted by a general dependence on the improper influence of money rather than "the people" or professional norms and the like). Hence, Lessig argues that an institution can be "corrupt" without having corrupt individuals in it. See id. An interestingly similar claim was made by a British visitor to Tidewater Virginia in the late 1700s, albeit perhaps tongue in cheek. See Allan Nevins, America Through British Eyes 31 
universities invaded by corporate money and "branding," the corporate world, and the American political order writ large. ${ }^{32}$

The story of power used wrongfully has many chapters. It spans the most intimate dimensions of home, the workplace (including the less secluded domains of enterprises large and small), and public life encompassing the oppressions inflicted or tolerated by the political order. The constitutional dimension of the problem concerns the blight on democracy brought by entrenched power in settings not readily remitted to a zone of privacy, a problem meant (many argue) to be addressed by the Guarantee Clause of the United States Constitution but left to fester unaddressed by either court or legislative resort to the protective meaning of the clause to safeguard a "republican" basis for our common life. ${ }^{33}$ Much of the common life of American citizens occurs in enterprises, either formally private or loosely classified as

(1948) (suggesting that planters have been harshly judged by those who blame them for sins of the fathers (those whose crimes brought slavery to Virginia) and have thus "confounded the necessity of the present with the evil of the past, have let the crimes of a few discolor the many, and the iniquity of a system vouch for that of individuals. ... Unless a man has been willing to break up this system at the cost of his own utter ruin, he has been pronounced a selfish barbarian, a loathsome maggot complacently fattening on corruption"). The description of a planter's day that follows, occupied with libations and naps attended by enslaved women, seems to belie the opening defense of the individual against the system. See id. at 32-35. Whatever the theory of the deep source of corruption - in human character or the money culture of American life of late-its scope is conceded to be vast. See Kaiser, supra note 28 (referring to Tom Mueller's "extensive footnotes [that] include a remarkable catalog of books and articles that document the "increasing incidence of fraud and corruption in many parts of U.S. society"").

32. See Joshua Hunt, The University of Nike: How Corporate Cash BOUght AMERICAN Higher EDUCATION 216-17 (2018) (recounting secretiveness about sources of corporate funding, concealment of sexual assault by athletes, and interference with academic judgment as a result of corporate cash). See generally Robert McCollom, The Last Sheriff in Texas: A True Tale of Violence And THE VOTE (2017) (describing the risky struggle against the power of a violent sheriff to control the vote in a South Texas county and thereby retain power); TAMAR Frankel, Trust and Honesty: American's Business Culture at a Crossroad (2006) (describing the spread of corruption through corporate America).

33. See U.S. Const. art. IV § 4; Luther v. Borden, 48 U.S. 1, 42 (1849) (holding that whether a state government is a republican government is a political question for Congress, not the courts); THE FEDERALIST No. 43, at 312-16 (James Madison). For a scholarly treatment of the Guarantee Clause arguing that the original meaning did not contemplate judicial enforcement, see Ryan C. Williams, The "Guarantee Clause," 132 HARV. L. REv. 602, 604-06 (2018) (describing Senator Sumner's view of the Clause as a "sleeping giant," suggesting the giant may show signs of awakening, and reciting the critical views of various contemporary scholars on the practice of judicial nonenforcement). 
state-sponsored (e.g., state universities), and becomes subject to forms of unaccountable coercive power. In such settings, the republican capacity to name and resist misconduct loses influence, as does the commitment to communal truth.

\section{THE Vote of No CONFIDENCE: DEFINITIONS AND FEATURES, FUNCTION, ORIGINS, STRENGTHS, LIMITATIONS, CONTEXTS}

In recent years, votes of no confidence have become a prominent method for groups to voice their displeasure with bad leadership. These votes have occurred in a variety of organizations, such as hospitals, medical associations, fire and police departments, and even a Gaelic football team. ${ }^{34}$ The preponderance of notable no confidence votes, however, has occurred in higher education, particularly from faculties voting against their institutions' presidents. This Article does not incorporate a close treatment of specific cases. Some of the patterns in such votes are described in Subsections III.C.2 and III.C.3 by comparing and contrasting their forms and patterns with details of the litigation at Case Western Reserve University School of Law against the dean and the University.

\section{A. No Confidence Vote: Defined}

In basic terms, a vote of no confidence announces the loss of support in a group whose support is a predicate, derived from

34. See Eric Andrew-Gee, Ontario Medical Association Head Resigns After No-Confidence Vote, GLOBE \& MAIL (Feb. 6, 2017), http://www.theglobeandmail.com/news/national/ontario-medical-association-headresigns-following-no-confidence-vote/article33920497/ [https://perma.cc/7UMXCG5B] (reporting on a vote of no confidence on the head of a medical association); Rick Armon, Resident Physicians at Summa Health Vote No Confidence in System President, AKRON BEACON J. (Jan. 1, 2017), https://www.beaconjournal.com /news/20170102/resident-physicians-at-summa-health-vote-no-confidence-insystem-president [https://perma.cc/J5WR-7S2V] (reporting on a vote of no confidence that took place in a hospital); Leslie Dixon, Oxford Fire Chief Resigns After Members Vote 'No Confidence,' Sun J. (Dec. 6, 2016), https://www.firerescue1.com/fire-chief/articles/150458018-Maine-fire-chief-resignsfollowing-vote-of-no-confidence/ [https://perma.cc/WBJ9-CENE] (reporting on a vote of no confidence in a fire department chief); Seán Moran, Mayo Footballers Vote No Confidence in Joint Managers-Reports, IRISH TIMES (Sept. 29, 2015), http://www.irishtimes.com/sport/gaelic-games/gaelic-football/mayo-footballersvote-no-confidence-in-joint-managers-reports-1.2370918 [https://perma.cc/S4WS$945 \mathrm{~N}$ ] (reporting that players on a football team passed a vote of no confidence in the team's managers). 
democratic norms and organizational realities, of a leader's ability to function. ${ }^{35}$ It occurs within the cultural setting of democratic societies, in cultures that foster an expectation, however well-articulated or neglected in a given sector, that acquiescence to a leader is required at the time of installation and during his or her term of office. ${ }^{36}$ In the most specialized institutions, the vote is a mechanism by which mission experts bring a group voice to force to the surface problems that, after fruitless efforts to air and attain responsive action, point toward leader exit as the solution. Indeed, the premise is that the leader is the problem because of bad behavior or inability to address institutional priorities. As a collective social understanding of legitimacy and embedded norms in institutions, it is an unwritten compact for key social enterprises, maintained without legal help yet recovering procedures and restating norms in recurring patterns of self-help: a modern oral tradition. ${ }^{37}$ In institutions that have a form of collective social ownership that relies upon a group with both expertise and a fiduciary obligation to carry the mission of the institution by playing a governance role, the vote serves as a safety valve.

The vote also occurs in membership groups with less reliance on expertise but which assert group voice against leaders who violate the

35. See Peter Schmidt, How to Fire Your President: Voting 'No Confidence' with Confidence, Chron. OF Higher Educ. (June 23, 2009), https://www.chronicle.com/article/How-to-Fire-Your-President-/47315 [https://perma.cc/TXN2-4JDV].

36. Faculties of law schools, at the time of a decanal appointment or a group demand for dismissal, have relied on a statement in the American Bar Association Standards. See generally ABA STANDARDS AND RULES OF PROCEDURE FOR APPROVAL OF LAW SCHOOLS 2019-2020 (2020). Law faculties cite these law school Standards to describe an institutionally specific normative basis of the no confidence vote. See id. The core norm provided by the standards is the requirement, embedded in an enforceable accreditation provision, that deans not be appointed over the objection of a substantial majority of the faculty. See id. at 10-11. ("Except for good cause, a dean should not be appointed or reappointed to a new term over the stated objection of a substantial majority of the faculty.") Law faculties also have a strong expectation as lawyers that a test of continuing legitimacy will be imposed on the dean of a law school. See id.

37. See Robert Scholes \& Robert Kellogg, The Nature of Narrative 25 (1966) (describing how the absence of writings about the vote of no confidence makes those who perform them akin to the performers of primitive oral songs, who follow a grammar "learned below the level of consciousness"); see also id. at 23 ("[In an oral tradition,] [w]e can speak of the elements of the song - the plot, the episodes, the conception of character, the knowledge of historical events, the traditional motifs, the diction - as being transmitted, but we cannot speak of the oral transmission of the song itself."). 
group's expectations for competence or fair treatment. The vote has no persuasive force for elected offices, which have formal removal mechanisms that match the weight of the electoral mechanic for filling the office. ${ }^{38}$ Outside the electoral context, however, an authoritative demand for a leader's exit, arising from a democratic ethos that respects group input, carries force even without a format given by a system of political authority that manifests the legitimacy of its role outside prescribed channels.

By contrast, because of demand, the for-profit corporation has developed mechanisms that allocate a kind of republicanism to large shareholders to force board responsiveness. ${ }^{39}$ In the case of investment as ownership, money talks. In the absence of an investment-driven claim on ownership and associated policies to give the claim real force, internal voice relies on moral stature and group-based expertise and commitment. Where money talks in the nonprofit sector, it may become a source of wrongful influence at odds with the normative ideal of a healthy bond with mission. It may also bring \#MeToo

38. See Jack Maskell \& Richard S. Beth, Cong. Research Serv., RL34037, "NO CONFIDENCE" VOTES AND OTHER FORMS OF CONGRESSIONAL CENSURE of Public OfFicials 1 (2007) ("Except through the process of impeachment, accordingly, no action by the Congress (or of either House) can have any practical effect similar to that of a parliamentary vote of no confidence."); see also id. at 2 (noting that some have gone so far as to argue that "impeachment was the proper, and exclusive, constitutional response for Congress to entertain when the conduct of federal civil officers is called into question, rather than a resolution of censure" and citing Congressional deliberations concerning a resolution in 1867 on the unfitness of office of Mr. Henry Smyth and the 1924 resolution calling for the resignation of the Secretary of the Navy).

39. See generally Jack B. Jacobs, Fifty Years of Corporate Law Evolution: A Delaware Judge's Perspective, 5 HARv. Bus. L. REV. 141 (2015) (discussing the mechanisms of for-profit corporations). In their recent article on the corporation and sexual harassment, Daniel Hemel and Dorothy S. Lund discuss (and rebut) critiques of the effort to stretch corporate law to check sexual misconduct in enterprises for the poor fit of such efforts with the task of assuring that managers adhere to making business judgments in the interests of the core corporate business purpose. See Hemel \& Lund, supra note 9, at 1668-71. Such a critique is a mark against deploying the term "republicanism" in connection with the role of large shareholders in extracting compensation for harm to third parties targeted by wrongful sexual power within the corporate structure. See id. Yet Hemel and Lund conclude that avoiding harm to investors resulting from un-remedied sexual misconduct "is entirely within corporate law's ambit." See id. at 1671 . Thus, the profit motive is not a sure response to the citizenship harms inflicted by organizational cultures that rely on top-down authority to limit internal expression, though it may prevent harms that arise from the misuse of such authority for wrongful personal gratification. See id. 
pressures to staff responsible for what nonprofits call "development."40

In part as a practical understanding, and more precisely as a normative claim, the vote of a principal group responsible for a nonprofit institution's mission has a presumptive weight unless there is a manifest conflict of interest on the part of the group expressing lack of confidence. A vote that is part of a larger power struggle that (1) does not concern a group's mission-driven expertise or governance role or (2) serves as late-stage virtue signaling by a previously passive faculty does not carry the same force as a vote arising from group knowledge gained from the group's execution of its mission. ${ }^{41}$ Like those of the large shareholder, the views of the mission-bonded group effectuating the work of a nonprofit carry weight. Those responsible for executing the mission have motives to monitor academic managers by using their asset of firm-specific knowledge about managers' conduct. A manager's loss of support from the professionals he or she must lead ordinarily has a sound basis. Without the support of a professional group responsible for a mission, when the problems underlying the loss of support threaten the capacity of a leader to function with any success, a formal claim on position becomes hollow.

Hence, a sometime shorthand conclusion- "it's political"obscures more than it reveals. In nonelective, nonprofit groups, the no confidence vote is the only mechanism for a solution to bad leadership that is immune to formal internal processes for correction. The resort to the no confidence motion is constrained by the social price and perceived risk of tearing down a smooth social surface, which is increased by the common absence of a codified recognition of the process. ${ }^{42}$ The lack of regularity, in the sense of the group action's

40. See infra Subsection II.B.2 (discussing the \#MeToo movement and its role in corporate sexual harassment).

41. In the context of power struggles, close calls could theoretically arise in institutions with specialized missions that were established at the founding and must be maintained by the internal expert group. An example might be a law school founded to pursue a distinctively public interest mission. If the faculty attempted to redirect the school's mission by revamping the curriculum and a dean overruled the effort, a vote of no confidence would fall within their expertise, but the weight of that expertise would be compromised by the faculty's sabotage of an agreed-upon mission. In addition, the import of the no confidence vote would be undermined by its role as a tactic in a power struggle rather than as a statement about the fitness of a leader. In the case of late-stage virtue signaling, the internal group is situated no differently than outsiders who develop an opinion based on public information.

42. A particularly high social price is a factor in the entire silence of faculties - defined here by the lack of votes of no confidence to precipitate disclosure and accountability - about sexual predation of the several types. 
being unauthorized, is paradoxically a strength derived from a form of weakness. When a vote takes place, it is a signal of deep organizational distress. The group has found the wherewithal to improvise a process, despite the lack of a set of rules that guide and reassure the group of the propriety and organizational approval of their deployment of voice. ${ }^{43}$ Voice emerges from a shared sense of crisis that brings a group to take unaccustomed risk, organize in an atmosphere of stealth and unease, and make a moral claim. As will be discussed in the comparison to litigation, however, the weakness is true weakness if the group cannot mount a successful effort, despite the existence of a seriously damaging state of affairs in the leadership of the entity. ${ }^{44}$

\section{B. The Model: Normative Content, Parliamentary Origin, and Application to Private Entities}

First, let us address the ideal model for a process leading to a vote by faculty to reject a leader and evaluate how well it serves a core function in the academy - supporting a robust exercise of free speech and academic freedom in connection with university governance. A further function that it may serve has a tint of republican ideals in it, one of expressing public norms supportive of moral, ethical, and competent leader conduct. That function is also democratic, but the republican hue demands that the reason for the vote be more than individual interest. Rather, the purpose is to hold leaders accountable by virtue of a collective voice shaped by public motives and concerns. ${ }^{45}$ That effort serves an epistemological purpose of

43. See supra note 36 and accompanying text (suggesting the incomplete articulation in some sectors of group rights to acquiesce to a leader's installation as well as understandings about acquiescence expressed in law school governance standards); see also infra note 226 (regarding faculty no confidence motions' potential use as "branding efforts" undertaken by faculty members in the wake of public scandal).

44. See infra Part III (recounting the lead up to, and the conduct and consequence of, a resort to litigation by a professor of law to address a sexual harassment scandal about which the faculty remained quiet).

45. See, e.g., Emma Vandelinder, MU English Department Votes No Confidence in Chancellor's Leadership, Columbia Missourian (Nov. 4, 2015), https://www.columbiamissourian.com/news/higher_education/mu-englishdepartment-votes-no-confidence-in-chancellors-leadership/article_4c8a52d6-832711e5-9ef3-5725103d82ec.html [https://perma.cc/JSM4-9HJS] (describing the University of Missouri's English Department voting no confidence in the school's chancellor, in part because of the chancellor's "lack of transparency and cooperation in decision-making, ... . his slow response time to major issues [such as racism] and for bowing to outside political pressures"). Public voices expressed through a no 
constructing a foundation of knowledge by unearthing and disseminating knowledge about patterns of behavior in organizations that carry substantive content and create an impact on social outcomes and on the formation of citizenship as broadly influenced by the role expectations internal to the organization. ${ }^{46}$ The standard internal channels for issues to be debated do not lend themselves to the airing of the knowledge of deep dysfunction about which an organization successfully maintains a culture of silence. Internally managed, decorous speech lacks the revelatory power of blunt description unleashed from the hesitations of the parlor, the boardroom, and the faculty meeting conference room.

\section{History of the Vote of No Confidence}

The ideal, the name, and the model for the vote of no confidence is the parliamentary motion of censure developed in England in 1741, arising from an attempt to dislodge Sir Robert Walpole from a position he had gained as a leading minister for the King. ${ }^{47}$ Because the Prime Minister came to be seen as the King's agent in Parliament, the vote of no confidence against the person appointed to the role was conceived as deeply controversial. ${ }^{48}$ Therefore, it was seen as an attack

confidence vote also arise from student and faculty outcry over such matters as alleged mishandling of race issues. See Kyle Arnold \& Max Denning, Update: Ithaca College Students Vote No Confidence in Rochon, ItHACAN (Nov. 30, 2015), https://theithacan.org/news/ithaca-college-students-vote-no-confidence-inpresident-rochon/ [https://perma.cc/MX8E-3HBU] (describing racial incidents on campus and concern about presidential leadership); see also Faith Meckley \& Kyle Arnold, Ithaca College Faculty Vote No Confidence in President Rochon, ITHACAN (Dec. 14, 2015), https://theithacan.org/news/majority-of-ic-faculty-vote-noconfidence-in-tom-rochon/ [https://perma.cc/V5AD-JA5M] (reporting a vote of no confidence by faculty of $77.8 \%$ of voters in president over race issues, following a vote of no confidence by $71.75 \%$ of students responding to a poll).

46. See supra notes 7-9 and accompanying text.

47. See John P. Mackintosh, The British Cabinet 52-61 (1st ed. 1962) (stating that Robert Walpole succeeded in initial resistance, though he eventually resigned and became the Earl of Oxford). For a thorough account of the unprecedented nature of the motion, which was called Sandys' motion after its proponent Samuel Sandys, and the response by Walpole, as well the idea of Kingly prerogative in choosing the First Minister, see TAPANI TURKKA, THE ORIGINS OF PARLIAMENTARISM: A Study OF SANDYs' Motion 34-44 (2007). The motion was later applied to Lord North in 1778 after the role of a leading minister had clearly become that of Prime Minister. See id.

48. See Mackintosh, supra note 47, at 64 ("[A]n address to His Majesty to remove one of his servants, without so much as alleging any particular crime against 
on the prerogative of the King, a figure still partially symbolic of sovereignty despite the emergence of parliamentary counterpower in the Glorious Revolution in the seventeenth century. ${ }^{49}$ Though Walpole had originally been a proponent of a radical view of the Glorious Revolution as a movement away from the existing system of monarchial rule and toward popular sovereignty, he altered his view when he gained power in Parliament. ${ }^{50} \mathrm{He}$ turned to a rejection of the idea that England had been transformed into a nation ruled by popular sovereignty. ${ }^{51}$ So the vote to dismiss Walpole because of the wishes of members of Parliament directly challenged a view dismissive of Parliament as a representative body responsible to serve the popular will. In effect, in power, Walpole began to embrace a top-down elite authority that denied absolutism but did not yield to a claim that the people ruled. ${ }^{52}$ The resulting no confidence debate in Parliament began tentatively with rules against transcription of debate and gradually evolved into a transparent process that drew on ideas of honor and accountability to force the resignation of both a prime minister and his or her government. The British vote in Parliament achieves a degree of democratic discipline from its beginnings in a heavily contested attack on what was perceived to be top-down authority..$^{53}$ The idea of

him, is one of the greatest encroachments that was ever made upon the prerogatives of the Crown.").

49. The history of kings in England is beyond the scope of this Article. It is worth noting, however, that the idea of the king as the embodiment of sovereignty, with a color of divine authority, did not simply vanish at the time of the Glorious Revolution. In his book on the American Revolution, Eric Nelson argues that there was sentiment among the American colonists to restore a monarchical rule in protest of Parliament's intrusion into colonial affairs. See ERIC NeLSON, The RoyAlist Revolution: Monarchy AND the AmERICAN Founding 1 (2014). Royalism in England, with the tint of divine authority, did not die overnight, thus lending added weight to the resistance to an effort by members of Parliament to oust the King's First Minister. In an important work arguing that the Glorious Revolution was more radical and violent than has been thought, Steve Pincus addresses differing views by historians on the extent to which the Anglican Church retained its prerevolutionary notion of "true divine right Protestant[ism]." See Steve PIncus, 1688: The FIRST Modern Revolution 401 (2009); see also Leanda de Lisle, The White King: Charles I, Traitor, Murderer, Martyr xxvi-xxx (2017) (describing the complicated mixture of British acceptance of both the king and Parliament as a source of sovereignty in a period of religious conflict). Whether remnants can be found in unstated claims by university administrators to special rights immune to human interference is also beyond the scope of this Article.

50. See PINCUS, supra note 49 , at $16-17$.

51. See id.

52. See id. at 17.

53. See id. 
honor implicates the resignation with grace of the target of the vote..$^{54}$ The tradition long remained unwritten yet subject to norms that disciplined the use of no confidence votes by way of strong consensus within the relevant political class. ${ }^{55}$ As democracy emerged in Great Britain, the first impulse had been to suppress the circulation of information about debate in Parliament, which thereby applied to the basis of the protest against Walpole, as well as the arguments and counterarguments. ${ }^{56}$ As with votes of no confidence in contemporary organizations, the formally available mechanism for discourse was not friendly to the epistemological work that might build a new foundation of knowledge about the disputes over inner workings of an organization, in this case Parliament, as a body consonant with a democratic ethos. ${ }^{57}$ If the debate was not known to the public, new structures of knowledge would not take form on which to build democratic practices. Over time, the premises for ongoing

54. The resignation of Lord North in response to a later vote of no confidence provides the example of an honorable concession to democratic feedback. See PETER Whiteley, LORD North: The Prime Minister Who Lost AMERICA 196-204 (1996) (accounting the parliamentary maneuvers, Lord North's reactions, and the King's resistance to North's resignation); see also TURKKA, supra note 47, at 37 (describing the argument that the exercise of power should not be contrary to the people's will, thereby making "general satisfaction or dissatisfaction ... the criterion in judging of the exercise of power").

55. See Alpheus Todd \& Sir SPEncer Walpole, Parliamentary Government in England: Its Origin, Development, and Practical Operation 120 (Marston \& Co. 1892) (stating that expulsion without a reason was understood to be reserved for only extraordinary necessity, or, in the words of the treatise, "for great occasions").

56. From the second half of the sixteenth century the British Parliament prohibited all reporting and publishing of its proceedings. The Parliament believed it should deliberate in private and regarded any attempt to publicize its proceedings as a serious, punishable offence. See About Hansard, PARLIAMENT OF VictORIA (July 17, 2009, 1:24 PM), https://www.parliament.vic.gov.au/hansard/about-hansard [https://perma.cc/RDN9-G4F6] ("By the late 18th century dissension among more progressive members of Parliament, the growing weight of public opinion and the increasingly outspoken attacks of the press persuaded the Parliament to relax its stance. In 1803 the House of Commons passed a resolution giving the press the right to enter the public gallery.").

57. See generally William Corbett, CobBetT's Parliamentary History of ENGLAND From the NoRMan CONQUEST, In 1066, to THE YeAR 1803 (1807) (describing the various sources used to compile a parliamentary history that are thought to be accurate). Workarounds defeating the formal rules seemed to have existed in published transcriptions of the debates that later have been pronounced authentic in various compilations. See id. These workarounds provide an early example of improvisation to channel protest outside the formal rules available for such voice. See id. 
epistemological work to emerge from a format for accountability were embedded in parliamentary usages, and even recorded on an information-rich website..$^{58}$

These aspects of the ideal no confidence vote as it has developed in Parliament are not realistic in private organizations in the United States. First, those participating in the vote are employees. No matter how strong their assurance of tenure and however much the entity is tied to the liberal values of open inquiry and commentary, they face danger to their security of position. Constitutional law as a protective venue for faculty, either as individuals or participants in group efforts, offers weak protection to faculty whose exercise of voice often produces retaliation damaging to their standing and access to resources. For that reason, faculty whose livelihood depends on their remaining in favor with those in command of the machinery of a university, for example, perceive the risk of helping canvass sentiment against the hierarchy to be high. ${ }^{59}$ And in known instances of internal expression about a leader problem, they have been high. ${ }^{60}$ Second, the circumstances that might produce open debate organized under the bylaws of a university are not common. While some votes do occur in formal faculty meetings, as took place at Harvard in 2005 and was scheduled for a repeat in $2006,{ }^{61}$ the genuine debates take place in

58. See generally U.K. PARLIAMENT, https://www.parliament.uk/ [https://perma.cc/XN67-YK42] (last visited Apr. 13, 2020) (displaying an information rich website for the United Kingdom's parliament).

59. See Telephone Interview with Anonymous, Faculty Member, Major Univ. (July 28, 2018) [hereinafter Telephone Interview July 28] ("My tendency is to see this fear, there is definitely fear if you want to talk about emotions, there's definitely a deep-seated anxiety that people have about their situation should they speak up. But I think it's fully rational. I think it's probably fully rational to believe that. Again, it would be irrational to think you would be fired perhaps, for speaking up against the university president, but again, the university can make your life miserable in myriad ways if it wants to. I think people really fear being on the outside, right? More than anything, they [feel] like, well, you want to be in the good graces of the administration, of the president, of the provost, of the dean. You don't want to have a hostile relationship with these people because they can make life difficult. Maybe you won't get that promotion. Maybe you won't get that raise next year, if these people don't like you. I think that's a realistic fear which people have, and as I say, it's really no different than any other employee has in our capitalist society.").

60. See infra Section III.C (describing the retaliation against Associate Dean Ray $\mathrm{Ku}$, Case Western Reserve University School of Law, when he reported concerns about the dean of the law school of Case Western Reserve University to Case Western administrators, and additional retaliation against an administrative assistant to the dean).

61. See Summers Gets Vote, supra note 1 . The 2005 vote was followed by a prompt statement of approval by the Harvard Corporation. See Sara Rimer, 
gatherings of a group with sufficient trust among the members to share views openly and without concern for negative repercussions. Deciding which colleagues can be trusted to engage in open discussion is a matter of fraught discussion among those first considering a no confidence action. For that reason, the current practice in universities does not follow a tradition of open, robust debate as might occur in a parliamentary style.

Professors, in Close Vote, Censure Harvard Leader, N.Y. TiMES, (Mar. 16, 2005), https://www.nytimes.com/2005/03/16/education/professors-in-close-vote-censureharvard-leader.html [https://perma.cc/P8NW-U6TU]. For an account of the resignation by President Summers to avoid an embarrassing second no confidence vote scheduled for late February 2006, see Marcella Bombardieri \& Maria Sacchetti, Summers to Step Down, Ending Tumult at Harvard President Faced Revolt; Bok to be Interim Head, Boston.COM NEWs (Feb. 22, 2006), http://archive.boston.com/ news/education/higher/articles/2006/02/22/summers_to_step_down_ending_tumult_ at_harvard/ [https://perma.cc/XVW2-2ZNL]. 


\section{Donors, Money, Sex, and Silence: The Missing Group Voice}

The factors that prevent the vote of no confidence in American universities and other nonprofit institutions from developing the same maturity of convention and broad understanding that is possible in Parliament are strongest in connection with sexual misconduct by persons with power inside the organization. The normal risk aversion to speaking against power is undoubtedly strengthened by broader cultural toleration for sexual misconduct by men, and even today women, with power. The sense of solidarity does not develop as it does when other kinds of misconduct or simple incompetence pose a direct challenge to the professional norms and mission-defined commitments of the group. It is unfortunate to say that the protection of the vulnerable from sexual predation has not been a professional norm but it appears impossible to deny the obvious. Where the harm to the victims is not understood as a systemic assault on the shared professional role to advance the mission, the group is not moved to action by an altruistic duty to rescue. Though I have argued that the vote of no confidence is not about mere private interest and that participating in one requires civic courage, the group's action typically cannot be said to arise from simple altruism.

Further, it is always possible that knowledge of such conduct is not widespread because the conduct is surreptitious and because the disapproval of what some would call gossip about sexual behavior can be strong. The impulse to look away at an embarrassing scene is regarded as good manners, a lesson in etiquette than can be only too readily misapplied in the workforce when the embarrassment would accrue to someone in power. One properly trained in etiquette may be inclined to avert his or her eyes at the sight of the boss manhandling his secretary. The individual alarm needed to bring a group into communication about a leader problem may never be sounded, thereby making outcry a victim of the comfort afforded by manners as well as by the ease granted by ready rationalization in preference to the afflictions of civic courage. In such a moment, etiquette shows integrity the door. Sadly, the possibility that unwillingness to speak can also be a feature of monetary advantage cannot be dismissed.

Certain nonprofits, aside from universities, may be even more subject to sexualized mistreatment of employees. In entities heavily organized around private fundraising, employees may have absolutely no recourse because of the array of incentives created by the need to cultivate donors. As anyone involved in a setting in which donors contribute significant resources would recognize, donors are spoken 
of with something akin to reverence. A recent report concerning the lack of any power on the part of female fundraisers in nonprofits to stop sexual harassment by donors they must approach is troubling. ${ }^{62}$ One fundraiser said that the result is less money for the charity she is working to fund..$^{63}$ The encouraging word is that fundraisers who know the problem have formed group efforts to change the culture. ${ }^{64}$ Presumably, open speech about abusive donors, or litigation, is entirely impractical, so the method being used is that of education about the problem in general, rather than confrontation that would result in even greater losses of funding to charitable organizations.

Before the series of university sex scandals affecting students, there was already a long-standing problem involving career-damaging or -ending sexual harassment and retaliation against female faculty. Strong women faculty were in some cases driven out of one university to another one, and other women left academia entirely. ${ }^{65}$ Faculty

62. See Debra Nussbaum Cohen, Women in Jewish Fundraising Say Harassment is Pervasive, JEwISH TEL. AgENCY (Feb. 26, 2018, 4:17 PM), https://www.jta.org/2018/02/26/news-opinion/united-states/for-women-in-jewishfundraising-harassment-is-an-occupational-hazard?utm_source=JTA\%20Maropost \&utm_campaign=JTA\&utm_medium=email\&mpweb=1161-3106-207459 [https://perma.cc/D3DT-BCNS] ("At the end of the day, in the nonprofit world, donors hold nearly all the power. Most big-money donors are male.").

63. See id.

64. See id.

65. See Tom Bartlett \& Nell Gluckman, She Left Harvard. He Got to Stay, Chron. Higher Educ. (Feb. 27, 2018), https://www.chronicle.com/interactives/ harvard-harassment [https://perma.cc/AG2K-X9DV] (describing the sexual harassment by Jorge Dominguez); see also James S. Bikales, Protected By DecadesOld Power Structures, Three Renowned Harvard Anthropologists Face Allegations of Sexual Harassment, HARV. CRIMSON (May 29, 2020), https://www.thecrimson.com/article/2020/5/29/harvard-anthropology-gender-issues/ [https://perma.cc/H8LJ-PREA] (reporting their denials); Joey Garrison, Harvard Bans Ex-Professor After Finding 'Unwelcome Sexual Conduct' Spanned Four Decades, USA TODAY (May 11, 2019, 2:44 PM), https://www.usatoday.com/story/ news/nation/2019/05/09/harvard-university-professor-jorge-dominguez-sexualharassment-misconduct-metoo-title-ix/1154497001 [https://perma.cc/BMK7-5U6E] (stating that Dominguez has been asked to leave the faculty). Though harassment has been and likely is still a factor in departures by talented women from the academy, those who leave should not be understood as "unworthy" of an academic post. A reader commented as follows: "[One should not imply that] flight from the unfavorable circumstance [of sexual harassment] is due to the women in question not being as 'worthy' to continue their academic careers, which elides the possibility of some women deciding in the wake of being harassed or worse that academia isn't worth the headaches/doesn't deserve them/had its chance and blew it. There's an unfortunate tendency by academics to regard those who moved from in-group to out- 
members with sufficient power-who are often male - in many instances commanded access to significant monetary resources (rich grants or other forms of donor aid) to the university. ${ }^{66} \mathrm{In}$ addition, sexual harassment of students by male faculty was far from unknown, and targets who made an issue of it were in some cases subjected to severe expressions of disapproval. ${ }^{67}$

The fact that sexual transgression against women occurred, and that once a woman was targeted and resisted she could not recover her standing in an academic institution against the displeasure of a powerful male, is well known by the generation who began to enter the academy as graduate students and then as junior faculty in the $1970 \mathrm{~s} .{ }^{68}$ The denial of tenure was a fairly standard scenario, sometimes having been preceded by sexually inappropriate treatment of these women. Heightened standards applied to their tenure case were frequently in contrast to a more forgiving standard that had been applied to the males who considered their candidacy or to the men who followed in the tenure queue. For women academics who reported sexual harassment, the regimen of federal anti-discrimination law under Title IX was inadequate and even perverse. ${ }^{69}$ Despite interpretations of changing mores as between men and women purportedly explaining behavior that was shielded from accountability and finally confronted by \#MeToo, toleration of male sexual predation was not a fit for much of the wider culture outside the academy or other institutional settings. Were it not the case that norms of sexually

group as castoffs rather than successful migrants to less-oppressive environs." See Statement of Anonymous Copy Editor (June 3, 2020).

66. See, e.g., Stephanie Saul, Harvard Professor Resigns Amid Allegations of Sexual Harassment, N.Y. Times (Mar. 6, 2018), https:www.nytimes.com/ 2018/03/06/us/harvard-professor-resigns-sexual-harassment.html [https://perma.cc/5UBD-D44J].

67. Feminist writer Naomi Wolf provides a striking example of the deep inclination within the broad culture to rally to protect the male whom a student target "outs" for sexual harassment. In the case of Wolf, she disclosed after twenty years that the eminent Yale Professor Harold Bloom had invited her to his home for scholarly interaction and had placed his hand on her thigh. See Naomi Wolf, The Silent Treatment, N.Y. MAG. (Feb. 20, 2004), http://nymag.com/nymetro/news/features/ n_9932/ [https://perma.cc/EA8J-43EC] (recounting the negative commentary about Wolf's revelation about Bloom and her attacks on her alma mater's response when she complained after twenty years).

68. See, e.g., Bartlett \& Gluckman, supra note 65.

69. See generally Anne Lawton, Between Scylla and Charybdis: The Perils of Reporting Sexual Harassment, 9 U. PA. J. LAB. \& EMP. L. 603 (2007) (describing the failure of university investigative procedures to protect the victim of sexual harassment by a fellow faculty member). 
proper and respectful behavior exist and have existed, the predicate for \#MeToo would be entirely absent. Hence, the record of longstanding unchecked misconduct in institutional settings must be seen as a form of institutional malfunction or systemic corruption in which many individuals are implicated, some perpetrating, others facilitating, and the many tolerating passively. If manners explain some portion of the silence about sexual misconduct, it cannot entirely account for the Epic Failures involving institutionally sheltered predation.

These highly visible institutional failures-long-term tolerance of sexual abuse of students being the most stunning and well publicized - provide a contextual basis to examine a cultural failure in universities, one that is unaddressed by the existing formal accountability mechanisms.

\section{Where Votes of No Confidence Happen Today}

If faculty votes were part of the ordinary governance process in most universities, a no confidence vote might require some preliminary private consultation, but it could soon become an occasion for the faculty to join together to debate and draft a resolution against their president, vote, and, if it passes, publish it in the proceedings of the faculty body, which would be readily available to the whole community. ${ }^{70}$ Ideally, the president would accept the verdict of her peers in the academy with grace. ${ }^{71}$ Admittedly, the foregoing depicts the epistemic ideal. One should not underestimate the depth of fear even within regularized proceedings in a university in which the target

70. At Harvard, the vote of no confidence in President Summers was noticed for a regular faculty meeting and passed in the meeting, but it was by no means an ordinary use of the notice procedure for a meeting of the Harvard faculty of arts and sciences. See Summers Gets Vote, supra note 1 (stating that the resolution was unheard of in Harvard's modern history). In 1939, President James Conant averted a planned motion that was understood to constitute a vote of no confidence by apologizing to the faculty at the beginning of the meeting in which the motion was to be lodged. He also pleaded that the faculty not allow his mistakes to harm Harvard for years to come. Jennet Conant, MAn of the Hour: James B. ConANT: Warrior SCIENTIST 170-72 (2017).

71. Lord North was the first British Prime Minister to accept the principle, upon learning of a vote of no confidence against him in Parliament, to acknowledge that the government had collective responsibility for policies and hence could be attacked "as a whole" by demanding the removal of a minister. See MAcKintosh, supra note 47 , at 64 . This history, though not well known, is embedded in the oral tradition by which faculties expect the recipient of notice of a motion of censure to yield to its significance as a critical loss of needed support. 
of a vote of no confidence may be thought likely to retaliate, and in which the notion of a cultivated voice seems incompatible with an attack on a person regarded as a colleague. The tension between an elite monopoly on public reason and an attempt at input by the average person is replicated even in the rarefied precincts of Harvard University. ${ }^{72}$

Instead, many such votes in America occur in improvised private settings, such as, for small colleges, reserved meeting rooms in restaurants or a faculty member's home. ${ }^{73}$ In others, members find some means of using the university system for email communication, sometimes without assurances that such a use by faculty for entitywide communication is permissible. ${ }^{74}$ Moreover, faculty members of American institutions must sometimes work against efforts by the university to inflate the balloting list by including in it the staff of the administration. ${ }^{75}$

72. See Richard Posner, Summers' Resignation and Organization Theory, BECKER-PosNER BLOG (Feb. 26, 2016), http://www.becker-posnerblog.com/2006/02/summers-resignation-and-organization-theory--posner.html [https://perma.cc/38MF-PFRM] [hereinafter Summers' Resignation] (explicitly arguing that the trustees are solely capable of assessing Harvard interests for the long term). See ROSENFELD, supra note 7, at 37-38 (describing "the history of modern democracy" as "riven with constant tension between the rule of expert truth, on the one hand, and the rule of majority instincts, on the other").

73. My own law college has experienced votes over a period of many years in such locations. The use of an off-campus location can be controversial, especially if the institution is subject to open meetings laws, but in any event, the meeting can be treated by critics as clandestine and hence discreditable to the group. Such responses play a role in the efforts by administrators to dismiss the vote as lacking all meaning for official action.

74. See Telephone Interview July 28, supra note 59 (explaining that the faculty senate "was not interested or willing to take up the question, and they certainly weren't willing, as it were, to call for, authorize or sponsor this kind of vote" and that the group that did a no confidence vote contained "senators with a right to send out email messages to all faculty by email [and] [s]o that's how we did it . . . because I doubt very much that the administration would have given us the emails").

75. It is a common responsive tactic after a vote of no confidence has occurred with majority support for the motion for the officials in the target's institution to argue that the denominator is too small, because it should include certain others, including non-tenure-stream faculty members and staff. In a long-running conflict at the University of Louisville regarding President James Ramsey, the president seemingly took matters into his own hands, or those of his helpers. In an Insider Louisville reader poll, Insider Louisville reported significant ballot stuffing that occurred in the online poll. See Joe Sonka, IP Addresses That Skewed Ramsey No-Confidence Poll Located at U of L's Grawemeyer Hall, Where President Office Is Housed, LOUISVILLE FutURE (Apr. 13, 2016), https://insiderlouisville.com 
Finally, despite the provenance of the vote of no confidence in British parliamentary history, such votes in American nonprofit organizations have not developed in tandem with the parliamentary practice..$^{76}$ Unlike the British context, the typical American nonprofit group or state university is not a self-governing body that creates a government understood to be responsible to its members. ${ }^{77}$ In the

/government/ip-addresses-of-users-who-skewed-ramsey-no-confidence-located-ofu-of-ls-grawemeyer-hall-where-presidents-office-is-located/ [https://perma.cc/ C6MH-GGGN]. The paper did a kind of electronic exit poll analysis, summarizing the voting patterns and locations as follows:

After the first 24 hours, well over 80 percent of voters supported a no-confidence motion, but in the span of two hours, the results suspiciously flipped to 78 percent supporting Ramsey. Of the 1,000 votes cast before the poll was taken down, 68 percent came from IP addresses on U of L's campus within a two-hour span on the day after the poll was posted - all supporting Ramsey. Based on Insider Louisville's IP data, up to 15 votes per minute were cast from the same computer, which the head of our IT department said suggests a script potentially was used to subvert the survey. At the very least, a user would have had to turn off his computer's "cookies" to override IL's intended one-vote limit and proceed to cast many votes in quick succession. Nearly half of the total votes in the survey came from three IP addresses at Grawemeyer Hall in the same two-hour timeframe; 146 votes came from two wireless users on the Belknap campus.

$I d$. Notably, the University of Louisville open records administrator denied a request by Insider Louisville for location and user information about the respondents. See id. Nonetheless, because Insider Louisville already had email address information, the media outlet was able to reconstruct an exit poll. See id.

76. See supra notes 58-61 and accompanying text.

77. As noted, by comparison to a parliamentary body, the governing structure of institutions of higher education in the United States have many variations in their governance, but the common factor is a governing structure that lacks an obvious logic for maintaining legitimacy in the face of negative opinion within "the body" responsible for its mission. See id.; see also Colleges and Organizational Structure of Universities, STATEUNIVERSITY.COM, https://education.stateuniversity.com/pages /1859/Colleges-Universities-Organizational-Structure.html\#ixzz5PoNenCpy [https://perma.cc/8HGW-XZ3P] (last visited Apr. 13, 2020) ("While a private liberal arts college may have a large board of trustees, and a public research university nested in a state system no trustees of its own, the vast majority of public and private universities are overseen by an institutional or system-wide governing board. . . A university's governing board, also known as the trustees, regents, or board of visitors, possesses fundamental legal authority over the university. The authority of the governing board is vested in it by the state wherein the school resides or, particularly in the case of older, private institutions, by legally binding royal or colonial charters."). Notably, "[p]rivate boards are generally self-perpetuating, with new trustees chosen by the membership of the standing board." Id. Though public universities have boards nominally representative of the public, the process by which 
British parliamentary context, "[a] government cannot operate effectively unless it can command a majority within the House of Commons. Should it fail to enjoy the confidence of a majority of the House, it has to hold a general election." "78 The government's legitimacy derives from the election of the members of the representative body that continues to support the prime minister. ${ }^{79}$

For American nonprofit entities, there is no transparent logic as to how its governance structure makes it legitimate ${ }^{80}$ Rather, nonprofit bodies of the sort under discussion here typically consist of a governing board, a principal administrator named by the board, and a large body of professional members primarily responsible for the work of the entity. ${ }^{81}$ Their basic case for the maintenance of legitimacy is

such faculty opinion can be transmitted for purposes of accountability to an informed body, such as members of the House in Great Britain or an engaged board of trustees, lacks the obvious vigor and tight logic of a parliamentary vote of no confidence. See $i d$. A vote by faculty expressing a loss of confidence carries some clout, though the clout is qualified by the "fuzzy" accountability logic in the university. See id. A selfperpetuating board is among the most insulated of governance structures possible, as a simple matter of logical implication from fact. See id.

78. HOUSE OF COMMONS INFORMATION OFFICE, PARLIAMENTARY ELECTIONS, FACTSHEET M7, MEMBERS SERIES, (2010).

79. See John D. Huber, The Vote of Confidence in Parliamentary Democracies, 90 AM. Pol. SCI. REv. 269, 270 (1996) ("The confidence vote procedure is part of a broad class of institutional arrangements that formalize a prime minister's dependence on majority support in the legislature.”). Huber provides useful explanation of the phenomenon of government-initiated confidence votes, in which the government places pressure on its supporters in a parliamentary body to express confidence in specific policies or programs. See id. at 269. Although Huber calls these procedures formal, for a table of Confidence Vote Procedures in Eighteen Democracies, he uses as his sources "the Constitution, the standing orders of the lower house, and interviews with at least one member of the permanent staff of the legislature." $I d$. at 271 . Thus, the parliamentary procedures are, in a certain sense, a hybrid of formal (authorized) and informal (belonging to the body without written documentation). See id.

80. My coauthor and I will provide a case study of an organization with governing documents that enabled the members to elect replacements for a board after obtaining their resignation through a vote of no confidence. See KUYKENDALL \& McKINNISS, supra note 26. The organization is the Ontario Medical Association, a large membership group that advances the interests of Ontario physicians by helping strengthen resources for their public mission but does not function as an operational body responsible to deliver services. See id. Given its organizational format with governance rules that resemble corporate election practices, the Association did have clarity about the ultimate source of legitimacy, but it took considerable work and the revelation by the members to recognize their capacity to supplant the board and then alter the bylaws for more responsive paths to board membership. See id.

81. Votes of no confidence occur in certain public service organizations, such as fire departments, police departments, libraries, and health organizations. These 
their contribution to society by adherence to their mission and to standards of decent conduct. For both of those tests, the most wellinformed group to attest to the retention of legitimacy, under the governance provided by the boards and the named leaders, is the professional group responsible for the mission and for the welfare of its beneficiaries. Nonetheless, given the large numbers of such organizations, the variety in form, and their dispersed locations, the understanding of the role of the professional group in attesting to or rebutting the bona fides of the organization as it is being governed by the incumbent leaders is not well formed. In the British Parliament, the practice evolved away from initial outrage against an effort to oust a leader approved by the King to an understanding that the Prime Minister was a result of an election of the members who stood for office with him as the standard bearer. ${ }^{82}$

Given the relatively shallow history of the American practice in nonrepresentative entities and the long history of the development and refinement of the practice in the British Parliamentary tradition, the American version of the no confidence vote lacks the maturity and clarity supplied by a cohesive British political culture. The case for the vote of no confidence in the situations and cultures described above is subject to confusion and controversy. ${ }^{83}$ The formation and execution

have members with special skills that give the members a sense of solidarity around a common calling and the requirements for them to pursue that calling competently and with the respect due to any person. Id. See Excerpts From 'No Confidence' Letter, HANFORD SENTINEL (Dec. 27, 2010), https://hanfordsentinel.com/news/local/excerpts -from-no-confidence-letter/article_b0e76f5e-11ec-11e0-9597-001cc4c002e0.html [https://perma.cc/ZE4L-573M], for a statement, with a bill of particulars, of a group of department heads in Hanford, Connecticut. Libraries often experience votes of no confidence and are a target of the usual critique. See John N. Berry, III, Editorial, The "No Confidence" Vote: A New Weapon for Library Staff, Effective but Dangerous, LIBR. J., Sept. 1, 2006, at 8 ("Used carelessly or too often, the no confidence vote can create the workplace equivalent of mob rule and thus undermine the credibility of the strategy and those who use it.").

82. Recent events in the British Parliament have unusual features that are beyond the scope of this Article.

83. The vote of no confidence that resulted in the resignation of President Larry Summers from his presidency at Harvard University created significant confusion and antagonism at Harvard within the faculty, among alumni of Harvard, and on the part other observers of Harvard as "a case study in the ability of college presidents to exercise management control in a historically collegial and decentralized environment." Lois Romano, Embattled Harvard President to Resign, WASH. PosT (Feb. 22, 2006), https://www.washingtonpost.com/wp-dyn/content/article/2006 /02/21/AR2006022101842_pf.html [https://perma.cc/YU4R-XZ6F] (quoting Professor of Law Alan Dershowitz as charging that "one group of faculty managed a coup d'etat not only against Summers but against the whole Harvard community"). 
of a no confidence vote is a process often fraught with anxiety about and ignorance of the process. ${ }^{84}$ The ignorance of the process sends those considering a no confidence action on a search for information and analysis. ${ }^{85}$ Absence of knowledge causes anxiety by those faced with a possible need for group voice. Moreover, the administrative hierarchy's reaction to a no confidence vote is typically formulaic, indifferent, and/or brusque. ${ }^{86}$ In an extreme response, a law school board fired all the untenured faculty after such a vote, even though none of these junior faculty had participated ${ }^{87}$ Votes of no confidence

84. Sean McKinniss, the coauthor of my forthcoming book, and I have spoken with faculty members who shared details of clandestine meetings to discuss no confidence votes at their respective institutions. One faculty member was said to have demanded to discuss a no confidence vote from his home because he thought his office telephone was wiretapped. See KuYKENDALL \& MCKINNISS, supra note 26. While some observers may view such a concern as unduly mired in conspiratorial thinking and even paranoia, facts about the atmosphere in many universities and other institutions make the fear understandable, whatever the facts of a university's willingness to spy on faculty members. Similar concerns exist regarding the use of institutional email services. See id.

85. Some faculty members provide information for others through professional publication of accounts of a vote of no confidence in which they were involved. See Zack, supra note 20, for a good example. The need of such information, and analysis of the reasons that such votes occur, with a basis in organizational logic, is considerable. My coauthor and I were told by a leader of a vote of no confidence by doctors in Canada that our advice about consulting one's conscience about one's true motives - moral and ethical or simple self-interest-gave her the fortitude to proceed. Telephone Interview with Anonymous, Member Physician, Canadian Doctors' Ass'n (Oct. 2, 2017) (noting that, “'[p]articularly at that point-where many of us were wondering, "Do we stop, or do we keep pushing forward?"-your words really helped").

86. See, e.g., Martin Lipton, Statement from Martin Lipton, Chair, NYU Board of Trustees, NYU (May 2013), http://www.nyu.edu/about/leadershipuniversity-administration/board-of-trustees/statement-from-martin-lipton--chair--

nyu-board-of-trustees.html [https://perma.cc/JU8Y-FBA6]. The President of the New York University Board of Trustees quickly issued a strong response to a vote of no confidence by faculty of the College of Arts and Sciences in the President, John Sexton. See Kevin Kiley, Not Your University, Inside HiGHER Ed (Dec. 19, 2012), https://www.insidehighered.com/news/2012/12/19/nyu-vote-no-confidence-

highlights-divergent-views-faculty-role-governance [https://perma.cc/J2TC-TDDY] ("I have widely consulted my colleagues on the board, and their observations align with mine: John's stewardship has been superb, he is widely and rightly acknowledged as an international leader in higher education, and he - and the strategic direction he has set for the university - enjoys the support of the board,' said board Chairman Martin Lipton in that statement.").

87. See KUYKENDALL \& MCKINNISS, supra note 26 (referring specifically to the vote of no confidence in the dean of the Detroit College of Law, the corporate predecessor to Michigan State College of Law). 
in universities are often denounced as nothing more than the selfserving behavior of an insulated and privileged faculty. ${ }^{88}$

This standard attack resembles one of the methods discussed by Tamar Frankel in her book on trust and [dis]honesty in American's business culture as a means by targets to debunk charges of dishonesty. ${ }^{89}$ The practice of graceful exit by the resignation of the target, in a concession to the notion of a gentleman's honor, may have been lost to the mists of time in today's American leadership culture. The result of the shallow roots in a culture quite different from the cohesive British political class is that groups struggle to understand the normative place of the vote of no confidence. In the university and other nonprofit institutions, the mixture of authority, lack of true ownership, reliance on expert groups responsible for mission, and periodic crisis caused by poor leaders leaves faculties and other professionals grasping for a guide to legitimate responses appropriate to a guardianship role for the entity's mission. Simplicity is not to be.

Yet an intriguing pattern of successful faculty efforts has emerged, even without the normative understandings that have given the original model its acceptance as a functional feature of democracy as practiced in the English Parliament (and in many others)..$^{90}$ Even so, success does not foster widely accepted norms. An oral tradition within universities and other organizations provides a poorly marked pathway through the thickets of a modern bureaucratic forest in which dangers haunt the imagination of faculty torn between the unknown dangers of speech and the continuing costs of silence. Scores of faculties have held votes that resulted in leadership changes. ${ }^{91}$ Still the process of developing and implementing a no confidence vote may

88. Judge Richard Posner expressed such views in commenting on a vote of no confidence by Harvard faculty members in President Lawrence Summers. See Richard Posner, The Summers Controversy and Academic Governance, BECKERPOSNER BLOG (Feb. 27, 2005), http://www.becker-posner-blog.com/2005/02/thesummers-controversy-and-university-governance.html [https://perma.cc/A76PVXRA] (arguing that the interests of the trustees, as well as their time horizon and primary focus, are in better alignment with the interests of the university than those of the faculty); see also Summers' Resignation, supra note 72 (referring to the Harvard faculty as "a faculty many of whose members are both smug and superannuated").

89. See also infra Part III (discussing votes of no confidence at universities). See generally FRANKEL, supra note 32 (discussing methods of debunking claims of widespread dishonesty).

90. See Sean McKinniss, No-Confidence Vote Database, SEANMCKINNISS.ORG, http://www.seanmckinniss.org/no-confidence-vote-database/ [https://perma.cc/ETM4-GF2B] (last visited Apr. 13, 2020) (displaying a database of successful votes of no confidence).

91. See id. 
generate dread and confusion, as well as inspire retaliation or falsehoods. We may anticipate not the oft-invoked specter of unduly frequent and poorly justified votes, but rather the likelihood of underproduction of the group statements that provide alerts to leadership pathology. From this incongruity arrives a question that is the focus of this Article: what can be done when a no confidence vote is warranted, but faculty, out of fear or, worse, passivity, will not pursue it? Is there a substitute for the no confidence vote?

\section{EPIC FAILURES IN THE NONPROFIT SECTOR: PROBLEMS AND RESPONSES IN THE UNIVERSITY TO SEXUAL PREDATION}

In the United States, except for the for-profit corporation, accountability logic is failing in critical organizational sites in which much of the nation's collective life occurs. ${ }^{92}$ Nonprofit corporations depend on weakly motivated boards of directors for monitoring the leaders of the organization. In addition to the formal availability of a monitoring board, such organizations develop internal mechanisms that purport to place leaders under potential scrutiny for misconduct or general failure as leaders. Unfortunately, these mechanisms have shown a pattern of failure in recent scandals. Universities are the disturbing exemplar of weak internal checks that have in recent years produced near-catastrophic failures of internal oversight, with sustained social harms of an extreme nature only ended by public exposure and outcry. ${ }^{93}$

92. The for-profit corporation has become increasingly accountable to investors who seek high returns, in part because of a reform of rules to make more efficient pressure on boards by activist shareholders seeking positions. See Loop et al., supra note 9 . The primary metric of accountability in these profit corporations is share price, which is driven mainly by decisions about the business approach. Nonetheless, the access of motivated shareholders to the pressure points on boards also creates incentives for management to prevent scandals that create legal liability for money damages or regulatory financial penalties. See Len Sherman, Why Boards Must Step Up to Deter Corporate Scandals, Forbes (Mar. 13, 2017), https://www.forbes.com/sites/lensherman/2017/03/13/why-boards-must-step-up-todeter-corporate-scandals/\#29c446f11b79 [https://perma.cc/2VFH-UPXL]. It is nonetheless notably the case that money is the coin of the realm for such shareholders, not morality or ethics. See generally FRANKEL, supra note 32 (discussing the driving motivation of corporate shareholders).

93. As this Article has been in draft, new revelations about cover up of widespread sexual assault of children in the Catholic Church has come to light. See Catholic Church Sexual Abuse Scandal: 7 Excerpts From the Grand Jury Report, N.Y. Times (Aug. 14, 2018), https://www.nytimes.com/2018/08/14/us/catholicpriests-pennsylvania-church-jury.html?action=click\&module=MoreInSection 
The most recent of these scandals have coincided with the emergence of the \#MeToo movement, a cultural phenomenon thought to constitute a sea change in attitudes toward the right social, cultural, and legal response to sexual predation. ${ }^{94}$ These \#MeToo scandals in universities are a grim revelation of the burden of a flawed administrative environment in the American university, but they also provide a ray of hope. The public responses to the facts of sexual predation and harassment, long in duration in certain universities, demonstrate that students, as a sympathetic class of complainants, can achieve a period of sustained public accounting. It is yet to be determined whether student voice can achieve actual change in the conduct of the administrative class, in addition to one-time class settlements in compensation for injuries or a related one-time set of administrative resignations and pledges of a new determination to be accountable.

The recent highly publicized and deeply damaging scandals in several universities have revealed a gap in accountability sufficient to insulate the culture of a leading nonprofit sector from scrutiny needed to prevent social damage. ${ }^{95}$

\&pgtype $=$ Article $\&$ region $=$ Footer $\&$ contentCollection $=$ U.S $\quad[\mathrm{https}: / /$ perma.cc/4H4S 4S52]. The duration over years - seventy years is alleged - and the geographic dispersion-worldwide is alleged - portrays successful resistance to accountability in self-governed organizations, free of outside monitoring even by criminal authorities. See id. The record of such duration and persistence of abusive conduct demands renewed attention to the shortcomings of internal organizational checks implicitly reliant on a morally attuned cultural atmosphere. See id. Further, some of the factspriest pedophile rings and use of whips on children being abused-beggar the imagination as they also inform a new understanding of the extent of misconduct that organizations are capable of producing and concealing. See id. A Pennsylvania grand jury wrote a 900 -page reporting that began, "[w]e, the members of this grand jury, need you to hear this." Id.

94. See RJ Wolcott, \#MeToo Founder Tarana Burke Speaks at MSU: 'This is a Survivor's Movement', LANSING ST. J. (Apr. 19, 2018, 8:53 PM), https://www.lansingstatejournal.com/story/news/local/2018/04/19/metoo-msu-

burke/534083002/ [https://perma.cc/28JM-ZFB7]; see also Kristen Jordan Shamus, \#MeToo's Tarana Burke Speaks at MSU for Survivors, not for Spin, DETROIT FREE PRESS (Apr. 19, 2018, 8:44 PM), https://www.freep.com/story/news/2018/04/19/ metoos-tarana-burke-appears-msu-survivors-not-spin/533259002/ [https://perma.cc/ MK8B-BX9T].

95. See generally Vicki Schultz, Reconceptualizing Sexual Harassment, Again, YALE L.J.F. (June 18, 2018) https://www.yalelawjournal.org/forum/ reconceptualizing-sexual-harassment-again

[https://perma.cc/G85X-FJ4G] (addressing the \#MeToo movement in connection with the broad issues raised by the sexual harassment scandals in Silicon Valley and Hollywood). Schultz develops analysis (with a resemblance to analysis I have developed) concerning the psychology of authority in certain settings. See id. She cites a number of studies on the sources of 


\section{A. A Preliminary Overview of Recent Sexual Scandals in Universities}

The facts of the university sexual scandals can only be called damning. The revelations that a respected university gave a sexual predator access to its facilities for abuse, disguised as medical care and committed on student athletes and local teen gymnasts, have shocked and galvanized public opinion and created massive liability for the institution. One other university sustained large financial liability and saw its president imprisoned..$^{96}$ At least two other universities await further development of the facts. ${ }^{97}$ The public reaction has brought a new clarity to the role demanded of university administrators and their boards: strong protection of students, faculty, staff, and visitors to a campus from sexual assault or molestation, importuning for sex, and other unconscionable treatment; timely exit of leaders not capable of,

male entitlement, with implications for a psychology of unaccountable power. See id. Schultz emphasizes gendered patterns in lack of accountability through a "worship" of maleness. See id. For her treatment of maleness worship, see id. at n.138 and accompanying text (citing Noah Berlatsky, It's Time to Stop Worshipping Powerful Men, QUARTZ (Oct. 14, 2017), https://qz.com/1102376/its-time-to-stop-worshippingpowerful-men [https://perma.cc/FK72-7MZZ]). I have not addressed maleness but aspects of ritual in settings of power.

96. See Marc Tracy, With Paterno Revelations, Ruling Deals Hit to Penn State's Wallet, N.Y. Times (May 16, 2016), https://www.nytimes.com/2016/05 /07/sports/ncaafootball/joe-paterno-jerry-sandusky-penn-state-ruling.html [https://perma.cc/4AZH-SDWW]; Aria Bendix, Former Penn State President Sentenced to Jail Over Sandusky Scandal, ATLANTIC (June 2, 2017), https://www.theatlantic.com/news/archive/2017/06/former-penn-state-presidentsentenced-to-jail-sandusky-scandal/529044 [https://perma.cc/9V4P-C973].

97. Facts are under investigation at Ohio State regarding the impact on male victims of sexual violation, heightened by political coverage of the denials of wrestlers' charges by Congressman Jim Jordan that he knew and ignored the molestation of wrestlers while a coach at OSU, statements by Jordan calling the wrestler's dishonest, and the filing of a lawsuit by one wrestler. See Rachael Bade \& John Bresnahan, 'A Cesspool of Deviancy': New Claims of Voyeurism Test Jordan Denials, Politico (July 6, 2018, 5:32 PM), https://www.politico.com/story /2018/07/06/jim-jordan-harassment-ohio-state-wrestling-699192 [https://perma.cc/ U94D-D9ME]; see also Catie Edmondson, Two Lawsuits Against Ohio State Keep Jim Jordan in the Cross Hairs, N.Y. TIMES (July 18, 2018), https://www.nytimes.com/2018/07/18/us/politics/jim-jordan-ohio-state-sexualabuse.html [https://perma.cc/QPE4-3PUC]. The University of Southern California has been facing revelations of medically abusive sexualized treatment of female students, which led to the resignation of the president of the university. See Karma Allen, University of Southern California President Steps Down Amid Sex Abuse Scandal, ABC News (Aug. 8, 2018, 7:53 AM), https://abcnews.go.com /US/university-southern-california-president-steps-amid-sex-abuse/story?id= 57103822 [https://perma.cc/UG2Y-3J3U]. 
or committed to, protecting basic norms of respect for those with weak or no power in the organization; and care for institutional ethical and moral integrity throughout the institution. At the schools enumerated above, that minimum expectation is acknowledged not to have been met in connection with the safety of students. ${ }^{98}$

\section{B. A Very Sad Story: Leader Failures and Social Harm at Michigan State University}

At Michigan State University (MSU), the failure of the culture during the Larry Nassar scandal was catastrophic, clearly and painfully on display during every step of the scandal's timeline. On an unknown day in 1992, Larry Nassar, a medical student at MSU, allegedly molested a twelve-year-old under the guise of providing medical treatment at a gymnastics facility near MSU. ${ }^{99}$ In 1994, Olympic medalist Jamie Dantzscher allegedly began to experience molestation under a similar pretense of medical treatment. ${ }^{100}$ The molestation continued for a period of six years. ${ }^{101}$ In 1997, Larissa Boyce, a sixteen-year-old high school student, complained to gymnastics coach Kathie Klages that she was molested as part of medical treatment and was disbelieved. ${ }^{102}$ In 1999, a student reported assault but was told that Nassar was "an Olympic doctor" and "knew what he was doing." 103 In 2000, a student told three university athletic trainers and one staff member of sexual misconduct and was told "she was fortunate to receive the best medical care possible from a worldrenowned doctor." 104 Fourteen years later, in 2014, the university investigated a Title IX complaint and declined to find that Nassar had

98. See Letter from Mich. House of Representatives, Law and Justice Comm. and Appropriations Subcomm. on Higher Educ., to Tom Leonard, Speaker, Mich. House of Representatives (April 5, 2018); Tim Arango, 5 Women Sue U.S.C., Alleging

Sexual Abuse by Campus Doctor, N.Y. TIMES (May 21, 2018), https://www.nytimes.com/2018/05/21/us/usc-doctor-abuse-lawsuits.html [https://perma.cc/KG9D-CSMN]; Ken Belson, Abuse Scandal Inquiry Condemns Paterno and Penn State, N.Y. TiMES (July 12, 2012), https://www.nytimes.com /2012/07/13/sports/ncaafootball/13pennstate.html [https://perma.cc/Z3QD-RETF].

99. See James Dator, A Comprehensive Timeline of the Larry Nassar Case, SBNATION (July 31, 2019), https://www.sbnation.com/2018/1/19/16900674/larrynassar-abuse-timeline-usa-gymnastics-michigan-state [https://perma.cc/V337-9H7J].

100. See id.

101. See id.

102. See id.

103. Id.

104. Id. 
violated any policy. ${ }^{105}$ MSU President Lou Anna Simon received notice of the resolution of an issue about an unnamed doctor. ${ }^{106}$ President Simon did not treat it as an action item but a matter for a routine informational referral. ${ }^{107}$

105. See Matt Mencarini, MSU Hid Full Conclusions of 2014 Nassar Report from Victim, LANSING ST. J. (Jan. 26, 2018, 1:52 PM), https://www.lansingstatejournal.com/story/news/local/2018/01/26/michigan-statelarry-nassar-title-ix/1069493001 [https://perma.cc/7FNU-XR3Z]; see also Gaslighting, NPR (Nov. 12, 2018, 6:00 AM), https://www.npr.org/transcripts /666227595 [https://perma.cc/9LAP-74PS].

106. See Dator, supra note 99. President Simon's account is in conformance with ordinary usage in a large university bureaucracy. The President in a large bureaucratic university receives reports and relies on subordinates to advise her whether action is required. In investigations of misconduct being undertaken by university investigatory bodies, the President's role does not permit intervention, either to protect or harm the subject of the investigation. President Simon's account was given in Congressional testimony and in an interview with detectives of the state of Michigan. See infra note 117. The latter resulted in criminal charges against her on the grounds that, in failing to state that she knew not merely that that there was a problem with a doctor but that the doctor's name was Larry Nassar, she lied to a detective. In the brief in opposition to bind over of the charges, lawyers for President Simon presented testimony by the detectives acknowledging that they did not inform former President Simon of specific criminal charges they were investigating, a predicate, according to the belief of Simon's attorneys, of a criminal charge. See Defendant's Brief in Opposition to Bind Over at 11-14, Michigan v. Simon, No. 182261-FY (56-A Dist. Ct. 2018). Nonetheless, the case was bound over for trial after a preliminary hearing in a county near the location of Michigan State University. For an explanation of the process of bind over in Michigan and the process that resulted in a bind over, see Tyler Silvestri, What Simon's Bindover for Trial Does and Doesn't Mean, ON THE BANKS https://onthebanksmsu.com/simon-bindover/ [https://perma.cc/8HCR-SSGN] (last visited June 18, 2020) (providing commentary at the time of the bind over and containing links to transcripts of the hearings) On May 3, 2020, Michigan Circuit Judge John D. Maurer dismissed all charges against Simon. See Kim Kozlowski, Judge Dismisses Charges Against Former MSU President Simon in Nassar Case, Detroit News (May 13, 2020 12:15 PM) https://www.detroitnews.com/story/news/local/michigan/2020/05/13/judgedismisses-charges-against-former-msu-president-simon-nassar-case/5183418002/ [https://perma.cc/M8NQ-THMG] [hereinafter Judge Dismisses] (containing an embedded opinion of Judge Mauer's holding that the District Court Judge abused her discretion in holding there was probable cause that Dr. Simon committed the crimes charged arising from her responses to questions in the interview). In his opinion, Judge Maurer left undisturbed the finding of the lower court that the detectives informed former president Simon of specific criminal charges under investigation. See id. On June 29, 2020, the Attorney General of Michigan filed a notice of appeal. See Claim of Appeal of People of the State of Michigan, Michigan v. Simon, No. 19-20329-FH (Eaton County Cir. Ct. 2019), appeal docketed (Mich. Ct. App. June 29, 2020).

107. See Preventing Abuse in Olympic and Amateur Athletics: Ensuring a Safe and Secure Environment for Our Athletes: Hearing Before the Subcomm. on 
On August 4, 2016, the Indianapolis Star published a story on sexual abuse in Gymnastics USA. ${ }^{108}$ On August 29, 2016, gymnast Rachael Denhollander filed a police report alleging sexual assault by Nassar committed on her in 2000 when she was fifteen years of age. ${ }^{109}$ The next day Nassar was relieved of clinical duties. ${ }^{110}$ Throughout 2017 and 2018, multiple Olympic gymnasts and medal winners announced they were molested by Nassar. ${ }^{111}$ In March 2018, William Strampel, Dean of the College of Osteopathic Medicine and former boss of Nassar, was arrested and charged with one felony count involving misconduct of a public official (of a sexual nature toward students) and three misdemeanors, one involving Strampel's alleged personal sexual assaults (for which he was acquitted) and two for willful neglect of public duty for not monitoring Nassar after the physician/predator had agreed to follow a protocol designed to protect students whom he treated. ${ }^{112}$

After conviction in federal court and state court, Nassar listened to victim testimony for eight days in the courtroom of state Judge Rosemarie Aquilina. ${ }^{113}$ As the sense of community injury and outrage mounted, President Simon yielded to the drumbeat from politicians and others, including faculty members who organized a planned vote of no confidence against her. ${ }^{114}$ She submitted her letter of resignation

Consumer Prot., Prod. Safety, Ins., and Data Sec. of the S. Comm. on Commerce, Sci., and Transp., 115th Cong. (2018), 2:07:57, https://www.commerce.senate.gov/ 2018/6/preventing-abuse-in-olympic-and-amateur-athletics-ensuring-a-safe-andsecure-environment-for-our-athletes [https://perma.cc/7P8H-PLEN] (statement of Lou Anna Simon, former President of Michigan State University).

108. Marisa Kwiatkowski et al., A Blind Eye to Sex Abuse: How USA Gymnastics Failed to Report Cases, IndiAnAPOLIS STAR (Aug. 4, 2016), https://www.indystar.com/story/news/investigations/2016/08/04/usa-gymnasticssex-abuse-protected-coaches/85829732/ [https://perma.cc/TMM4-45M8].

109. See Dator, supra note 99.

110. See id.

111. See id.

112. See id.; see also Beth LeBlanc, Strampel Guilty of Misconduct in Office, Not Guilty of Criminal Sexual Conduct, Detroit News (June 12, 2019, 10:21 AM), https://www.detroitnews.com/story/news/local/michigan/2019/06/12/strampel-

guilty-misconduct-office-not-guilty-criminal-sexual-conduct/1429780001

[https://perma.cc/2LY5-A52P].

113. See Dator, supra note 99.

114. See id. See infra note 226 (noting the phenomenon of late faculty votes of no confidence following scandal exposed by outside investigation); see also Tyler Silvestri, Nearly 1,900 Pages of Former President Simon's Nassar-Related Emails Released, https://onthebanksmsu.com/nearly-1900-pages-of-former-presidentsimons-nassar-related-emails-released/ [https://perma.cc/DM6D-K3XC] (last visited June 18, 2020) (describing the mixed content of outrage and affection in the emails 
as President of Michigan State University, ending her term of service from 2005 until 2018 as the first woman President of MSU. ${ }^{115}$ On June 4, 2018, former President Simon testified to a Senate subcommittee on possible flaws in university systems that legalize bureaucratic routine:

I think going forward, we have to think very seriously about how we think about the voices and how we hear them; the processes that are very bureaucratic and done for lots of reasons including legal reasons that may have cumulated into the wrong, unintended consequences; and we have to continue to try to make systems better with people and with encouragement to have the highest standards. That is our collective responsibility, that is our moral responsibility and I keep thinking about ways in which voices . . . can be heard differently. ${ }^{116}$

Among the revelations of the long-continuing sexual abuse of MSU students by a doctor for gymnasts was the impossibility of getting anyone in an administrative position to take action. The first failures occurred by supervisors of the doctor early on. They believed him and hired experts who said he provided medical treatment, not sexual predation. They did not believe young women who knew they were being molested. Other failures occurred as the problem continued and higher-level administrators overlooked and gradually denied the facts and failed to act on them with the requisite urgency. Toward the end of the scandal, President Simon saw the problem primarily as one of legal liability and public relations. ${ }^{117}$ The result of the inadequacy of

received by President Simon during the period leading to her resignation and providing a link to them); see also RJ Wolcott, MSU Faculty Call for Vote of No Confidence in MSU President Simon, LANSING ST. J. (Jan. 23, 2018, 5:32 PM), https://www.lansingstatejournal.com/story/news/local/2018/01/23/msu-faculty-callvote-no-confidence-msu-president-simon/1058471001/ [https://perma.cc/HUK5$3 \mathrm{CRC}]$.

115. See Dator, supra note 99. Simon's retirement followed over a year later. See Julie Mack, Former President Lou Anna Simon Retires from Michigan State University with \$2.45M Payoff, MLive (July 31, 2019), https://www.mlive.com/news/2019/07/former-president-lou-anna-simon-retiresfrom-michigan-state-university-with-245m-payoff.html [https://perma.cc/A3TEK9QZ].

116. Sexual Abuse of Olympic and Amateur Athletes, C-SpAn, 2:14:50 (June 5, 2018), https://www.c-span.org/video/?446373-1/usa-gymnastics-president-stevepenny-invokes-abuse-hearing [https://perma.cc/6MUM-4CCN].

117. To her credit, in Senate testimony, the President acknowledged flaws in the systems of lawyering and bureaucratic routine that have been built in large universities. See Preventing Abuse in Olympic and Amateur Athletics: Ensuring a Safe and Secure Environment for Our Athletes: Hearing Before the Subcomm. on Consumer Prot., Prod. Safety, Ins., and Data Sec. of the S. Comm. on Commerce, Sci., and Transp., 115th Cong. (2018) (displaying the statement of Lou Anna K. Simon, 
accountability mechanisms internally was that young women were abused for years and the president, who was otherwise thought to be successful, was forced to step down. ${ }^{118}$

After the doctor was convicted and leadership was changed at the top, the continuing revelations mounted with shocking and cumulative effect. As noted, the dean of the medical school was arrested after having already been terminated from his deanship. ${ }^{119}$ The severity of the charges against him, which implicated him in personal misconduct as well as neglect of duty to protect students treated by Nassar, multiplied the sense there had been unchecked predation at the

President Emeritus, Michigan State University). That said, the MSU culture in which she had made her entire career was not one of transparency, or safety for those who attempt to report misconduct upward. The University had a Title IX rebuke in its record concerning the treatment of women who reported sexual assaults by MSU athletes. See RJ Wolcott, Feds: MSU Mishandled Sexual Assault Complaints, LANSING ST. J. (Sept. 1, 2015, 7:02 PM), https://www.lansingstatejournal.com/ story/news/local/2015/09/01/msu-agrees-bolster-response-sexual-violence/71528172 [https://perma.cc/F6LQ-9JA2]. One response was to crack down on faculty members if they made jokes about "going postal" or "killing" someone for repeating timeconsuming mistakes. The policy was called "zero tolerance" and was enforced against faculty members for jokes while Dr. Nassar was continuing to molest MSU students, after students had complained over the years. For the 2015 rebuke, see Press Release, U.S. Dept. of Educ., Office for Civil Rights, Michigan State University Agrees to Changes Its Response to Complaints of Sexual Harassment, Sexual Violence (Sept. 1, 2015), https://www.ed.gov/news/press-releases/michigan-state-university-agreeschange-its-response-complaints-sexual-harassment-sexual-violence

[https://perma.cc/MZG9-XGLS]; Resolution Agreement, OCR Docket Nos. 15-112098 and 15-14-2113, Michigan State University, (Sept. 1, 2015); Resolution Letter from Meena Morey Chandra, Director, U.S. Dept. of Educ., Office for Civil Rights, to Kristine Zayko, Deputy General Counsel, Michigan State University (Sept. 1, 2015), https://www2.ed.gov/documents/press-releases/michigan-state-letter.pdf [https://perma.cc/QV3B-M8T2]; Jason Cody, MSU Improves Timeliness of Title IX Investigations as Government Report is Released, MSU TODAY (Sept. 1, 2015), https://msutoday.msu.edu/news/2015/msu-improves-timeliness-of-title-ix-

investigations-as-government-report-released [https://perma.cc/JW4F-P5W3], for activities relating to the Title IX action and response.

118. Simon resigned on January 24, 2018. See Dator, supra note 99. For support Simon had long enjoyed, see David Jesse, MSU Board: Lou Anna Simon to Stay as President, is 'Right Leader' for MSU, DETROIT FrEE Press (Jan. 19, 2018, 3:12 PM), https://www.freep.com/story/news/local/michigan/2018/01/19/msusimon-president-right-leader-msu/1049238001/ [https://perma.cc/UL85-T5U2]. Shortly before her resignation, longtime Trustee Joel Ferguson voiced strong support for President Simon's performance (since her appointment in 2005). See Lacy \& Jesse, infra note 205.

119. See David Jesse \& Gina Kaufman, Sources: Police Arrest Larry Nassar's Michigan State University Boss, Detroit FreE Press (Mar. 26, 2018, 7:58 PM), https://www.freep.com/story/news/local/michigan/2018/03/26/larry-nassar-williamstrampel-arrest/460785002 [https://perma.cc/U42H-BX79]. 
largest, by enrollment, public university in Michigan. ${ }^{120}$ The provost of the University acknowledged that she reappointed him despite a record that included facts about his vulgarity toward students and faculty. ${ }^{121}$ The University was reported to have invested $\$ 500,000$ in having a company monitor the Facebook accounts of the victims. ${ }^{122}$

C. Case Western Reserve University School of Law Previews \#MeToo: Individual Faculty Litigation as a Substitute for Group Voice

Another Epic Failure in the university setting came to light in connection with the dean of Case Western Reserve University School of Law, and it involved litigation undertaken in 2013 by a faculty member as a type of one-man vote of no confidence. ${ }^{123}$ Though the facts that prompted the lawsuit had been rumored in the law school community, with coverage in the alternative press, one faculty member, then Associate Dean Ray Ku, had a first-person experience

120. See Cheyna Roth, Ex-MSU Dean Who Oversaw Larry Nassar is Found Guilty of Multiple Charges, NPR (June 12, 2019, 12:15 PM), https://www.npr.org/2019/06/12/731985152/ex-msu-dean-who-oversaw-larrynassar-is-found-guilty-of-multiple-charges [https://perma.cc/89BD-5PTQ] (reporting that Strampel "was cleared of felony second-degree criminal sexual conduct").

121. See David Jesse, Michigan State University Provost Abruptly Resigns in Wake of Nassar Report, DeTROIT FreE PRESS (Sept. 5, 2019, 12:34 PM), https://www.freep.com/story/news/education/2019/09/05/msu-provost-june-youattresigns/2220940001/ [https://perma.cc/EZW9-V9AP] (quoting Youatt's defense of her review of Strampel and her concession that she knew of "several accounts of inappropriate remarks and a number of concerns about uncouth and sometimes offensive language during the review period").

122. See MSU Paid Firm $\$ 500,000$ to Monitor Larry Nassar Victims During Sentence Hearing, GUARDIAN (Mar. 28, 2018, 4:55 PM EDT), https://www.theguardian.com/sport/2018/mar/28/michigan-state-universityconsulting-fees-larry-nassar-abuse [https://perma.cc/34NR-QAQT].

123. See Doug Brown, Sex, Politics and Revenge: Lawrence Mitchell was Supposed to Bring Stability to Case Western Reserve University's Law School, Not Treat It as His Personal Pickup Playground, Cleveland Scene (May 6, 2014), https://www.clevescene.com/cleveland/sex-politics-and-revenge-lawrence-mitchellwas-supposed-to-bring-stability-to-case-western-reserve-universitys-law-school-nottreat-it-as/Content?oid=4307875 [https://perma.cc/TQ7P-7YNR] (reporting Ku's lawsuit against Mitchell and the University); see also Paul Caron, Shanghai Law Students Seek to Oust Former Case Western Dean, Say \#MeToo Movement Should Apply in China, TAXPROF BLOG (Feb. 7, 2018), https://taxprof.typepad.com/ taxprof_blog/2018/02/chinese-law-students-seek-to-oust-disgraced-former-casewestern-dean-say-metoo-movement-should-in-ch.html [https://perma.cc/44UZNF4J] (describing Mitchell's resignation "amidst a lawsuit alleging rampant sexual impropriety and retaliation against a professor who tried to blow the whistle"). 
in connection with the uproar that followed the installation of a new dean in the Cleveland school. ${ }^{124}$

The beginnings of a crisis started in August 2011 at a party held in Cleveland, Ohio, at the home of the newly installed dean of Case Western Reserve University School of Law, Lawrence Mitchell. ${ }^{125}$ The party was an auspicious moment for a law school that had suffered short tenures by recent deans. ${ }^{126}$ The new dean was a distinguished scholar with a strong track record as a scholarly entrepreneur. ${ }^{127}$ Unfortunately, his conduct that night became an opening note in stories in the Cleveland alternative press, which reported student descriptions of drunken decanal behavior at their events in bars and purported propositions by the dean for "threesomes." 128 What had begun with high hopes for a new leader with transformative ideas and with staying power was quickly becoming a decanal crash landing as the new dean squandered goodwill. ${ }^{129}$ As the August 2011 partygoers disbanded for their homes, they took impressions with them of a dean whose manners and persona raised eyebrows. ${ }^{130}$ They soon were aware that the word among students was more than an eyebrow raiser. ${ }^{131}$ It was alarming.

One party attendee, Associate Dean Raymond $\mathrm{Ku}$, eventually concluded that the dean's behavior on the evening of the party was no anomaly. ${ }^{132}$ His concern with what he saw and experienced at the party grew quickly as he worked with the new dean. He sought help from Case Western administrators with respect to what the Cleveland alternative press has since called "rampant sexual impropriety and retaliation." ${ }^{133}$ The administrators at Case Western Reserve University

124. See Brown, supra note 123 (describing an incident in which Mitchell allegedly made sexual comments to $\mathrm{Ku}$ ).

125. See id. (stating that Ku's genitals were brought up to him by the Dean at a faculty party at Dean Mitchell's house).

126. See id.

127. See id.

128. See id.

129. See id. (describing the many positive changes Mitchell had made at the law school before sexual behavior came to light).

130. See id.

131. See id.

132. See id.

133. Sam Allard, Disgraced Former CWRU Law Dean Lawrence Mitchell is Now a Professor in Shanghai, Cleveland ScENe (Feb. 6, 2018, 12:50 PM), https://www.clevescene.com/scene-and-heard/archives/2018/02/06/disgracedformer-cwru-law-dean-lawrence-mitchell-is-now-a-professor-in-shanghai [https://perma.cc/RTE2-65XZ] (describing the aftermath of Mitchell's behavior at Case Western Law). 
had, as noted, faced problems in the past with the performance of deans at the law school. ${ }^{134}$ In this instance, their inner response at facing a report from an associate dean about sexual harassment by a dean must have been less a vision of the recent past than a faint foreshadowing of the lament today of edgy administrators, hearing an explosive charge against a colleague: "Et tu, \#MeToo?" The questioning exclamation would have been an anachronism when Ray $\mathrm{Ku}$ entered the office of the official at Case to whom he made his first report. Little did Case Western's administrators know, but they were experiencing the leading edge of the coming movement for targets of sexual aggression to name their tormentor and demand recourse. Unlike Brutus, \#MeToo is not an old friend or ally, but the blow it strikes the administrative class is heavy.

Upon hearing from Professor $\mathrm{Ku}$, the university conducted an investigation but announced that Ku's reports of misconduct were unsubstantiated. ${ }^{135}$ The next day, $\mathrm{Ku}$ resigned as associate dean. ${ }^{136}$ After a sabbatical, Ku returned to campus and learned that the dean had relieved him of an administrative leadership position with Case Western's Center of Law, Technology, \& the Arts. ${ }^{137}$ During this period, students also began to speak out about the dean's allegedly inappropriate behavior, but the faculty seemingly preferred to avoid conflict. ${ }^{138}$ Nevertheless, the whirlwind of complaints and allegations accelerated to maximum speed. Ku shocked the city of Cleveland, the Case Western community, and the legal academy by filing a no-holdsbarred narrated complaint that laid out chapter and verse of alleged bad conduct. ${ }^{139}$ A period ensued in which Case Western officials and the dean strongly denied all allegations, including an allegation that $\mathrm{Ku}$ 's report to Case Western officials of his concerns had led to instant retaliation by the dean. ${ }^{140}$ After a siege of muted warfare between the dean and Ku's lawyer, with continuing affirmation by the university

134. See Brown, supra note 123.

135. See id.

136. See id.

137. See id.

138. For an extraordinary account of the alleged retaliatory conduct by Mitchell against an assistant to Mitchell who reported the student complaints, as well as the retaliation against $\mathrm{Ku}$ for his reporting, see generally Affidavit of Daniel J.N. Dubé (Nov. 14, 2013) (on file with author) (alleging several instances of sexual misconduct against Mitchell).

139. See Brown, supra note 123.

140. See id. 
of support for the dean, the parties reached a settlement. ${ }^{141}$ In addition, the dean announced his departure, which Mitchell asserted resulted from his recognition that he could not continue in light of distractions. ${ }^{142}$ Even after the resignation and before the suit was settled, Case Western law faculty members still demurred on the question of Mitchell's conduct. ${ }^{143}$

The $\mathrm{Ku}$ litigation and its denouement are of interest for two reasons. First, the subject of the lawsuit is significant in light of the emergence of the \#MeToo movement. As is widely known, not only are current harassment problems being exposed and acknowledged by employers, but even past misconduct is subjecting individuals to accountability. An episode of litigation about sexual harassment, occurring in the relatively recent past at a major university law school, casts light on recent organizational responses to a recurring issue in the workplace, including in universities. The university is a setting that might be expected to foster a protective environment free of the sorts of concerns that result in a faculty member's decision to file risky litigation and endure the potential fallout in recrimination and gossip. Yet sexual harassment does occur in the university, and it is not necessarily confronted by administrators when they learn of complaints. Second, private, individual litigation, such as Ku's, is commonly viewed as impractical for many reasons - personal cost in time and stress, the relatively small damages that a faculty member can claim for mistreatment in the absence of termination of employment, the potential difficulty of finding the right lawyer for the problem, and the resources that an institutional target can array against an individual. That individual litigation can become a functional replacement for a vote of no confidence during Epic Failures is an insight worth exploration.

\section{Introduction: Individual Litigation in Place of Group Voice}

The $\mathrm{Ku}$ litigation provides a mini case study of individual litigation as a substitute mechanism for a vote of no confidence, which depends on moral suasion rather than the potential power of a court's

141. See David Lat, A Super Salacious Lawsuit, Settled: What Do the Parties Have to Say About the Settlement in Professor Raymond Ku's Lawsuit Against Larry Mitchell, Former Dean of Case Western Law?, Aвоve L. (July 8, 2014 12:13 PM), https://abovethelaw.com/2014/07/a-super-salacious-lawsuit-settled/ [https://perma.cc/UG8L-A4T6].

142. See Brown, supra note 123.

143. See id. 
mandate, including mandates requiring depositions and production of records. The $\mathrm{Ku}$ example illustrates the institutional drive to control the narrative of an entity's history and permits consideration of the comparative resources of administrators as against either collective voice in a no confidence vote or individual litigation. The story of Professor Ku's choice to proceed alone highlights the individual courage and creativity in a faculty member's solitary action to bring about accountability in the university setting. ${ }^{144}$ Risk aversion is part of the story in any effort by a group or by one of its members to oppose a leader's problematic conduct.

Professor Ku's lawsuit ended with the departure of the dean. ${ }^{145}$ The departure occurred after the public exposure of an alleged problem that, if true, rendered the dean's continuing service objectionable on a normative and practical basis. The nature of the problem could have brought about an opportunity for faculty to cohere around a group moral voice. As discussed previously, votes of no confidence are customarily used when groups, using their collective voice and wisdom, reject their leader. ${ }^{146}$ At Case Western, no such vote occurred. Nonetheless, Ku's actions, as detailed below, partially replicated the experience of a no confidence vote. The events at Case Western provide a striking instance of the presentation of concerns within a faculty by one individual, in litigation, as a personal demand for a judicial intervention and as a mechanism to publicize claims regarding a leadership crisis.

This instance of individual litigation that served a public purpose has a resonance with litigation of individual cases by lawyers whose efforts can impose sufficient costs on those municipalities that target minority residents for the collection of revenue to finance government. Individual legal defense of minor misdemeanor and even civil charges in Ferguson, Missouri, brought political attention to systemic injustice through misuse of the police and courts as a means of collecting fines and penalties to avoid the use of taxes to fund municipal services. ${ }^{147}$

144. See generally Former Case Western Dean Reportedly Leaves Shanghai University After Controversial Appointment, JONATHON TURLEY (July 18, 2019) https://jonathanturley.org/2019/07/18/former-case-western-dean-reportedly-leavesshanghai-university-after-controversial-appointment/ [https://perma.cc/R2FQ-J6QD] (discussing Professor Ku's actions in relation to the Case Western dean).

145. See id.

146. See supra Part I.

147. See generally Beth A. Colgan, Lessons from Ferguson on Individual Defense Representation as a Tool of Systemic Reform, 58 WM. \& MARY L. REV. 1171 (2017) (explaining how legal defense of minor offenses in Ferguson brought nationwide attention to systemic injustice). 
Such defense brings individual relief to targets of abusive practices in the police and courts and also exposes patterns of illegal treatment of defendants and creates political discussion. ${ }^{148}$ While the plight of a poor population, unable to defend itself against police enforcement of minor offenses for improper purposes is a civil rights concern, with all that that portends, the persistence in universities and other organizations of sexual harassment that goes unaddressed has been recognized in the recent past as a serious problem. ${ }^{149}$

The sense that sexual aggression toward women, and sometimes men, was just part of the fabric of organizational and work life, has been no more justified than the understanding that poor areas have no means of defense against overly aggressive law enforcement. In both instances, lawyers have a potential role to play in making such conduct costly by imposing high transaction costs on each instance, where possible, and exposing the individual instances and the responses by administrators to efforts by targets to bring about organizational intervention. Lawsuits help expose and document the pattern of mistreatment that goes unopposed by authorities with the power to intervene.

The vote of no confidence is a form of pure self-help, done without legal aid. ${ }^{150}$ Litigation applies the lever of the lawyer's skills and resources to force public accountings. In the case of Ferguson, the limitation is simply resources: the number of lawyers available to handle low-stakes offenses that become a predicate for jailing poor people and accumulating new monetary fines. ${ }^{151}$ In the university setting, the limitation is, similarly, the small monetary stakes, the sense within faculties that litigation is futile, and the lack of interest on the part of many lawyers in representing faculty suing a university,

148. See id. at 1230-32.

149. See, e.g., Deirdre Fernandes, In the Wake of Harassment Case, Harvard Report Finds 'Prolonged Institutional Failure,' Bos. GLoBE (May 2, 2019, 7:08 PM), https://www.bostonglobe.com/metro/2019/05/02/wake-sexual-harassment-caseharvard-report-finds-prolonged-institutional-failure/acxNoEklqC9HaJhobwltRJ/ story.html. (describing a decades long siege of sexual harassment of women faculty and students by Harvard star Professor Jorge Dominguez about which Harvard appeared not to care and subjecting "[h]undreds of students, staff, and junior faculty" to the consequences); see also Bikales, supra note 65.

150. See supra Part I.

151. See Colgan, supra note 147, at 1247. 
which limits the pragmatic possibilities of individual resort to lawsuits. ${ }^{152}$

So, problems of leader accountability in nonprofit institutions and similar problems of accountability by municipalities or other state institutions for wrongful use of local civil and misdemeanor enforcement against targeted groups share characteristics. They display recurring patterns of weak or unethical leadership, ${ }^{153}$ long periods of dysfunction or misapplication of power, ${ }^{154}$ an absence of means by which a public voice from those suffering from maltreatment or other systemic failure can be shaped and heard, ${ }^{155}$ and

152. For evidence of futility in tenure denial lawsuits, see Robet Hamill, To

Sue or Not to Sue, InSIDE Higher ED (May 14, 2010), https://www.insidehighered.com/advice/2010/05/14/sue-or-not-sue [https://perma.cc /SR5X-72UB] (finding in a review of 70 judicial opinions that "for those cases that went to trial or were appealed, the plaintiff lost nearly every time"). Though American courts are not fairly lumped with Courts of Chancery of Charles Dickens's England, Dickens nonetheless provides a perennially pertinent picture of litigation against "monied might" as an invitation to endless misery.

This is the Court of Chancery, which has its decaying houses and its blighted lands in every shire, which has its worn-out lunatic in every madhouse and its dead in every churchyard, which has its ruined suitor with his slipshod heels and threadbare dress borrowing and begging through the round of every man's acquaintance, which gives to monied might the means abundantly of wearying out the right, which so exhausts finances, patience, courage, hope, so overthrows the brain and breaks the heart, that there is not an honourable man among its practitioners who would not give-who does not often give - the warning, "Suffer any wrong that can be done you rather than come here!"

Charles Dickens, Bleak House 3 (1853).

153. See Barbara Kellerman, Bad Leadership: What It Is, How It HAPPENS, Why It MATTERs 37-38 (2004) (listing seven types of bad leaders, e.g., rigid, insular, intemperate, incompetent, callous, corrupt, and evil).

154. See Jean Lipman-Blumen, The Allure of Toxic Leaders: Why We Follow Destructive Bosses and Corrupt Politicians-and How We Can SURVIVE THEM 82 (2006) (describing preference to retain leaders rather that to permit their casual removal).

155. There is ambiguity about the level of employment or other protection afforded to faculty for speech about governance rather than issues having to do with academic freedom in scholarship and teaching. See generally Garcetti v. Ceballos, 547 U.S. 410 (2006) (providing employee-speech jurisprudence opinion limiting protected employee speech declining to address the implications for academic speech). For expressions of concern, see Oren R. Griffin, Academic Freedom and Professorial Speech: Post-Garcetti World, 37 Seattle L. Rev. 1, 2 (2013). See generally Bridget R. Nugent \& Julee T. Flood, Rescuing Academic Freedom from Garcetti v. Ceballos: An Evaluation of Current Case Law and a Proposal for the Protection of Core Academic, Administrative, and Advisory Speech, 40 J.C. \& U.L. 115 (2014) (advocating for the clarification of Garcetti's holding to provide "[c]ore 
the possession of considerable resources and will to suppress information and to rationalize and perfect systems of denial and evasion. ${ }^{156}$ For that reason, alternative means of resistance, whether in a group, as in a university faculty under a perceived siege, or among citizens subjected to governmental bad conduct, demand to be analyzed and explained to enable wider awareness of self-help tools often dismissed as impractical.

In reviewing a book on lies by employers to mislead employees about rights, including rights to disclose violations of legal rules, Cynthia Estlund emphasizes the problem that employees lack knowledge or, if informed, fear reprisals if they speak, despite legal protections. ${ }^{157}$ She thus affirms that "employees' knowledge of the law is a necessary if not a sufficient condition for their own pursuit of a remedy, and thus for enforcement of the entire edifice of employment law."158 Employees of universities have varying levels of sophistication, but they flounder in seeking legal redress of mistreatment, as do students subjected to assaultive behavior. ${ }^{159}$ Despite the serendipitous character of matches between the right lawyer and an individual's legal need that could provide knowledgeenhancing exposure of system problems, it is worth recognizing the functional role of an individual lawsuit to correct accountability shortfalls. In examining the similarities between an instance of individual faculty litigation against a law school dean and the typical pattern of a faculty vote of no confidence against a university

[a]cademic [s]peech" of scholarship and teaching, but remitting "[a]dministrative and [a]dvisory [s]peech" to advocacy of internal protective mechanisms that universities may adopt).

156. See Cynthia L. Estlund, Free Speech and Due Process in the Workplace, 71 IND. L.J. 101, 119 (1995) [hereinafter Free Speech] (asserting that in light of her careful assessment of the values of employee speech and the needs of employers that "the available evidence strongly suggests that employees continue to experience retaliation and the threat of retaliation for speech that the law purports to protect and that employee silence resounds where speech should be free") (citing ALEXIS DE ToCQueVILle, Democracy in AMERICA 61 (J. P. Mayer ed., George Lawrence trans., 1965) (examining the workplace meticulously as "a school for democracy")).

157. See Cynthia Estlund, Response, Truth, Lies, and Power at Work, 101 MinN. L. REV. 349, 351 (2017) [hereinafter Response]. For the article under review by Professor Estlund, see generally Helen Norton, Truth and Lies in the Workplace: Employer Speech and the First Amendment, 101 MinN. L. REV. 31 (2016) (discussing lies told to employees by their employers).

158. Response, supra note 157, at 351; see also Free Speech, supra note 156, at $122-23$.

159. See supra Section III.B (describing the long duration of universityemployed athletic doctor's molestation of female gymnasts). 
administrator, important factors include faculty risk aversion, shortfalls of group voice for faculties who consider a vote of no confidence, and the formation of public views about a claim by faculty that a leader has engaged in conduct that should result in his dismissal. ${ }^{160}$ Though personal litigation does not demand dismissal, as does a vote of no confidence, the urgency of a leader's termination can be implicit in an individual legal action for personal injury.

As noted, allegations of the kind brought against the Case Western law dean have since become far more prominent and less easily dismissed by institutions inclined to circle the wagons and target the complaining person rather than the alleged wrongdoer. ${ }^{161}$ The recent abuse tragedy at Michigan State University was a stunning revelation of the failure of vigilance in a higher education institution. ${ }^{162}$ While victims were not targeted, they were chastised by MSU personnel to whom they reported sexual penetration disguised as medical treatment by MSU's Dr. Larry Nassar. ${ }^{163}$ The cultural cues within the ranks at MSU did not bring the statements by the young women to the attention of higher administrators, and when it began to become public, the president perceived her job as that of managing university liability rather than responding with a visible demonstration of remedial action to a crisis within the culture of the university as well as immediately offering the full force of university resources to help the women victimized while in their care. ${ }^{164}$

The legal framework in which a university functions, as a large legal entity with resources to manage and obligations on the part of those tending to them to protect the fisc, causes top administrators to be innately cautious when facing claims that could implicate financial liability. After vigilance in the ranks has failed, the managerial effort to assess and respond to the scale of the wrongdoing is unlikely to keep pace with that demanded by the accelerating public reaction. Large entities have embedded cultural dysfunctions and are often clumsy as well.

160. See discussion supra Section II.A.

161. See discussion supra Section III.C.

162. See Kim Kozlowski, What MSU Knew: 14 Were Warned of Nassar Abuse, 8 Women Reported Abuse Claims, At Least One of Which Reached President, Detroit News (Jan. 18, 2018, 12:00 AM), http://www.detroitnews.com/story/tech/ 2018/01/18/msu-president-told-nassar-complaint-2014/1042071001/ [https://perma.cc/BN6S-ESKG].

163. See id.

164. See id. 
In a smaller setting with lesser financial stakes, an institution may move more quickly, albeit after resistance, to liquidate its exposure to bad publicity and lower money stakes. As demonstrated by Professor Ku's lawsuit, in an instance of wide knowledge of bad conduct but passive group behavior in a small setting, it is possible for one person to create an effect similar to that of a no confidence vote. ${ }^{165}$ A lawsuit for individual harm to one person can be leveraged to place on the public record a statement about an alleged pattern of behavior that is outside the norms of conduct for a leader. ${ }^{166}$ The situation involving Professor $\mathrm{Ku}$, Dean Mitchell, the law school, and its assorted constituents is instructive because it illustrates how one person can instigate and employ a no-confidence-vote-like measure to success. Professor $\mathrm{Ku}$ was able to defy conventional thinking and prevail over the common advice against all such attempted lawsuits by faculty members experiencing uncorrected abusive behavior. It is true that, according to his legal complaint, Professor Ku initially faced, alone, the denigration from the hierarchy that faculty proponents bear collectively, as well as from the uninformed gossip among casual observers who assumed $\mathrm{Ku}$ was simply a weak administrator complaining about the dean's exercise of discretion to dismiss and replace administrators. ${ }^{167}$ Litigation creates a high risk for an individual who undertakes it, but it also confers a communicative capacity that can overcome expressions of disdain for the motives of the faculty member while also providing a full airing of the alleged misconduct of the leader.

\section{The Ku Lawsuit: A Brief Account}

After a period of absence from the law school, Professor Ku took action by filing his lawsuit. ${ }^{168}$ The litigation he filed overcame the limitation of the no confidence motion as group-improvised speech. A highly competent lawyer filed a complaint filled with explosive factual allegations, in great and disturbing detail. ${ }^{169}$ The complaint contained a compelling narrative, one discrediting to both the dean and

165. See generally Brown, supra note 123 (describing the lawsuit brought by Professor $\mathrm{Ku}$ ).

166. See supra Section III.C.

167. See Complaint with Jury Demand at 13-16, Ku v. Mitchell, No. CV-13815935 (Ohio Ct. Com. Pl. Oct. 23, 2013).

168. See id.

169. See supra notes $137-153$ and accompanying text. 
the university. ${ }^{170}$ So discrediting were the allegations about the dean that he filed a motion in court asking to have the complaint suppressed on the grounds that the charges were "immaterial, impertinent and scandalous." 171

Because complaints are privileged from charges of slander, the motion may well have been meant to invoke a normative claim about permissible discourse and institutional manners to influence the relevant community's response to the filing and thereby reinstate institutional protocol. But silence had been broken with the thunderclap made by a shaming burst of speech. Commitments to etiquette within faculties (unlike the permission for impertinence court filings grant) are one factor in the difficulty of persuading faculty members to organize a group effort. The motion was denied by the court, ${ }^{172}$ thus underlining that the claims on faculty manners that constrain internal group self-help have no force within the judicial forum.

The complaint also placed the university administrators' conduct in disrepute. ${ }^{173}$ It alleged that rather than check the conduct of the dean, the Case hierarchy instead permitted the dean to engage in reprisals against Professor $\mathrm{Ku}$, who was frozen out of law school activities in which he would normally play a role. ${ }^{174}$ Of particular bad odor was the charge that the retaliation began after Professor Ku advised the higher administration of the dean's allegedly bad behavior toward various women as well as $\mathrm{Ku}$ himself. ${ }^{175}$

The aftermath of the filing conformed, in part, to the sequence of statement and response and partial resolution often associated with a no confidence vote. First, the fact of the lawsuit became public by way of press printings of a press release and quotations from the complaint. ${ }^{176}$ The press release by Ku's lawyer was, however, unlike the typical announcement of a vote of no confidence. Faculty groups

170. See generally Complaint with Jury Demand, supra note 167 (outlining Ku's causes of action).

171. Defendant's Motion to Strike at 1, Ku v. Mitchell, No. CV-13-815935 (Ohio Ct. Com. Pl. Nov. 7, 2013).

172. See Denial of Defendant's Motion to Strike, Ku v. Mitchell, No. CV-13815935 (Ohio Ct. Com. Pl. Nov. 7, 2013).

173. See Complaint with Jury Demand, supra note 167, at 9.

174. See id. at 19-20.

175. See id. at 9.

176. See David Lat, Law School Dean Accused of Sexual Harassment Takes Leave of Absence, ABOvE L. (Nov. 6, 2013, 10:15 AM), https://abovethelaw.com /2013/11/law-school-dean-accused-of-sexual-harassment-takes-temporary-leave-ofabsence/ [https://perma.cc/HHM6-3TWS] [hereinafter Dean Accused]. 
generally do no more than announce the fact of a vote of no confidence. They usually decline to provide a bill of particulars. Reasons include the fact that such a bill of particulars merely provides targets for the administration to rebut by speaking into a void created by the inability of faculty to deploy voice in response to claims by well-staffed administrators. In addition, the faculty lacks a common understanding of what type of statement is most likely to be persuasive. There is no standard for such a statement by faculty acting in an improvised form of self-help. The fact of no confidence stands as the undeniable truth: the leader can no longer lead. With litigation, the facts can be contained in the filing and do not stand as an undeniable truth. Rather, they enable a strong voice to provide chapter and verse of charges against the leader. They also provide the faculty member with a voice, that of his lawyer, for responding to counter speech by administrators. Ku's lawyer was equal to the moment.

Second, upon the filing of the complaint, Case Western promptly issued a strong denial of the allegation of retaliation, presumably based on a crimped legal view of Professor Ku's protectable employment rights, in time for inclusion in the first stories about the suit:

This situation is categorically not an instance of retaliation. Professor $\mathrm{Ku}$ continues to hold a full time, tenured faculty position at the School of Law. The lawsuit itself includes inaccuracies, as well as an inflammatory flier that has been found to be materially false. The university will have additional comment upon more thorough review of the suit and opposing counsel's press release. ${ }^{177}$

After a brief period, Dean Mitchell issued a standard "catch-mybreath" styled announcement of a temporary leave, expected to be brief, and a confirmation of his record as dean:

To Faculty, Staff, and Students:

The past two and a half years have been a time of great progress and achievement for our law school. The recent initiation of litigation against the university and me, however, has proven to be a distraction to all of us.

In order to allow us to continue the work we have begun without further disruption, I have asked the university to permit me to take a temporary leave of absence. This will allow the university to conduct its independent review of this matter. I am confident that this review will be done

177. Rachel Dissell, Case Law Professor Sues Dean Lawrence Mitchell and University, Says He Was Retaliated Against for Reporting Sexual Harassment of Students and Staff, CLEVELAND.COM (Oct. 23, 2013), http://www.cleveland.com /court-justice/index.ssf/2013/10/case_law_professor_sues_dean_l.html [https://perma.cc/C8NT-7YQ7]. 
expeditiously and that this review, again, will affirm that neither I nor the university have done anything wrong or improper. I am also confident that it will put this behind us. I intend to take full advantage of the legal process to seek justice.

We have dramatically improved admissions efforts, broadened our global reach, and developed and implemented an innovative new curriculum. The momentum is just beginning. I look forward to continuing our work together. Thank you for all that you have done, and all that you will do.

Best,

$\mathrm{L}^{178}$

The Case Western President followed the announcement by Mitchell with an email to the students, interpreted by some as placing some distance between the university and Mitchell. ${ }^{179}$ The first paragraph established a tone of calm, with a hint of apology in the first sentence of the second paragraph:

To the Students of the School of Law: Earlier today you received an email from Dean Mitchell announcing that he is taking a leave of absence. We believe he made the right decision for the school, as it allows all of you to focus more squarely on the important work of learning and gives your faculty and staff greater opportunity to concentrate on guiding and supporting you in preparing for your future. It also gives the dean the opportunity to concentrate more completely on his own situation.

We regret the distractions you have experienced in recent weeks, as well as the sense of disruption this new transition may create. ${ }^{180}$

The email closed by promoting a new, recently adopted curriculum and praising recent accomplishments of the Case Western law students. ${ }^{181}$

From November 2013 until March 2014, the school went through the predictable interim period during which the administration states for the record that the leader will return, while those in the rank fret about whether the promise of a return is true. ${ }^{182}$ The delay in acknowledging the fact of a permanent removal, commonly announced as a voluntary resignation, can prolong tension among those who have feared the administrator and hoped for a departure. The time spent in an atmosphere of uncertainty is damaging to faculty

178. Dean Accused, supra note 176.

179. E-mail from Case W. Reserve Univ. to the Students of Case W. Reserve Univ. (Nov. 7, 2013) (on file with author) (regarding Dean Mitchell's leave of absence).

180. See id.

181. See id.

182. See Brown, supra note 123. 
morale and perhaps to productivity but is generally not counted as a cost to the institution. It is even possible that, in some instances of group voice demanding exit, there may be a motivation to demonstrate to the rank that relieving them of uncertainty is not a priority. In those situations, group voice against the preferences of the hierarchy can be punished by indirection and unreadable delays. A determined hierarchy might even threaten to appoint a much worse leader as a means of emphasizing the lack of control by the faculty over managerial prerogative.

Certain features of the standard playbook in a response to a vote of no confidence were deployed by Dean Mitchell. Generic claims of personal, discreditable motives are often made in response to a vote of no confidence by the official hierarchy's statement against the entire group. ${ }^{183}$ Indeed, writing by figures such as Judge Posner and others generically charge that all votes of no confidence by tenured faculty members are the result of an entrenched, self-serving group that has succeeded in writing its own employment rules and which lacks a needed long-term time horizon for assessing leadership. ${ }^{184}$ The dean's demand for suppression of the complaint as "scandalous" was of that kind. ${ }^{185}$

In response to an individual lawsuit, the only target of attack is the person filing the lawsuit. The logical source of the attack is the individual defendant, in the Case Western instance, the dean. ${ }^{186}$ But the general claim in an attack on an individual is generic with some added detail about an alleged special motive of the person lodging charges. As the lawsuit freed $\mathrm{Ku}$ to make concretely discrediting charges that would not be made in a statement of no confidence, the dean could seize upon legal filings to make damaging claims about $\mathrm{Ku}$ of the sort that universities always decline to make about "personnel matters."

183. FRANKEL, supra note 32, at 179 ("Attributing bad motives to the opponent is a well-known defensive practice against the accusation of criminal behavior.... [T] justify their own behavior dishonest people will attribute dishonesty to their victims ....").

184. See Summers' Resignation, supra note 72 (referring dismissively to the perspective of the Harvard faculty).

185. See Michelle Park Lazette, Lawrence Mitchell's Attorneys File Motion to Strike 'Scandalous' Material from Lawsuit Against Him, CRAIN's Cleveland Bus. (Nov. 7, 2013, 1:30 AM), http://www.crainscleveland.com/article/20131107/ FREE/131109844/ [https://perma.cc/Z954-3KSA].

186. The dean did indeed launch an attack on Ku's motives, claiming $\mathrm{Ku}$ was disappointed he was not chosen as dean rather than Mitchell and that his lawsuit was to distract from his performance. See id. 
In the motion to strike, Mitchell argued that Ku made "irrelevant and salacious allegations" out of resentment for not being named dean and in order "to cover up and distract from his unsatisfactory performance" as associate dean and director of an IP program. ${ }^{187}$ In opposition, Ku replied that "[d]efendant Mitchell's motion ... was a publicity stunt: he used the judicial process to have his lawyers and expensive corporate public-relations consultants at Dix \& Eaton make a media splash by impugning [P]rofessor Ku's motives for filing suit, without offering a shred of evidence supporting his ascription." 188 Though the underlying facts remain disputed by Mitchell, it is nonetheless the case that the attack on $\mathrm{Ku}$ is similar to attacks on groups that launch no confidence votes, in that prefabricated countercharges generically and without evidence are sometimes used to impugn the motives of the group as only narrowly self-interested. Yet the factors that weigh against successfully coordinated group effort, in an atmosphere of perceived risk by group members, and against an individual lawsuit sure to attract assertions of professional incompetence on the part of the complainant, render such generic claims spurious. Without specific evidence that the motives for the action are merely to obtain better, more advantageous job terms for the group or for an individual, the attacks are unconvincing.

\section{Denouement: Exit as Dean, Promise to Return as Faculty}

The denouement of the Mitchell example of a lawsuit as a means of dislodging a leader reached the final stage in March 2014, when Mitchell resigned his deanship after a period of approximately three months following his leave of absence because of "distraction." 189 In his March resignation letter, Mitchell described a lack of enthusiasm for his role as dean of the law school:

Upon thorough reflection, I have concluded [that] I cannot return to my job as dean with the same energy and enthusiasm that characterized my earlier service. . . At this point, it is in the best interest of the law school for me to step down as dean. I will retain my position as tenured professor and continue to seek to serve the school however I can. ${ }^{190}$ strike).

187. See id. (detailing specific allegations in Mitchell's attorneys' motion to

188. Plaintiff's Opposition to Defendant's Motion to Strike Under Fed. R. Civ. Proc. 12(f), Ku v. Mitchell, No. CV-13-815935 (Ohio Ct. Com. Pl. Nov. 7, 2013).

189. See Brown, supra note 123.

190. Id. 
In this instance of the target's final exit as administrator, it may have appeared that Case Western distanced itself from the resigning dean and let him make his own statement. In fact, though, through its regular e-newsletter, the University also issued a statement of formulaic but weak praise: "Mitchell's decision to step down to support the best interests of the [law] school is the most recent of a series of examples that demonstrate his dedication to the institution, which Mitchell will continue to support as a faculty member and scholar at the school." $" 191$

The article has no university official associated with it but speaks in the voice of the University. The statement devoted several paragraphs to praising accomplishments of Mitchell, including praise for launching a women's leadership initiative. ${ }^{192}$ Given the frequency with which top officers of an institution issue a release praising the resigning official and giving a color of regularity to the departure as unrelated to any effort to dislodge or discredit him, the impersonal character of the announcement may involve some distance. The student newspaper did not detect distancing but saw the University "align[ing] itself with Mitchell" and editorialized:

The article published by The Daily on March 4 is an embarrassment to the university's name and should be removed from the public view. As an editor, it is beyond me why the institution didn't limit that post to a short announcement about the dean's resignation-nothing more, nothing less. Instead the university placed itself on the wrong side of the fence. ${ }^{193}$

Notably, the administrative "dance" associated with Mitchell's departure was typical of a departure by a leader after a vote of no confidence. Leaders depart with praise by the next level above them. The vote against them is said to have been unrelated to the exit. It is not unusual to represent that the departing leader will return to the institution as a faculty member and for the person in fact not to return. The failure of return fades into history, unannounced. ${ }^{194}$

191. Lawrence E. Mitchell Resigns as School of Law Dean, CASE W. RESERVE UNIV.: DAILY (Mar. 4, 2014), https://thedaily.case.edu/lawrence-e-mitchell-resignsas-school-of-law-dean/ [https://perma.cc/Q7VV-6WQT].

192. See id. (noting his creation of the Women's Law and Leadership Institute).

193. Tyler Hoffman, University's Handling of Dean's Departure Is a Disgrace, OBSERVER (Mar. 22, 2014), http://observer.case.edu/universitys-handlingof-deans-departure-is-a-disgrace/ [https://perma.cc/L9ZW-5EDZ].

194. A 2007 resignation of the law school dean at Michigan State University College of Law followed that pattern. A letter from the President of the Law College was released asserting that the vote of no confidence lacked any basis and indicating that the dean's departure was not related to the vote. The letter emphasized that the 
Litigation of the kind undertaken by $\mathrm{Ku}$ disrupts, but does not suppress, the reassertion of narrative control by the administrative hierarchy over the institutional history. The specifics of Ku's allegations remain on the public record. The civic memory within Cleveland is occasionally refreshed by updates in the alternative press of Mitchell's activities.

\section{Et Tu, \#MeToo? Administrators Feeling Ambushed}

Administrators who work to keep a cap on faculty reports of administrative abuse are surely shell-shocked when a slumbering public is aroused by reports of sexual abuse of students and young minors entrusted to the medical care of a doctor at the institution they administer. As \#MeToo gathers steam, more than one top administrator has been confronted with public outcry about long existing but somehow unprevented and unpunished sexual predation against students. ${ }^{195}$ Institutions tend to protect those whom they have elevated to prominence and have often displayed a willingness to discount and tolerate significant dysfunction, even denying misconduct in office or by others critical to the organization or protected by customs of deference. ${ }^{196}$ \#MeToo delivers an unexpected, unwelcome blow, not from a betraying friend but from a sudden blast of disorderly speech.

Sexual misconduct that continued without administrative intervention has also occurred at other prominent universities, including the University of Southern California, Ohio State

faculty lacked authority to dismiss the dean. Letter from Clif Haley, President, Mich. State Univ. Coll. of Law, to Faculty of Mich. State Univ. Coll. of Law (Apr. 2007) (on file with author). Though the dean was described as intending to return to the faculty, in fact he never returned. No announcement of that fact was ever made. For the press release announcing the resignation, see Dean of College of Law Resigns, Search to Begin, Mich. State Univ. Coll. of Law: MSU Coll. of Law News (Apr. 23, 2007), http://www.law.msu.edu/news/2007/releases/dean-search.html [https://perma.cc/USM6-TD65].

195. See, e.g., supra Section III.B.

196. Recent episodes at distinguished institutions demonstrate the gap in accountability and preference to minimize sexually charged allegations against valued researchers or administrators. See, e.g., Bartlett \& Gluckman, supra note 65; Katherine Mangan, Rochester Faculty Senate Censures Professor Accused of Harassment, CHRON. Higher EdUC. (Feb. 27, 2018, 10:30 AM), https://www.chronicle.com/article/Rochester-Faculty-Senate/242650 [https://perma.cc/346D-5J53]. 
University, and Pennsylvania State University (Penn State). ${ }^{197}$ Each of these cases revealed a capacity within institutions of higher education to become the setting for sexual abuse of vulnerable persons, including in the case of Penn State, children brought to the athletic facilities by a football coach. ${ }^{198}$ At the University of Southern California, it was alleged that a gynecologist on the staff of the university used the pretext of medical examination to examine women without the ordinary protocols to protect them from sexualized invasion of their bodies by the doctor's bare hands, in a manner inconsistent with any requirement of treatment. ${ }^{199}$ The facts of the Ohio State matter are still being developed, but they involved the sexual abuse by a university physician of male wrestlers who were subjected to handling of their genitals when they were treated by the doctor for matters unrelated to their sexual organs. ${ }^{200}$ As described, the law dean at Case Western Reserve University allegedly engaged in sexualized interactions involving demeaning language directed at some faculty members, inappropriate relationships with students, and retaliation against his associate dean for reporting certain of these matters to the Case Western administration. ${ }^{201}$ The court filings placed on the public record an account of institutional drama intended for erasure by Case Western administrators. ${ }^{202}$ Searing dramas internalized by victims without voice found a setting for their retelling.

197. See Scott Stump, USC Women Share Allegations of Sexual Abuse By School's Former Gynecologist, TODAY (June 14, 2018, 8:17 AM), https://www.today.com/news/usc-women-share-stories-alleged-abuse-school-s-

gynecologist-t130966 [https://perma.cc/7JSV-57PS]; Catie Edmondson, More Than 100 Former Ohio State Students Allege Sexual Misconduct, N.Y. TIMES (July 20, 2018), https://www.nytimes.com/2018/07/20/us/politics/sexual-misconduct-ohiostate.html [https://perma.cc/8RCP-UJY6]; Belson, supra note 98.

198. See Belson, supra note 98.

199. See Stump, supra note 197; Matt Hamilton, 30 More Women Sue USC over Former Gynecologist As New Interim President Welcomes Freshmen to Campus, L.A. Times (Aug. 15, 2018, 6:40 PM), http://www.latimes.com/local/lanow/la-me-lnusc-lawsuits-20180815-story.html [https://perma.cc/2VNZ-WYNV].

200. See Edmondson, supra note 197; Catie Edmondson \& Marc Tracy, 'It Can Happen Even to Guys': Ohio State Wrestlers Detail Abuse, Saying \#UsToo, N.Y. TIMES (Aug. 2, 2018), https://www.nytimes.com/2018/08/02/us/politics/ohio-statewrestlers-abuse-me-too.html [https://perma.cc/N8ZC-X5EW].

201. See David Lat, Lawsuit Accuses Prominent Law School Dean of Sexual Harassment (and More), ABove L. (Oct. 23, 2013, 12:39 PM), https://abovethelaw.com/2013/10/lawsuit-accuses-prominent-law-school-dean-ofsexual-harassment-and-more [https://perma.cc/83FH-7EDQ] [hereinafter Lawsuit Accuses Dean].

202. Unfortunately, there is an inherent capacity for humans to deny or whitewash unpleasant facts, from sexual misconduct in genteel university settings in 
In the Michigan State example, the courtroom became the outlet for catharsis and the airing of previously submerged social knowledge. Impossible to convey in its full emotional effect, the courtroom outpouring afforded narrative power to student victims and other victims of a predatory doctor who had long [mis]treated female athletes. ${ }^{203}$ The testimony of victims occurred over a period of eight days. ${ }^{204}$ The steady drumbeat of outrage led to the resignation of the President of Michigan State University after years of command over the board and the faculty. ${ }^{205}$ In defiance of the expressed wishes of the faculty, the university board of trustees immediately named as a replacement a former governor of Michigan. ${ }^{206}$ In response, the faculty at the university voted no confidence in the board, a fruitless effort to dislodge the political power of elected officials. ${ }^{207}$ The matter did not recede from newspaper coverage or public memory. Events reviving

the present to past atrocities in states or to dysfunctional family disputes. See, e.g., Antoon De Baets, Combatting Crimes Against History, Hist. News Network (Feb. 10, 2019), https://historynewsnetwork.org/article/171033 [https://perma.cc/KM7UHQQ5].

203. See Meghan Louttit, Giving Larry Nassar's Victims Their Own Voices, N.Y. Times (Jan. 24, 2018), https://www.nytimes.com/2018/01/24/insider/larrynassar-victims.html [https://perma.cc/7ATF-37P2].

204. See Dator, supra note 99.

205. See id. The sense that Simon had been a success amid the complications of a massive academic enterprise was expressed by one trustee when pressure for her departure begin to grow. See Eric Lacy \& David Jesse, As Pressure Grows to Dump Lou Anna Simon, 7 of 8 Trustees Remain Supportive of MSU President, LANSING ST. J. (Jan. 21, 2018, 8:14 PM), https://www.lansingstatejournal.com/story/news/local/ 2018/01/21/msu-trustee-foster-says-board-majority-supports-lou-anna-simon/ 1051873001/ [https://perma.cc/NAY4-374B] ("[Trustee Joel] Ferguson added there would be 'terrible collateral damage' if Simon is no longer president and described her as 'the best president we've had in my over 30 years on the board.'"); see also Roger Groves, Michigan State Got It Right with President Lou Anna Simon, ForBES (June 17, 2013), https://www.forbes.com/sites/rogergroves/2013/06/17/michiganstate-got-it-right-with-president-lou-anna-simon/\#56ac78ab2290 [https://perma.cc/

KSX8-QPRT] (stating in an admiring profile that "Simon has been president since January 2005 [and] I was curious about why MSU experienced consistent success (albeit not always as part of the super elite) during her tenure").

206. See id.; Fernanda Zamudio-Suaréz, Top Faculty Committee Upset with Michigan State's Choice of Interim Leader, CHron. Higher Educ. (Jan. 31, 2018), https://www.chronicle.com/article/Top-Faculty-Committee-Upset/242397 [https://perma.cc/G49K-DU5Z].

207. See Dan Murphy, Michigan State Faculty Delivers No-Confidence Vote on Board of Trustees, ESPN (Feb. 13, 2018), https://www.espn.com/collegesports/story/_id/22424667/michigan-state-faculty-delivers-no-confidence-voteboard-trustees [https://perma.cc/M26R-AM7L] (discussing the faculty's decision to make a no confidence vote despite having no power to remove the trustees from their positions). 
memories of the perceived incompetence and even bad faith of MSU, including after the installation of an interim president, have continued and will continue.

In contrast to the types of problems brought to light by faculty votes of no confidence, sustained coverage of the aftermath, as well as the emergence of new victims, wrested control over the narrative from university officials. The story has found multiple occasions for news coverage: criminal charges against university officials, ${ }^{208}$ final settlements with litigants, controversial statements by the nowdeparted interim president, the search for a new president, and additional human interest stories about the victims, many of whom are prominent in the world of gymnastics. The loss of President Simon's well-regarded stewardship of the university on other dimensions is of considerable weight. That loss, in part, cancels the narrative that had built up around her long incumbency, celebrated in the university's sense of history as having augmented university resources, with perceived coups such as winning large government grants for science. ${ }^{209}$ The need to replace her in a crisis mode rather than as a smooth transition to a new leader inflicts real damage to the university, as well as reputational injury. The erasure of the narrative of success of a first woman President at MSU, with replacement by a narrative of the Epic Failure in connection with sexual predation, is an unusual total displacement of institutional narrative control. The effort by the interim president to maintain institutional control over "the story" and his eventual forced departure deepened the transfer of narrative control to forces beyond the university's capacity for erasure of social knowledge and focus.

The impact of all of these scandals, except the Ohio State wrestling matter, was the forced departure of a top leader. As has been recounted, the president of MSU resigned under pressure. At Penn State, the president resigned, and, as a result of evidence of his

208. See Matt Mencarini, Kara Berg, \& RJ Wolcott, Ex-MSU President Lou Anna Simon Charged with Lying to Police About Nassar Investigation, LANsing ST. J. (Nov. 20, 2018, 2:18 PM). In late 2018, former President Simon became one of the targets of criminal charges. Id. Those charges were eventually dismissed. See Judge Dismisses, supra note 106.

209. See, e.g., Lindsay VanHulle, Simon Leads 10 Years of Growth at MSU, LANSING ST. J. (Feb. 7, 2015, 9:22 PM), https://www.lansingstatejournal.com/story /news/local/education/2015/02/07/simon-leads-years-growth-msu/23045365/ [https://perma.cc/LE2N-7HN5] (providing a laudatory description of her ability to attract visionary projects and move the university into a leadership role in technology and the state economy). 
personal knowledge, he was convicted of a criminal charge. ${ }^{210}$ The president of the University of Southern California resigned under pressure after having allowed the problematic doctor to resign quietly and receive a sum of money. ${ }^{211}$ The dean of the law college at Case Western resigned in connection with the settlement of a lawsuit brought against him and the university by the former associate dean. ${ }^{212}$

The extent of harm from these Epic Failures is incalculable-to the victims, to society in general, to the institution, and to those leaders and credulous persons whose habits of maintaining a surface of normalcy brought them loss of careers, reputation, and possibly even personal liberty.

\section{E. Empirical Treatment of Votes of No Confidence}

Votes of no confidence are not rare, and they are not futile. ${ }^{213}$ Such votes enjoy a degree of success but are also little documented, analyzed, or theorized with any scholarly diligence. We have found considerable evidence of their basis in a collective sense by faculty groups at many schools of a problematic culture. ${ }^{214}$ This type of culture works to disempower faculty, and often succeeds in rendering faculties passive, on the belief by faculty that engagement is futile, and that the fear of open dissent or critique of administrators is a normal response to the power of administrators. ${ }^{215}$ The culture descends into a

210. See Aria Bendix, Former Penn State President Sentenced to Jail over Sandusky Scandal, ATLANTIC (June 2, 2017), https://www.theatlantic.com/news/ archive/2017/06/former-penn-state-president-sentenced-to-jail-sandusky-scandal/ 529044/ [https://perma.cc/C3BM-ZD84].

211. See Susan Svrluga, USC President Steps Down, Effective Immediately, in Wake of Sex-Abuse Scandal, WASH. Post (Aug. 8, 2018, 2:20 PM), https://www.washingtonpost.com/news/grade-point/wp/2018/08/08/usc-presidentsteps-down-effective-immediately-in-wake-of-sex-abuse-scandal/?utm_term=. 2bdaee663a69 [https://perma.cc/4EQP-TGPM].

212. See Allard, supra note 133.

213. See KuYKendall \& McKinniss, supra note 26.

214. Id.

215. Telephone Interview July 28, supra note 59 . One faculty member at a major university explained:

I think we all feared that the vote of no confidence could end up being merely symbolic and would not really turn into anything more structural or substantive. That was the fear for concern all along. It never really dampened our enthusiasm to have that vote. But I think we knew that getting a vote of no confidence was going to be a whole lot easier, really than changing the university as a whole in some fundamental way. And that the latter would take a lot of energy and commitment. And in the end it just wasn't 
cynicism that might be regarded as antithetical to the aspirations of the university as an incubator of liberal values in a democracy. The mixture of administrator overreach and faculty defeatism cedes academic choices, the academic culture of the university, and the welfare of students to administrators guided by business models and authoritarian impulses. The result of the climate created is instances of bad conduct by university administrators that go unaddressed in the absence of faculty voice as a check, many of these being well known. ${ }^{216}$ In some institutions, the atmosphere has so degenerated that an overpowering tyranny has "broken" the faculty. The vote of no confidence occurs when the just-right mixture of administrative wrongdoing and residual faculty spunk meet.

Our research confirms that votes of no confidence in higher education perform a function, at least in the timing of leader departures. My coauthor has amassed data on nearly 180 faculty votes

there on the part of people to move forward. . . Now another thing I learned is that in a very interesting way there are a lot of faculty who are every bit as timid and cowed by authority as minimum wage workers.

Id.

216. See generally LiONEL S. LeWIS, WHEN POWER CORRUPTS: ACADEMIC Governing BoARds in the SHAdow OF THE AdELPHI CASE (2000) (addressing an extraordinary scandal that illustrated the powerlessness of a faculty as well as students against a President backed by a supine board chosen and dominated by a president bent on empire building and self-enrichment). A long running siege of Adelphi University, a commuter school on long Island, bled faculty, lost student enrollment, and reduced classes for students as staff numbers increased and the presidential salary ballooned and was punctuated in 1995 by a faculty vote asking for the President's resignation. The New York Times advocated new leadership in response. See The Plundering of Adelphi, N.Y. TIMES ARCHIVES (Oct. 14, 1995), https://www.nytimes.com/1995/10/14/opinion/the-plundering-of-adelphi.html

[https://perma.cc/8AKN-9ZRE]. The crisis only ended when the Regents of New York removed the board and named a new board that then fired the President. Id.

The state Regents removed 18 of the 19 trustees - most of whom were recruited by Dr. Diamandopoulos - for neglect of duty and misconduct on Feb. 10. The Regents cited the trustees for granting excessive compensation to Dr. Diamandopoulos, for failing to evaluate his performance and for allowing some trustees to engage in private business with the university. The old board contested the Regents' ruling for three days, and then resigned, clearing the way for the new board to take over.

Bruce Lambert, New Trustees of Adelphi U. Dismiss Embattled President, N.Y. TIMES (Feb. 21, 1997), https://www.nytimes.com/1997/02/21/nyregion/new-trustees-ofadelphi-u-dismiss-embattled-president.html [https://perma.cc/D5ZF-XMPL]. 
of no confidence against college presidents. ${ }^{217}$ Leaders who receive a vote of no confidence often leave within a year of their vote. ${ }^{218}$ Thus, the evidence supports a view of no confidence votes as an effective tool for not only voicing displeasure with leaders but also compelling a leader's ouster. Despite the part of our story that tells of success, the limitations are both (1) probable underproduction of public statements about a leader crisis and (2) the fact that a no confidence statement is ordinarily relatively bare of information about the leader problem. ${ }^{219}$ The usual choice of impromptu groups announcing a vote is to avoid a bill of particulars by a flat notice to the relevant decision group about the leader's tenure. I offer the following formulation as a typical attempt by a group to limit the content of the statement and thereby avoid a set of allegations that would be subject to immediate contestation: "NAME group lacks confidence in Mr./Ms./Dean/President Name." ${ }^{220}$ The reticence is rational, since the gravamen of a vote of no confidence is the simple fact that the leader lacks a capacity to lead. The institutional refusal to credit that fact

217. See Sean McKinniss, No-Confidence Vote Database, Higher EdUC. GOVERNANCE, http://www.seanmckinniss.org/no-confidence-vote-database/ [https://perma.cc/SAT2-SKQZ] (last visited Apr. 13, 2020).

218. See KUYKENDALL \& MCKINNISS, supra note 26. In our dataset, over half of college presidents who received a no confidence vote departed within a year of their vote, though they rarely attributed their exit to the no-confidence vote. Id.

219. Underproduction can be achieved by administrative guile. See Cory Weinberg, Law Faculty Plotted to Oust Dean, GW HATCHET (Feb. 25, 2013, 3:24 AM), https://www.gwhatchet.com/2013/02/25/law-faculty-plotted-to-oust-dean/ [https://perma.cc/L2G6-AHHU]; see also Elie Mystal, How to Oust the Dean of Your Law School: A Law Dean Who Says He Wasn't 'Ousted' Was Probably Freaking Ousted, ABove L. (Feb. 25, 2013, 2:49 PM), https://abovethelaw.com/2013/02/howto-oust-the-dean-of-your-law-school/. [https://perma.cc/B96W-A45X]. At the law school at George Washington University, an effort by faculty to bring a vote of no confidence was thwarted by preemptive administration plotting-by means of elevating the target, dean of the Law School, to a higher administrative position. After contentious communications with the dean concerning his leadership style and its impact on faculty governance, half of the faculty signed petitions, in accordance with Faculty Senate provisions, contained in sealed envelopes. Were these delivered, a formal vote would occur in which a vote of half the faculty would then present the President of the University with a demand for removal of the dean. Before the envelopes could be delivered, the dean was suddenly elevated to vice provost of the University. Though the remedy of removal succeeded de facto, the remedial feature provided by open pressure resulting in a removal was thwarted, as was the chance for a public faculty statement of governance principles and core institutional values. The student paper refuted the cover story enabled by the sudden promotion of the dean before the vote could occur. See id.

220. A group formulating a vote of no confidence typically avoids any content other than the basic statement of no confidence provided above. 
amounts to a concession that the person has been awarded a position that is one of command, even edict, not leadership.

\section{F. Limitations and Alternatives to Avoid Epic Failures}

Despite the function of no confidence votes as a gap-filling process where accountability is lacking, they are not a sure solution when a leader is creating a sense of crisis in a group, for reasons of incompetence, poor fit for the organization, or lack of ethical or moral standards. ${ }^{221}$ Because it is sometimes impractical to organize a group response, faculties or individuals harmed by problematic leaders sometimes turn to formal legal remedies for unresolved problems affecting the proper functioning of an organization. ${ }^{222}$

In general, despite low frequency and uncertain effect, the picture that emerges is that votes of no confidence perform a function in specific instances in which leader exit does result. Their occurrence helps add to a public record (aided by our compilation) of problematic conduct in public interest entities. Among our findings are evidence of the misuse of resources to obscure forms of regular dysfunction as well as the occasional extraordinary scandal, the instinct and practice of protecting leaders and intimidating those who wish to report misconduct, and the not-unusual payout to bad leaders when a vote of no confidence results in a resignation.

We also find instances of formal resignation but retention of power and emoluments. Public exposure, in which the reason for departure and the reform of organizational power arrangements in which the problem leader participated, is a critical test of how a particular path to forcing a leader out contributes to long-term accountability in an institution. A leader's exit constitutes a form of personal accountability. But, when done without a genuinely open inventory and admission of the facts surrounding the departure and the plans for remediation, if the problem appears to be symptomatic of a general organization failure, the departure is not redemptive or reparative. It is a relief, however, for the group that suffered the bad conduct. That relief is not to be minimized.

Votes of no confidence arise as a last resort, when a group perceives no other means of holding a leader to account for a pattern of behavior that the group sees as unacceptable, even intolerable. They do not occur in every instance of problematic leadership that causes

221. See supra Parts II, III.

222. See supra Part II. 
group disaffection. The disincentives that prevent sufficient trust within a group fearful of the power of an administration to retaliate may well underproduce the check on leaders by collective voice. In addition, periods leading up to outcry inflict long stretches of institutional drift. The waiting game dissipates internal focus on the work of the body. Attention is diverted to speculation about how a perceived crisis will end. Despite concern that votes of no confidence can be overused and deployed as a form of mob rule for petty reasons, the fear factor in professional groups is likely far from trivial. Faculty with a conservative temperament may disapprove of efforts to undermine or reject the authority of a hierarchy. Such cautious faculty members may well discount the type of complaint against an administrator as involving an overreaction and oversensitivity to a normal range of human behavior.

In the instance of sexually aggressive behavior by a male with power over women, and on occasion subordinate males, there has been, until quite recently, a cultural willingness to dismiss such conduct as expectable but somehow tolerable manifestations of human sexuality. The \#MeToo movement has made the extent of this problem readily apparent and insisted on ending normalization. In some instances, faculty may agree there is a problem but encounter differences among subgroups about the nature or urgency of the problem. The sensitivity of charges of sexual misconduct likely curtails open speech about a colleague. Hence, many schools and other entities have failed to assure respectful treatment of faculty in connection with their right not to be subject to retaliation for speaking truthfully about seriously disabling flaws in a leader, ${ }^{223}$ even including failure to intervene where evidence of sexual impropriety is brought to a leader's attention by another administrator. ${ }^{224}$ Sexual impropriety particularly challenges the capacity of universities for self-policing and even raises an issue about the vote of no confidence as a safety valve when formal accountability mechanisms fail.

223. See Telephone Interview with Anonymous, Faculty Member, State Univ. Secondary Campus (May 30, 2018) [hereinafter Telephone Interview May 30] ("I lost my cool, I just jumped up and started screaming. I was like, why y'all doing this to me because I was unable to sleep and unable to eat.").

224. See supra Section III.C (describing retaliation by the dean of Case Western Reserve University Law School against the associate dean for reporting concerns about his allegedly improper sexualizing of the workplace). 


\section{G. Summary}

The \#MeToo movement adds public momentum to the realization that sexual misconduct in university settings demands better systems of accountability - and an internal culture capable of treating power abuse involving sex as a matter of group protection of institutional integrity and even moral acceptability. The \#MeToo rubric makes the issue of response to poor leadership particularly salient in universities. The sexual predation scandals present powerful demonstrations that institutions have failed to respond to information requiring immediate action to protect the members as well as student athletes in the university. Yet the absence of votes of no confidence also suggests the possible limitations of group commitment to the health of an institution, either due to members being unaware of misconduct or unwilling to publicly address it or even to risk private discussion and acknowledgment.

These scandals are thus the tip of the iceberg in connection with university and nonprofit leadership. Faculty members have often found themselves searching for a means of addressing the refusal of those who might remove a bad leader and somehow forcing the exit of the leader as immediate relief from an atmosphere associated with that person. As discussed, the vote of no confidence has often been chosen to fill the accountability gap presented by an unyielding support of a hierarchy for a bad leader. In simplest terms, the no confidence vote is a self-help public declaration, taken as a last resort by a group that has concluded it has no other recourse. 225 Since top university administrators are expected to function as a leader to the faculty, often called a first among equals, the announcement means the "leader" is no longer a leader for faculty colleagues. Votes of confidence that occur because of a public scandal stand on a different footing in terms of bringing institutional self-knowledge, or bottomup epistemological truth, to the surface. ${ }^{226}$

225. A "vote of no confidence" is defined as "a formal vote by which the members of a legislature or similar deliberative body indicate that they no longer support a leader, government, etc." Vote of No Confidence, MERRIAM-WEBSTER DICTIONARY (11th ed. 2018). This is a simple dictionary definition that refers to the origin of the organizational vote of confidence that has developed in democracies as an extension of the practice that developed in the British Parliament starting with a vote against the leadership of Robert Walpole. See supra Part II for an account of the background of votes of no confidence, the form they typically take, and the role they play in making leaders in nonprofit bodies accountable.

226. Notably, a vote of no confidence brought against a leader as a response to an unanticipated scandal does not fit this classic use of the no confidence vote as 
The no confidence motion has had a visible but opaque role in institutions of higher education.227 The no confidence vote is nonetheless controversial, to some degree, because of generic arguments made against it by administrators and others resentful or skeptical of the ability of faculties to "fire their boss." 228 Most employees assume they have no means to fire their boss, not even a very bad boss. In a strong economy, quitting and getting another job is a solution that works for many. Nonetheless, the Internet produces advice to employees on what do to about a bad boss, including trying to have her fired. ${ }^{229}$ For those who have no say about throwing out their boss, the question can arise, "why can faculty members fire their boss?" This reaction is at its most forceful where the issues relate to faculty concerns about governance, academic values, and other less well appreciated aspects of academic culture.

In our forthcoming book, my coauthor and I argue that faculty voice has force as an unregulated outlet capable of declaring a crisis of competence, ethics, or even morality. Arguments against such extraordinary, unauthorized resort to public voice mistakenly presume, without evidence, the existence of a sound state of affairs

the capstone of a period of unrest and disaffection about a leader. If there has been no undercurrent of a movement against a leader, a vote of no confidence brought after outside signaling of a crisis, such as a sexual scandal, is not necessarily the end point in a leader's effectiveness because of a systemic concern by the group. In such a fact pattern, the vote is more akin to "virtue signaling," and may or may not represent a genuine statement that the group has formed a consensus that a leader is corrupt, abusive, or ineffective. Depending on the facts, the vote has an element of what is loosely called "branding," meaning that the group wishes, by disassociating with the leader, to protect the brand.

227. See Schmidt, supra note 35 (discussing the lesser clarity about the function and effect of the vote of no confidence outside the original context of a representative body such as Parliament).

228. See, e.g., William G. Tierney, Averting the Nuclear Option, 93 ACADEME 49, 49-50 (2007) (calling the no confidence process of removal of a university president "lamentable" and suggesting no confidence votes result from "communications failures"); Kenneth A. Shaw, A Vote for Confidence in College Presidents, Chron. Higher Educ. (Apr. 8, 2005), https://www.chronicle.com /article/A-Vote-for-Confidence-in/12228 [https://perma.cc/J2HQ-5FA6]; Joseph Petrick, No Confidence in No-Confident Votes, 93 ACADEME 52, 52-53 (2007) (advocating that means be found to avert no confidence votes by solving leadership problems in ways that are less damaging to the institution than no confidence votes).

229. See Sherrie Campbell, 6 Effective Tactics for Handling a Toxic Boss, ENTREPRENEUR (Sept. 27, 2018), https://www.entrepreneur.com/article/320696 [https://perma.cc/GXM7-C35Q]; Glassdoor Team, How to Get Your Boss Fired, GLASSDOOR (Feb. 21, 2012) https://www.glassdoor.com/blog/boss-fired/ [https://perma.cc/H6KW-TH8U]. 
amenable to harmonious resolution. The view of a normal state of affairs in the typical instance of such faculty initiatives is unwarranted.

The sexual scandals, long kept quiet but now being heard, have belied the notion of organizational regularity and revealed that even as certain groups, women, minorities, gay men and women, the young, and others have been brought into the academic and professional world, they have in truth been excluded from building an organizational epistemology that incorporates their knowledge. What they have known has been treated as trivial and akin to gossip that cannot inform the communal truth of the organization. If insiders with power do not tell the story for groups lacking in voice within an organization, are there outsiders capable of filling the void with compelling accounts of the organizational wrongs?

\section{NARRATIVE BLACK HOLES: LOSING CONFIDENCE IN NO CONFIDENCE?}

Scandals that resonate with \#MeToo have hit universities and other institutions with financial liability and potentially corrosive reputational damage. No internal mechanism, official or improvised, has been adequate to the need for moral response. The stranglehold on epistemic authority in institutions that have adopted closed systems disempowering unmanaged voices from below the top tier of leaders shuts off open speech about sexual wrongs. The bland speech produced by the administrative class crowds out unwelcome messages. Blunt naming of sexual molestation of vulnerable students or recounting the use of crude language to subordinate faculty or other professionals is off-key and harsh. The danger such speech poses to the speaker's security of position and sense of acceptance by peers produces an excess of self-policing that maintains seeming normalcy - until a scandal erupts. After a scandal is exposed, the policing goes underground, with the same managerial impulse to maintain harmony and propriety, and with new recruits protecting surface harmony from the disruptive effects of truth.

A. Narrators and Their Limitations-Then and Now, Paradoxes of Secrecy Over Time

Before the \#MeToo voices brought pressure to bear on nonprofit administration, faculties, and other professional groups had long turned to the vote of no confidence to expose leaders whose misconduct or incompetence attracted their protest. These votes had 
some success, but they did not receive heavy press coverage. In light of the university's prestige, the no confidence vote at Harvard University received significant attention. ${ }^{230}$ But the effort at New York University, despite its location in the voracious media market of New York City, received minimal coverage. ${ }^{231}$ Unlike the issues with which faculty and other groups are often concerned, the recent \#MeToo and rankly sexual scandals have brought intense national attention to an accountability shortfall in institutions with responsibility for critical social functions. ${ }^{232}$ Religious bodies, fundraising groups, and other bodies responsible for the welfare of vulnerable persons have been found callous, unfeeling, and ruthless. Without transparency in an institution's normative superstructure, a sense of impunity can infect the institution's administrators. Time and context empower and disempower narrators within an institution. At the top, potential narrators maintain silence about what they know or fail to know. New managers do not want to know about seamy facts of occurrences before their arrival. From the ranks, social knowledge remains locked in the knowing looks or warnings from colleagues about the known but unspoken story of shared secrets, unspoken because unspeakable. The persistent deflection of institutional accountability for individual conversions of institutional power into personal sexual power poses a mystery about speech along dimensions of time, silence, fear, and motive.

\section{B. Motives to Speak?}

\section{Inside Organizations}

Some unit leaders engage directly in wrongful conduct. Others choose to protect perpetrators of wrongful conduct for reasons that resist a single explanation. Motives may include personal friendship, perceived class solidarity, indifference to the effect on those subject to abusive conduct, belief in the wrongdoer's net value to the

230. See, e.g., Rimer, supra note 61.

231. But see Goodwin, infra note 250 (constituting one of the sole published accounts of the NYU imbroglio); see also E-mail from Anonymous N.Y. Univ. Employee to author (May 31, 2020) (on file with author) (asserting that, "[t]he vote of no confidence in Sexton-or rather, the several *votes* of no confidencereceived little media attention. There was a story or two in The New York Times and an op-ed, but that was about it. The vote at Harvard was considered much more newsworthy.")

232. See supra Section III.D. 
organization, or a preference to maintain control in the form of silence within the ranks about the empirical connection between authority and habits of abuse. ${ }^{233}$ The meta-message of \#MeToo is that there has been a widespread collective willingness to silence the targets of sexual misconduct and to protect the predators. A hackneyed response to revelations about long-past misdeeds against women has been, "it was a different era when the rules were different." ${ }^{234}$ In a curious merger of a past and present perspective, self-nominated narrators of presentday revelations purport to describe knowledge from the past that was kept secret. There is a suggestion that the method of secret-keeping, underpinning the rules of power and the required submission to it, were known, with the paradox that the institution's secrets were not known and are also known as a shared social memory. About the history of the rules, strange knowledge reigns. We learn of a retrospective on the workings of institutional knowing: the rules have been not to know. The retrospective tone hints at a new day. ${ }^{235}$ When

233. See generally Memorandum from Gregg L. Bernstein et al., Zuckerman Spaeder LLP on Investigation of Bishop Michael Bransfield, Former Bishop of Diocese of Wheeling-Charleston to William E. Lori, Archbishop, Archdiocese of Balt. (Feb. 21, 2019) (reporting sexual misconduct within the Catholic Church surrounding Bransfield). A secret report commissioned by the Catholic Church and unearthed by the Washington Post offers a reason for silence surrounding a person given authority in a nonprofit institution, specifically an allegedly abusive Catholic bishop. See id. at 3 ("The Vicar General and Judicial Vicar, in particular, acknowledged that they were aware of Bishop Bransfield's tendencies and sexual harassment, but took no steps to prevent it based on a combination of fear and loyalty toward the Bishop.").

234. See Elizabeth C. Tippett, Weinstein May Be a Monster, But the Lawyers Who Enabled Him Are the Real Villains in \#MeToo Takedown 'She Said', CONVERSATION (Sept. 12, 2019, 3:54 PM), https://theconversation.com/weinsteinmay-be-a-monster-but-the-lawyers-who-enabled-him-are-the-real-villains-in-metootakedown-she-said-123481 [https://perma.cc/A8U9-7NAA] (describing the long running complicity of lawyers in helping Harvey Weinstein cover his tracks and quoting lawyer Lanny Davis saying, "powerful men of an older generation were changing their understanding of the meaning of the word consensual"); see also Jonathan Zimmerman, Where Does MLK Fit in Today's \#MeToo World?, BALTIMORE Sun (Apr. 6, 2018, 7:00 AM), https://www.baltimoresun.com/opinion/op-ed/bs-edop-0408-mlk-metoo-20180404-story.html [https://perma.cc/ZV5D-T9CN] (arguing that "we shouldn't read our own values onto people like King, who operated under different norms and rules").

235. "The only thing that's surprising about Weinstein's conviction for rape is that he has actually been convicted." Hadley Freeman, With Harvey Weinstein's Conviction, the Old Excuses No Longer Apply, GuARDIAN (Feb. 25, 2020, 8:11 AM), https://www.theguardian.com/commentisfree/2020/feb/25/harvey-weinstein-rapeconviction-movie-industry-hadley-freeman [https://perma.cc/KZ62-BTLJ]. 
scandal reappears, volunteers come forward once more to explain the old rules governing institutional knowledge, and to herald a new day.

Despite these belated recollections, the institutional management of knowledge about dysfunction and bad conduct reduces the volume of useful history of American universities. ${ }^{236}$ The official institutional history is cleansed of a recounting of the moral failures and governance flaws that would inform the judgment and understanding of future faculty members and provide a comprehensive public record of governance problems in universities. The purposeful erasures support an atmosphere of moral timidity within the academy. ${ }^{237}$ Administrators who may wish to expose

The initial allegations that he raped women were so unsurprising - they felt almost inevitable, really - that as soon as they were published in 2017, first in the New York Times, followed days later in the New Yorker, Weinstein's career was finished. There were no anguished discussions about giving him the benefit of the doubt, no solemn handwringing about how complicated relations between the sexes are these days. It was as if we all had always known - which, to a certain extent, many of us had.

Id.

For a deconstruction of the rhetoric around "a new day" and what we know and have known about "yesterday," see Tim Mulkern, Mad Men: Justifying Sexism and Gender Roles Through Nostalgia, Global Critical Media Literacy Project (Mar. 24, 2019), http://gcml.org/mad-men-justifying-sexism-and-gender-roles-throughnostalgia/ [https://perma.cc/4XXW-239L] (arguing that the depiction of a time when the rules were different intentionally recreates and idealizes roles showing male dominance and romanticized sexual harassment of female careerists and treating skeptically the purported representation "of a former time period" as "normative" for the time yet presenting gender roles as models for emulation).

236. In a 1962 group of lectures, historian Allan Nevins produced eye-rolling accounts of clownishness and graft in the coming-of-age of the land grant universities. His narrative of a slice of university history in the United States departs from the bland or relentlessly celebratory tone of approved voices about the achievements of the Morrill Act. See generally Allan NEVINS, The StATE UnIVERSITIES AND DEMOCRACY (1962) (presenting a new tone about academia). Delivered at the invitation of his University of Illinois alma mater to celebrate the centennial of the Morrill Act, Nevins produced prose about graft and anti-intellectualism that lacked the usual detachment of the professional historian and could have subjected him to critique for a flawed tone. A book review at the time nonetheless praised the book as inspiring and presumably not for being unsparing. See Roy Nichols, Book Reviews and Book Notes, 31 PA. Hist. 380, 390-91 (1964) (reviewing NEvins, supra note 236).

237. See Debra R. Comer \& Gina Vega, Moral Courage in Organizations: Doing the Right Thing AT Work xvi (Debra R. Comer ed., 2011) (developing the argument that organizations tend to make acting on the basis of moral concerns difficult and arguing for efforts to encourage the development of great moral courage in organizations in the interests of ethical behavior). 
morally significant poor behavior or cover-ups appreciate that their task is defined as preventing disclosures that discredit the university culture, protecting other administrators, and keeping alumni happily uninformed and generous with pledges of monetary support. Faculty members learn to adopt language that conceals more than it reveals, and thus to stay in line with administrative wishes. Civic courage is replaced by falseness and courtier behavior, or silence. Talk among faculty members laments the futility of reports up the chain and skitters away from admitting or sharing the futility of lamentation. Faculty members and epistemic democracy, unlike fools and their money, part their way by choice.

In the event of a vote, the hierarchy employs standard means of controlling the public narrative and attempts to deflect, in the immediate moment and thereafter, a narrative that departs from the preferred official story and would disrupt efforts at protecting the university brand. The faculty has few means of contesting the institutional narrative set out by university press officers.

As a result, the public narrative of no confidence votes is standard, brief, and, generally, false. The private, enacted narrative is not admitted into the discourse of official keepers of the institutional persona and in the ordinary case, never reaches wide circulation among those who might form a judgment about the needs of the institution for moral reform or make demands for changing its adherence to the usages of hierarchical immunity.

In addition, internal discussion that would inform newcomers about the episode is discouraged and even labeled "unprofessional." The brief moment of shared work toward an improved epistemology of the organization fades. Scurrying away from the facts of the event becomes the norm as courage wanes among participants in a vote. Those who might claim a share of epistemic authority to narrate organizational history retreat into silence, leaving the institutional podium to be monopolized by the administrative class.

When narrators from outside the mission-bonded, professional ranks emerge to force an abrupt ending to the old rules on sexual power and the rule of silence in organizations, a new dynamic forms around the catastrophic effect of public concern about something so odious as sexual molestation of students. Intensity of coverage from investigative journalism has a long-tail duration, with endless triggers for new interest. The list is long, with the opening focus with the trials of a predator, high-dollar settlements with victims, and charges against top administrators. The Michigan State scandal has produced 
narrative-style books about the victims' experience, ${ }^{238}$ board volatility with dismissals of an interim president, ${ }^{239}$ political posturing, ${ }^{240}$ government-issued reports summing up the claims of bad conduct, ${ }^{241}$ and the need for repeated administrative mea culpas and promises of reform. ${ }^{242}$

A critical component of success ${ }^{243}$ by students who have been subject to sexual predation is the adoption of their cause by journalists who provide continuing coverage in an environment of fact-rich disclosures of wrongdoing so indecent and pervasive that no defenders come forth to claim propriety or consent. A typical no confidence vote, with less sensational or easily comprehended grounds, does not sustain journalistic coverage. Instead, it typically receives little more than a one-day use by a local paper of a press release announcing it,

238. See generally Rachael Denhollander, What Is a Girl Worth?: My Story of Breaking the Silence AND Exposing the Truth About LarRy NASSAR and USA Gymnastics (2019); Abigail Pesta, The Girls: An All-American Town, a Predatory Doctor, and the Untold Story of the Gymnasts Who BROUGHT Him DOWN (2019).

239. See RJ Wolcott \& Eric Lacy, Engler's Impending Departure from Michigan State Prompts Strong Reactions, LANSING ST. J. (Jan. 16, 2019, 9:09 PM), https://www.lansingstatejournal.com/story/news/local/2019/01/16/msu-fire-johnengler-michigan-state-larry-nassar-survivors/2581373002/ [https://perma.cc/2QL4NNNB] ("John Engler told the Detroit News Editorial Board that survivors of Larry Nassar's abuse 'who've been in the spotlight . . . are still enjoying that moment at times."').

240. See Maya Goldman, Here's Why the Larry Nassar Scandal Has Become Part of the Gubernatorial Race, Mich. RADIO NPR (Sept. 23, 2018), https://www.michiganradio.org/post/heres-why-larry-nassar-scandal-has-becomepart-gubernatorial-race [https://perma.cc/NJ6Z-TKQM] ("Whitmer says Schuette and Republicans should not politicize this case. 'I've had it with these guys who want to use this Nassar case as a political gimmick for their own sick political gain,' she says. Schuette plans to speak about the issue at a campaign event Monday.").

241. See Letter from Meena Morey Chandra, Reg'l Director, U.S. Dep't of Educ., to Samuel L. Stanley, President, Mich. State Univ. (Sept. 5, 2019), https://msu.edu/ourcommitment/_assets/documents/OCR-MSU-Agreement2019.pdf [https://perma.cc/HU5H-85WL].

242. See, e.g., Emily Guerrant, Stanley Sets Course of Action Following Federal Reviews, MSU TODAY (Sept. 5, 2019), https://msutoday.msu.edu/news/2019/ stanley-sets-course-of-action-following-federal-reviews/ [https://perma.cc/95WD95XF]; see also Samuel L. Stanley, Sept. 5, 2019: Message on U.S. Department of Education Investigations, Mich. ST. U. OfF. President (Sept. 5, 2019), https://president.msu.edu/communications/messages-statements/2019_community_ letters/2019_09_05_message_to_community.html [https://perma.cc/S4JG-P7NW].

243. The term "success" is not intended to suggest that exposure of the wrong is sufficient to bring justice or erase the injury, one which lingers throughout the life of a victim of such predation. 
with a dismissive response by an institutional spokesman. ${ }^{244}$ If the target eventually resigns, the newspaper will print an announcement provided by the press office of the university, typically carrying a claim that the resignation is not a result of the no confidence vote. ${ }^{245}$

\section{Public Attention}

Sex changes the operative principles of media attention. The general rule of journalism applies to university scandals: sex sells. The rule within the university, before journalism enters the mix, is pretend and avoid. The story begins to sell only if someone breaks through the passivity of newspapers that cover the university as a local story or finds an out-of-town paper happy to run a scoop. Years can pass with local papers declining to follow leads, until a critical cultural moment arrives. For sex to sell, a narrator must emerge, and the wall of silence must break. At ground level, the fascination with sex is expressed in the opposite of narration: a looking away that blocks revelation. These dynamics of avoidance display evidence of cultural durability, at least in the United States. ${ }^{246}$

Nonetheless, unlike institutional votes of no confidence seeking to oust an incompetent academic or other nonprofit leader, public attention about sexual misconduct with real live victims can lead to a greater degree of publicity. This is deeply distressing to the leaders in those universities who treat it as an obstacle to the business of the university and move quickly to squelch public uproar with a mixture

244. See, e.g., Jordan Friedman, Nine 'No Confidence' Votes That Made Headlines in 2012-2013, HufFington Post (June 17, 2013, 1:46 PM), https://www.huffingtonpost.com/jordan-friedman/nine-no-confidence-votes-

_b_3448606.html. [https://perma.cc/K9CJ-8DFN]; Ariel Kaminer, Fourth No Confidence Vote for the President of N.Y.U., N.Y. TIMES (May 11, 2013), https://www.nytimes.com/2013/05/11/education/fourth-no-confidence-vote-for-thepresident-of-nyu.html [https://perma.cc/EC98-BZLR].

245. See Friedman, supra note 244; Kaminer, supra note 244.

246. By contrast, the \#MeToo movement encounters significant cultural resistance in nations still protective of hierarchical prerogatives, particularly of males toward women, even on the street. See Kim Willsher, 'They Just Don't See Us As Human': Women Speak Out on France's Harassment Problem, Guardian (Aug. 3, 2018, 8:14 AM), https://www.theguardian.com/world/2018/aug/03/they-just-dontsee-us-as-human-women-speak-out-on-frances-harassment-problem

[https://perma.cc/Q25U-5B97] (describing how the \#MeToo campaign, sparked by Hollywood producer Harvey Weinstein's predatory and sexually abusive behavior with female actors, provoked a backlash in France, where cultural differences, among them French ideas of "seduction," were cited to counter it). 
of reassurance and stonewalling. ${ }^{247}$ A common locution, easily found in an internet search, is "we take allegations of [FILL IN THE BLANK] very seriously." ${ }^{448}$ That statement cuts two ways. It can mean, "we are serious about rooting it out and holding offenders to account." Or it can mean, "the charge is extremely serious and thus very hard to prove." Reassurance and a stone wall can be made with the same building supplies. Nonetheless, the standard toolbox of media handlers can fail to stop the growing outside scrutiny. The vast public interest and journalistic stamina in covering these most discrediting sex scandals differ from the scant attention given by the press to statements about faculty disempowerment and questionable decisions by the top leaders of a university.

For example, the vote of no confidence in the president of New York University raised serious issues about the need for a faculty role to scrutinize disfiguring mutations of the university by expansion into authoritarian nations, in which the values of the free academy would be at risk. ${ }^{249}$ Despite the importance of the issue, and the prominent players involved in the board's support of the president, there was no continuing coverage of the dispute. The New York Times printed little more than press releases on both sides and minimal analysis. It also ran an op-ed by Professor Jeff Goodwin, a leading faculty proponent of the no confidence vote. ${ }^{250}$ By contrast, once the Indianapolis Star breached the silence about the abuse of athletes by a Michigan State University (MSU) doctor, coverage was extensive, even bringing a

247. See Kim Kozlowski, MSU Board Backs Engler As He Apologizes to Nassar Victim, Detroit News (June 21, 2018, 2:31 PM), https://www.detroitnews.com/story/news/local/michigan/2018/06/21/englerapologizes-criticizing-nassar-victim-email/722315002/ [https://perma.cc/D4MNAL6S].

248. Before settling the lawsuit with Associate Dean Ray Ku of Case Western Reserve University School of Law and following considerable outcry about the University's backing of the dean against his associate dean, with detailed allegations of retaliation against $\mathrm{Ku}$ in the complaint, Case Western issued the following statement: "First, the university takes seriously all allegations of sexual misconduct." See Brown, supra note 123.

249. See Kevin Kiley, Not Your University, Inside Higher Educ. (Dec. 19, 2012), https://www.insidehighered.com/news/2012/12/19/nyu-vote-no-confidencehighlights-divergent-views-faculty-role-governance [https://perma.cc/R6JN-WJB4].

250. See Jeff Goodwin, The War in Washington Square, N.Y. TIMES (Mar. 20, 2013), https://www.nytimes.com/2013/03/21/opinion/the-war-at-nyu.html [https://perma.cc/2E32-Y7AY]. 
Washington Post reporter to East Lansing for on-site investigatory work. ${ }^{251}$

What is the result at MSU? There is a new president, but whether the culture of the University's governance has a diagnosis for recovery, improvement, or entire reformation is questionable. The new President has announced initiatives, given reassurances, and labeled the previous administration flawed. ${ }^{252}$ Given the extent of the catastrophe, the statements are to be expected. Yet how likely might it be that the culture that maintained silence for years and then slowed the response as the facts became known will be transformed by a new university functionary, recruited from the presidency of another university? Could a deep cultural audit explain the resistance for years to see and report the threat to vulnerable female student athletes? Would the university that failed to protect the students be capable of performing one? The removal of a president who had been honored until she was present at the time the news broke, and for whom the worst charge voiced at the time of her resignation was that she just didn't "get it[,]" lay. Skeptics are dubious.

As these public spectacles erupt and produce aftershocks counted in years, the vote of no confidence remains the simultaneously dowdy and controverted primary outlet for the airing of internal organizational knowledge about nonsexual leader misconduct: the type of malfeasance or misfeasance that does not garner media interest. In local settings, the intensity of a gathering opposition to an administrator can become briefly a strong focus for local interest and opinion, spreading from faculty to a more general public. A siege involving city department heads in Hanford, California that became a regular topic in local news provides a good example of the kinds of issues that a vote of no confidence seeks to address with the forced exit of a leader. ${ }^{254}$ Though no confidence votes typically avoid a listing

251. E-mail from Susan Svrluga, Reporter, Wash. Post, to author (Jan. 25, 2018, 10:45 EST) (on file with author) (advising author of scheduled trip to East Lansing on January 25, 2018).

252. See Stanley, supra note 242.

253. Matt Friedman, Column: Here's What's Wrong with Simon's Resignation Letter, DETROIT FREE PRESS (Jan. 25, 2018, 5:08 PM), https://www.freep.com/story/opinion/contributors/2018/01/25/lou-anna-simonresignation-letter-msu/1067001001/ [https://perma.cc/JFY5-M7RF]. "The letter leaves a reader thinking that, when it comes to the sheer magnitude of the abuse crisis, that the ex-president didn't 'get it' and has led a broken culture, leading to several PR missteps in recent days." Id.

254. See Excerpts from 'No Confidence' Letter, supra note 81. 
of charges, where the entity seeking to oust a leader is a public service body that serves the citizenry, the group sometimes attempts to share a collective voice that produces a set of charges for public consumption.

Fire departments and police departments, by their character, acquire a democratic connection with a local public. They expect commonality and solidarity if they publicize problems with which a general public could identify. In Hanford, California, city government employees produced a public bill of particulars against a city manager that typify the issues with which votes of no confidence are concerned. ${ }^{255}$ In a long-running scandal at Adelphi University that eventually resulted in official action dismissing the President and the board of trustees, faculty outcry helped bring significant corruption to public attention. ${ }^{256}$ The alleged offenses involved bypassing the faculty's input, diverting resources away from the core mission of teaching and scholarship, and generally misusing power to benefit the president and to replace administrators with friends and at higher compensation. ${ }^{257}$ The scandalous diversion of resources and mission distortion was sufficiently understandable as ordinary corruption to attract media attention, which resulted in eventual action by higher state authority.

Let us next consider the role of outside pressures as a possible source of useful social knowledge for society generally and for the epistemology within organizations exposed to public scandals. Does public exposure, with attendant mobilization of public interest and opinion formation, build a new framework of sustainable knowledge and vigilance? Does it advance the commitment of the citizens of a republican political order to develop and sustain active citizenship within organizations exposed to public scandal? Or do public accountings force only a sliver of knowledge into the controlled discourse of mission-bonded institutional life?

Organizations today prefer control of voice from the ranks and suppression of internal input about dysfunction or wrongdoing. Can open scandal alter that calculation at the top, or might it only deepen the determination to control discourse, and provide a new context for control? Can it be a source for a renewed ethos in an organization situated in a nation with a democratic ethos and republican aspirations? What kind of epistemic work can scandal achieve?

255. See id.

256. See Lambert, supra note 209.

257. See LEWIS, supra note 216. 


\section{C. \#MeToo: Social Knowledge in Search of a Voice}

With the emergence of the \#MeToo movement and the movement's airing of social knowledge revealed by the particulars of misconduct within these organizations, other monitoring mechanisms join the vote of no confidence as a means of seeking relief from ongoing wrongs. These mechanisms are evolving in the \#MeToo context and have the capacity to command widespread, even national interest. The epistemological enterprise that the vote of no confidence has only partially fulfilled as a means of building knowledge within the organization is thus seemingly supplemented by an outside entry into the project. It gains momentum with lawsuits and public statements by student victims and the consequent required investigation by law enforcement previously unmotivated to root out sexual transgressions in local institutions. The lawsuits and the public statements convey an isolated and suppressed internal voice from the organization to the outside world. Though these public revelations and voices unavoidably enter into organizational channels as well as attract attentive listeners throughout the entity, they do not instantly transform the inner workings of the managerial approach to organizational self-understanding. The preference of the administrative hierarchy to control the sources that shape the organizational epistemology does not yield to the crisis of outside voices. Rather, the eruption of voices that cannot be silenced deepens institutional concern for control over public messaging, which also calls upon internal control as a go-to response.

As major sexual scandals involving student molestations, faculty bodies, administrators, students, student newspapers, and boards of trustees inundate the narrative of institutional normality, the no-longer confident official narrators struggle to address the Epic Failure. The adequacy of the form by which epistemic democracy takes shape to absorb and make sense of the failure is unclear. An entity long devoted to restricting talk to prescribed channels while reposing epistemic authority in administrators invariably turns to administrators to make the kind of public comment that is meant to reestablish a sense of normalcy. Yet the intervention of politicized outside discussantsenforcement agencies that impose fines, write damning reports, and charge administrators with crimes - is not necessarily a win for epistemic expansion pointing toward a shared moral community. Government agencies and their elected heads have political motives that can produce biased reports which are then received as authoritative by outsiders while insiders may give them lip service. 
The findings may or may not be an acute or insightful account that would be produced by what might be made an ideal: an audit undertaken as an effort at psychological assessment of the dynamics that could produce extended silence about a sexual predator.

Outside the context of civil penalties and government reports after investigation, prosecutors may play a role with criminal enforcement. Unfortunately, prosecutors have incentives to target administrators with political prosecutions, ${ }^{258}$ a move that may appear to be a useful form of accountability but may lack a sound basis in evidence. It may also exacerbate the internal tendency toward control over speech by risk-averse administrators. The end result may not be an advance of public knowledge about patterns of misconduct and organizational malfunction. The United States Department of Education is subject to crosscutting pressures that can affect the factfinding in a report about a university, pointing either toward a hardhitting exposé or a mild rebuke.

Lawsuits offer a different venue for the isolated target of sexual harassment or sexually aggressive physical contact. They also have some potential appeal for less-fraught forms of mistreatment of faculty or violation of their rights to engage in open discourse in connection with their institutional governance role. The obstacles to success are considerable. The first problem is practical: finding legal representation for cases that may have low stakes. For faculty members concerned about threats to traditional academic values or to their own personal interests, stakes tend to be too low to make the lawsuit economically viable. A faculty member investigating the prospects for a lawsuit discovers that lawyers do not consider the case to have sufficient value to agree to a contingency fee arrangement. A faculty member, however certain of the injury, is reluctant to pay from often limited funds for an uncertain result.

These considerations also vary with the nature of the problem. Courts do not necessarily provide an outlet for voices of individuals

258. I have published an op-ed arguing that the criminal prosecution of former Michigan State University President Lou Anna Kimsey Simon is political and is not well-based in facts or law. See Mae Kuykendall, Law Prof: Prosecuting Former MSU President in Larry Nassar Scandal is Unfair, Detroit FreE Press (June 29, 2019, 6:00 AM), https://www.freep.com/story/opinion/2019/06/29/nassar-msu-lou-annasimon/1514136001/ [https://perma.cc/PH8S-SPRA]; see also Judge Dismisses, supra note 106; Claim of Appeal of People of the State of Michigan, Michigan v. Simon, No. 19-20329-FH (Eaton County Cir. Ct. 2019), appeal docketed (Mich. Ct. App. June 29, 2020). 
whose problem is not shared by the group and who must therefore pursue a solitary cause. Lawyers look for a clear and readily explained violation of a highly specific right and for an injury with quantifiable value. Unfairness or injustice alone is of minimal interest to a lawyer contemplating a contest with a large institutional target. Litigators consider how a jury would respond to a client's claim of injury. The litigator is unsentimental. Does the potential client have a story of mistreatment that would garner the sympathetic interest of a jury? For a professor or other professional, much that occurs in a large institution is seamy, unfair, and unpleasant. Those there know it well. Communicating the institutional malaise to a jury or even a judge within the parameters of the requirements of pleading a legal injury, asserting a monetary loss, and presenting an appealing account of victimization worthy of repair is most often a near impossibility. The injury must be extreme, the facts outrageous, and the story eyepopping. As much as the atmosphere in academic settings can become and often is toxic, it is a toxicity that eludes the understanding of the outside world.

\section{MOVING FORWARD AND NAVIGATING \#METOO WITH VOTES OF NO CONFIDENCE}

The intervention of outsiders that follows an Epic Failure is episodic and the depth of coverage is often shallow, indifferent, or sensational. Unlike the vote of no confidence, such outsider interventions are not built on deep knowledge of the relevant facts of dysfunction within the organization. It is not clear how much they add to the voices that emanate from within the organization on the part of the victims of sexual predation. In certain respects, they feed unoriginal, unenlightening soundbites of outrage. They do not build a body of social knowledge for organizations, though they add to the historical record memorializing Epic Failures. In that sense, they provide the same messaging function of recurring votes of no confidence. Something is wrong in American nonprofit organizations.

If media coverage of scandal provides an unstable combination of victim outcry and outsider inventions by the press and government bodies, might insider litigation, as took place as Case Western Reserve University School of Law, function as a means of forcing exits of bad leaders and thus a basis for organizational self-scrutiny through internal critique? In rare instances, a faculty member's lawsuit against an administrator becomes an outlet for a formal exposure of wrongful sexual speech and conduct tolerated in the work setting. The obstacles 
to open speech against administrators vary depending on the nature of the issue, with sexual misconduct most protected. The forms by which voice may emerge also vary with the nature of the issue and the fear of retaliation launched by the wrongdoer or the group. For all who wish to expose the abuse of power, the first barrier is the silencing message from entrenched rules protecting power itself and from a cultural disposition to avoid trouble and to disapprove of those who bring trouble. In the case of \#MeToo, the barriers have been an unusually deep reticence about resisting male sexual power when it is paired with other claims to power. There has been a strong inheritance from a history that has been well recounted as part of the breaking of silence and that has been portrayed in popular culture, such as the cable program, Mad Men.

A lawsuit by an individual seeking to act for the collective, with no buy-in or prescribed format, is unlikely. For deeply entrenched power that is structurally subversive of academic values as expressed in shared governance, ${ }^{259}$ the courts lack a template for intrusion into the internal politics of another institution. In the absence of legislation protecting university governance from the distortive influence of administrative aggrandizement, federal courts have no sense of any mandate or permission to referee university governance to prevent the creation of entrenched, unaccountable power. Even if what is called by some "the corporatization" of the university is alleged to harm the core mission of state-funded and/or controlled universities, the federal courts are simply not a venue for litigation and exposure of the unrepublican effects of trends in the university. The Republican Guarantee Clause of the Constitution has not provided a template for federal courts to claim a role in refereeing the dysfunctions of the nonprofit sector. ${ }^{260}$

The \#MeToo revelations pose a complication in discriminating a generalized culture problem from a problem caused by a leader. Indeed, the aftermath of the Michigan State sexual predation scandal

259. By comparison, for-profit corporations have a developed body of law that gives judges some mandate for review, however well, i.e., robust (or weak), one might adjudge the conventions by which judges are involved as corporate monitors. For information on this topic, see Mae Kuykendall, Good Greed: Do Activists Shareholders Force Internal Accountability in Profit Corporations? (on file with author), which provides a treatment of the incentive structure in profit corporations in comparison with the relative paucity of such incentives in non-profit corporations.

260. The potential of the undeveloped constitutional norm implicated in the Republican Guarantee Clause is beyond the scope of this Article. See supra note 33 and accompanying text. 
has shown the murkiness of the search for responsibility for a terrible harm to students that continued for years. The effort to hold the top leader - the former President - criminally responsible has foundered with a prosecution dismissed by a judge who found that no reasonable person could conclude that any evidence supported the crime charged - that of lying to the state police of Michigan. ${ }^{261}$ Because Michigan State has not produced all the documents that various parties have demanded, those who wish to assign criminal responsibility to the former President cling to the view that new and telling evidence lurks in the reams of paper passed between university administrators over the years of a man's crime spree against the female athletes trusted to his care. ${ }^{262}$ The criminal law process, in its search for an individual who should bear the stigma of a harsh criminal penalty for the long failure of the university culture, lacks potential to build an epistemology of organizational dysfunction. The public dramaperhaps a psychodrama - seeks a uniquely villainous individual to whom great moral blame can be assigned. Yet the effort by prosecutors, under pressure to yield satisfaction to a public lacking deep knowledge but convinced that moral evil must be avenged, is poorly designed to yield either organizational self-knowledge or deeper understanding of the pathologies of nonprofit entities. Communal truth goes begging once more as internal silence descends. The ongoing risk of an effort to exact such a price from administrators blocks the creation of new avenues within the entity for previously private knowledge to become embedded into the working understanding of the enterprise. Current administrators retreat to the hooded language of command and caution with a performance of humility and concern, former administrators subject to vilification remain quiet at risk of their liberty, and the institution evolves in the direction of secret proceedings against those whose conduct is brought into question. ${ }^{263}$ Developments relating to criminal proceedings

261. See Judge Dismisses, supra note 106; Claim of Appeal of People of the State of Michigan, Michigan v. Simon, No. 19-20329-FH (Eaton County Cir. Ct. 2019), appeal docketed (Mich. Ct. App. June 29, 2020).

262. See Kate Wells, Here's Why MSU is Keeping 6,000 Documents from Nassar Investigators, MICH. RADIO NPR (Dec. 25, 2019), https://www.michiganradio.org/post/here-s-why-msu-keeping-6000-documentsnassar-investigators [https://perma.cc/JX63-94JW] (describing the basis in attorneyclient privilege and related insurance coverage concerns for MSU's refusal to release certain emails and quoting a new trustee: "I just met with Rachael Denhollander, and she was saying the same thing: short of releasing these things, people are probably never going to be completely satisfied").

263. See supra note 29 and accompanying text. 
against a former top leader are met with official statements explaining that comment is not possible. ${ }^{264}$ The proceedings of a criminal process, such as the preliminary hearing for former President Simon, may reveal information about the involvement and interactions of other administrators with the person charged, but the likelihood that press coverage would contribute to institutional knowledge is low. With the three-factor new speech performance-command language mixed with a posture of humility, the imposed silence of former administrators with the consequent loss of their social knowledge, and the turn to secret proceedings internal to the organization for entity self-protection against scandal - the norm of silence is fully restored, command logic and fear of open speech reinforced, and passivity given a new urgency.

The vote of no confidence, by contrast, is muted when it happens and thereafter remitted to the narrative erasure of the institutional officials. In a no confidence vote, history is written by those who retain power and then pass it on to the like "guardians" of authorized institutional narrative. Nonetheless, for some who helped organize group voice and lodge a successful demand for a leader's departure, a new understanding of their citizenship in the institution can arise. Despite mixed views among the group and even within one person, the exercise supports the development of "citizen" agency among some faculty members. ${ }^{265}$ The seeds of that new awareness can grow

264. Emily Guerrant, Statement on Charges Filed Against Former President, Mich. ST. U. (Nov. 20, 2018), https://msu.edu/ourcommitment/news/2018-11-20Simon-Charges-Statement.html [https://perma.cc/DK4B-XP9J].

265. A faculty member who worked with others to bring a no confidence petition-despite being relatively pessimistic about the effect on her trust of others and the long-term impact of the effort, which caused a departure-concluded after discussion that the experience had some benefits in bringing about a greater connection with others and gaining knowledge:

I am more pessimistic, I am less trusting. I did get some fabulous women friends out of it, and admiration for those women like you would not believe. I should have mentioned that earlier, cause that was the best thing for me personally, to come out of it, was the closer relationship with those women. I-I'm more-I'm way more likely to speak up on campus issues, and I have done ever since. And I never, you know I never bothered to even learn much about it before. And then I found myself, like people were asking me questions about my opinion on stuff. And that had-people I didn't know before. And so, it changed other people's view of me, it changed my own willingness to speak up. It changed my own desire to know stuff.

Statement of Anonymous, Faculty Member, Regional State Univ. (June 20, 2019) [hereinafter Statement of Anonymous]. 
or wither with time, die for lack of care, or find themselves among thorns that choke the tender roots of communal knowledge. The no confidence vote nonetheless provides, episodically and uncertainly, openings to a shared epistemic authority over the communal life and self-presentation of the entity.

The relevance of the vote of no confidence to problems specific to ones perceived to have been brought to an organization by a leader leaves a possible doubt about its long-term efficacy. Aside from issues of specific individual memory and agency, those who bring such votes sometimes are unsure whether forcing a leader's departure provides long-term relief from problematic trends that may have been present without regard to the specific issues making the leader unacceptable to the body. But they do not regret the no confidence effort, either with or without expulsion of the leader. ${ }^{266}$ The strengths of the vote are mixed with weaknesses. Because of the lack of a mature tradition, groups' actions that depend on a type of volunteerism and improvisation are not reliable as a mechanism to address serious problems of leader misconduct, or cultural bad patterns. But they are a supplement, a safety valve, to the absence of good accountability practices in nonprofits.

\#MeToo is distinctively a problem of a culture that chooses silence in the face of certain kinds of abuse within the body. Whether they have direct knowledge or involvement with a specific instance of misconduct, leaders are not free of blame. Leaders bear responsibility for challenging the environment that led to \#MeToo and creating an atmosphere that both discourages misconduct and moves group dynamics (reflective in part of the wider culture) away from a culture of silence around sexual misconduct or other abusive conduct harmful

266. Despite uncertainty about the long-term beneficial effect on an institution's culture, there is reason to think that that forced exits of those who perpetrate or enable such misconduct can lead to more diverse replacements for them. See Audrey Carlsen et al., \#MeToo Brought Down 201 Powerful Men. Nearly Half of Their Replacements Are Women., N.Y. TIMES (Oct. 29, 2018), https://www.nytimes.com/interactive/2018/10/23/us/metoo-replacements.html

[https://perma.cc/GG73-EKVT]. Moreover, the sense that one person's departure was critical to the institution can persist, even in the face of concerns over replacements. Michigan State University College of Law brought a vote of no confidence against the dean in 2006. He resigned in 2008. In my personal experience as a faculty member, despite a divisive period that followed with a new permanent dean, no faculty member who participated ever regretted the decision. But those most committed to the expulsion of the dean also viewed the trends within the law college in terms of faculty voice as negative. 
to individuals' dignity. A passive culture generally embedded in "command logic" is dangerous for larger reasons of citizenship development in society generally but especially dangerous for the project of building enterprise epistemology that begins to mesh the public speech of those with power with the hitherto segregated understandings of those without voice in the entity. Those without power have uniquely suffered from norms of silence in organizations. Those without voice have included persons with nominal stature but forms of knowledge gained from pathologies in organizational culture. Those lacking in all organizational power or standing have been without voice or protection.

What about the profit motive? Though prone to drift and ethical laziness without something more to prick the conscience, profit organizations respond to a lever from investors over their pursuit of return. They gladly fall into patterns of comfortable, self-regarding managerial arrangements, but they face unhappy investors who demand accountability. In for-profit corporations, the matter of conscience, for the outside force, is money, and money does indeed talk.

For universities, money also matters. But the imperative of fundraising, rather than investor return, changes what money can and does say to the recipients of funds. For the funding group or individual, "What's in it for me" is not about financial return. As a result, the line between sources of money and a discipline over internal conscience is indirect at best and can be a source of pressure to protect wrongful conduct. ${ }^{267}$ Far from checking, it can fuel \#MeToo bad conduct. That type of pressure is strongly associated with athletics in universities. ${ }^{268}$ Those who contribute to the university and care about athletics can be sources of pressure to keep the athletes insulated from accountability. When scandal strikes, the outside force is the unorganized community at large, sometimes aroused, never empowered, and only on occasion

267. See Debra Nussbaum Cohen, Women in Jewish Fundraising Say Harassment is Pervasive, Jewish Telegraphic AgENCy (Feb. 26, 2018, 4:17 PM), https://www.jta.org/2018/02/26/news-opinion/united-states/for-women-in-jewishfundraising-harassment-is-an-occupational-hazard?utm_source=JTA\% 20Maropost\&utm_campaign=JTA\&utm_medium=email\&mpweb=1161-3106207459 [https://perma.cc/V3EL-8PXM] ("At the end of the day, in the nonprofit world, donors hold nearly all the power. Most big-money donors are male.").

268. See, e.g., Paula Lavigne \& Nicole Noren, OTL: Michigan State Secrets Extend Far Beyond Larry Nassar Case, ESPN (Jan. 25, 2018), http://www.espn.com/espn/story/_id/22214566/pattern-denial-inaction-informationsuppression-michigan-state-goes-larry-nassar-case-espn [https://perma.cc/4CXXVJ2X]. 
capable of feeding and maintaining an atmosphere of crisis. ${ }^{269}$ It rarely is enough.

\section{CONCLUSION}

Problems of accountability and seriously bad behavior within the ranks or by leaders of nonprofit institutions are real and can persist over time without oversight. In the absence of adequate designs for regular accountability, gap fillers arise, but all have shortcomings. Each gap filler fails as a reliable check on bad behavior because it depends on improvisational responses, either by risk-averse or compromised insiders or by uninformed outsiders with mixed incentives, motives, and bona fides as narrators. There are no handbooks to guide groups considering a no confidence vote. Without guidance, the fear factor is a high barrier. ${ }^{270}$ Press coverage of universities and other nonprofits can be passive and then, if a scandal is broken, shallow and uncreative with stories that barely go beyond a headline new event. Criminal process comes after the damage has

269. Such an effect certainly occurred at the most salient of sexual scandals involving an abuse of authority by university staff. See, e.g., Steve Friess, Michigan State University Is Botching Its Reputation-Rehab, ATLANTIC (Mar. 19, 2018), https://www.theatlantic.com/education/archive/2018/03/michigan-state-universityis-botching-its-reputation-rehab/555932/ [https://perma.cc/RL3P-SYY2]; see also, e.g., Michael Bérubé, At Penn State, a Bitter Reckoning, N.Y. TimES (Nov. 17, 2011), https://www.nytimes.com/2011/11/18/opinion/at-penn-state-a-bitter-reckoning.html [https://perma.cc/7E7E-938W]; Sarah Parvini, Paul Pringle \& Harriet Ryan, Anger, Questions at USC After Second Medical School Dean Departs over Inappropriate Behavior, L.A. TIMES (Oct. 6, 2017, 8:20 PM), http://www.latimes.com/local/lanow/ la-me-usc-varma-20171006-story.html [https://perma.cc/T9XK-ZD52]. But eruptions about allegations against individual athletes attract a mixed response, much of it preferring protection of star athletes for purposes of winning teams. See Walt Bogdanich, A Star Player Accused, and a Flawed Rape Investigation, N.Y. TIMES (Apr. 16, 2014), https://www.nytimes.com/interactive/2014/04/16/sports/errors-ininquiry-on-rape-allegations-against-fsu-jameis-winston.html?_r=1 [https://perma.cc/ HU37-JFYT]. It is by no means clear that the \#MeToo movement will fundamentally alter the storyline in alleged student-athlete sexual abuse of other students given the intense pressure by fans - the community - for winning teams.

270. See supra note 53 ("there is definitely fear if you want to talk about emotions, there's definitely a deep-seated anxiety that people have about their situation should they speak up . . . it would be irrational to think you would be fired perhaps, for speaking up against the university president, but again, the university can make your life miserable in myriad ways if it wants to. I think people really fear being on the outside, right? More than anything, they [feel] like, well, you want to be in the good graces of the administration, of the president, of the provost, of the dean . . I think that's a realistic fear which people have, and as I say, it's really no different than any other employee has in our capitalist society."). 
occurred and is subject to the political agenda, good faith, and competence of prosecutors. Individual litigation by a person targeted for mistreatment is rare because the resources to engage in a lawsuit against a well-funded institution are limited, and the courage to commence legal action is not common.

The function of these gap fillers is not certain. Nonetheless, without them, serious misconduct would go unchecked, with harms to citizenship broadly conceived in the context of a democratic nation, to the mission of institutions conceived to serve the public interest, and to individuals left vulnerable to abusive uses of power, and corollary secretiveness. Rejected leaders would rule in the absence of support within the ranks for their leadership and inflict the damages associated with the inefficiency of lodging "command authority" in an individual whose undiluted rule destroys the beneficial effects of hierarchy and coordination that overcome the transaction costs of contracting in the free market. ${ }^{271}$ Rather than efficient coordination, the logic of command and obedience stymies the purpose of hierarchy as a means of embedding contract into institutional arrangements in service to a mission. Time with a leader who cannot achieve the advantages of hierarchy and coordination inflicts institutional loss and damages the organization as a source of models for civic capacity and engaged citizenship.

The vote of no confidence enables groups to deploy their special understanding and knowledge of a bad leader to raise a claim for the person's departure. The heart of the claim is that the leader no longer has followers and that consent by the group is an ongoing requirement for effective leadership. The claims in such votes also contain moral and ethical assertions about the type of conduct that is acceptable within an institution of mission-oriented undertakings. The voicing of norms of acceptable conduct is an important contribution of such group undertakings because it brings into light a value system that is an anchoring principle for the community-one which draws on common understandings about and supports the growth of a shared epistemic life within a genuine community. Votes of no confidence do not manage to create a public history of patterns of bad leader conduct or of methods by which unmanaged voice can arise but they permit periodic glimpses of organizational citizenship and signal that American nonprofits experience recurring leadership problems. Case

271. See supra note 5 and accompanying text. 
studies of such votes would preserve a greater store of public value from their periodic occurrence..$^{272}$

Though the press has brought to light problems not being addressed and scandals being covered up within organizations, journalism rarely creates public knowledge about systemic dysfunction. The press is better suited to revealing secrets than to providing deep knowledge of the entire pattern in which secrets are kept. The press's limited function is to sound a fire bell alerting the public and the institution itself to sins of commission and omission. The result can be to bring a halt to misconduct, but the task of sorting out the inner world that fostered it is generally more than the press can achieve.

Criminal process aimed at higher level officials has limited value as a knowledge-producing exercise. If not aimed at their own primary bad conduct or their direct personal proximity to the primary bad conduct, criminal prosecution of top officials may be more harmful than helpful, particularly if not well founded in law and facts. A charge based on an idea of what the person could have known, should have known, or speculatively did know cuts off the development and dissemination of institutional knowledge. Both the target of criminal prosecution and all others with a continuing official role or even a former role decline to speak in public or even in private. The target must not speak about the institutional flaws that led to the disaster. Before she was prosecuted, former President Simon testified to Congress and had the capacity to be a resource about the factors that may have enabled the long-running disaster of unchecked sexual abuse by a university doctor to take place at a great state university.

Finally, litigation can be successful, as with the case of Associate Dean Ray $\mathrm{Ku}$, who successfully sued an individual for his alleged primary bad conduct as well as the University for concealing it. $\mathrm{Ku}$ prevailed by reaching a settlement and placed his personal knowledge on the public record, circulating a narrative of the conduct in a legal complaint. Individual litigation, however, has very little chance of occurring. Further, in the nature of litigation, $\mathrm{Ku}$ has receded into public silence about the settlement and the case facts. Individual litigation cannot be considered to be a significant safeguard or source of widespread public knowledge of institutional patterns and problems. The Ku litigation does nonetheless provide a useful role model of civic courage by a person in such an institution where the

272. Case studies will be available in KUYKENDALL \& MCKINNISS, supra note 26. 
leadership and the general culture are inadequate to expose and stop the alleged wrongdoing. Where that is the circumstance, particularly where sexual misconduct is alleged, the core mission and aspirational ethos of the institution can be damaged. Whether the \#MeToo movement will alter the problem of institutional love of secrecy is not yet known. ${ }^{273}$ There is the concern that secrecy merely takes a new form of star chamber proceedings cloaked in administrative control and, once more, antithetical to the project of nourishing an institutional self-knowledge from the whole body. Institutional embrace of secrecy and management of internal voice die hard.

The focus of the no confidence vote on leaders is not a cure for systemic problems in universities or other nonprofit enterprises. They occur against strong opposition from institutions, with efforts to portray them as forms of "mob rule" and forces for instability and reputational harm without benefit. Yet they will always be a potential factor in any setting that has not crushed a democratic ethos that leaves room for improvised group demand for a leader's dismissal. The strange juxtaposition of Larry Summers, a respected American economist only thought by many colleagues to be unsuited as a leader of Harvard University, and Benito Mussolini, a fascist, dangerous leader to his nation and to world peace, demonstrates the function and staying power of the vote of no confidence. It occurs across dimensions of time and context and works against a misconceiving of hierarchy as undiluted command rather than coordination within a framework of consent and institutional citizenship. Despite the relative absence of documentation in institutional history and public records, the practice of no confidence votes signals an unspoken crisis in the culture of American nonprofit institutions. The atmospherics and performances of institutional command logic place our common citizenship and republican values in peril.

Yet there is the capacity of a group to form outside the grip of a hierarchy set against open discourse. There is the oral tradition that persists without the need for permission. It cannot be talked into bureaucratic oblivion or "drowned by drops" in Dickens's Court of Chancery. ${ }^{274}$ The vote of no confidence will not disappear. With roots

273. For an optimistic treatment of the overall social benefits of the movement, see Anna North, 7 Positive Changes That Have Come From the \#MeToo Movement, Vox (Oct. 4, 2019, 7:00 AM), https://www.vox.com/identities/2019/10 /4/20852639/me-too-movement-sexual-harassment-law-2019 [https://perma.cc/ F5UL-KKGD] (noting that, among other positive changes, there is currently a trend by states to ban nondisclosure agreements about sexual harassment settlements).

274. See DiCKENS, supra note 152, at 63. 
in an improvisation in Great Britain's Parliament, the idea of "no confidence" has a sturdy claim on mission-bonded groups that encounter corrupt or incompetent leaders. Despite the failures of groups to act altruistically to aid isolated victims of sexual misconduct, the moral core of the vote is nonetheless uniquely about institutional integrity. Where leaders and groups fail, other methods of redress yield some success, and, like the no confidence vote, provide glimpses of a crisis without providing the communal knowledge that is the epistemic ideal for a well-functioning organization. Only the vote achieves a small success in the quest for an enriched communal knowledge, as individuals "change [their] own willingness to speak up" and find themselves "meeting people they didn't know before." 275

275. See Statement of Anonymous, supra note 265. 